Modelado del comportamiento de una reacción de Oxidación Catalítica en un Reactor de Lecho Fluidizado

Tesis que para obtener el grado de Maestra en Ciencias en Ingeniería Química

Presenta

I.A. Ilda Olivia Santos Mendoza 


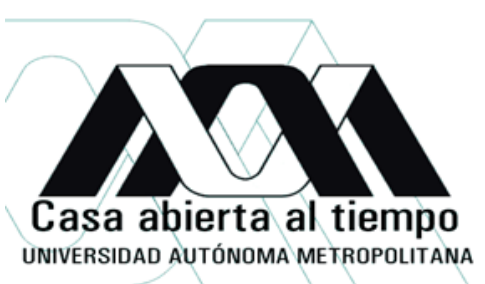

\title{
Modelado del comportamiento de una reacción de Oxidación Catalítica en un Reactor de Lecho Fluidizado
}

\section{TESIS QUE PARA OBTENER EL GRADO DE MAESTRA EN CIENCIAS EN INGENIERÍA QUÍMICA}

\author{
Presenta:
}

I. A. Ilda Olivia Santos Mendoza

Asesores:

Dr. Carlos Omar Castillo Araiza $\quad$ Dr. Richard S. Ruiz Martínez

Jurado Calificador :

Presidente: Dr. Carlos Martínez Vera

Secretario: Dr. Carlos Omar Castillo Araiza

Vocal: Dra. Miriam Nohemí Moreno Montiel 


\section{Resumen}

El presente trabajo de investigación tuvo como objetivo principal elucidar el comportamiento de un reactor de lecho fluidizado para la Deshidrogenación Oxidativa de Etano $\left(\mathrm{DHO}_{2}\right)$ sobre un catalizador multimetálico MoVTeNbO desarrollado por el Instituto Mexicano del Petróleo (IMP). Para ello se realizó un estudio termodinámico de las principales reacciones en la DHO- $\mathrm{C}_{2}$ y se encontró que esta reacción no está limitada por la termodinámica: $\mathrm{Ka}\left(298^{\circ} \mathrm{C}\right)=1.7607 X 10^{15}$ y $\Delta G_{298}^{\circ}=-128.08 \mathrm{KJ} / \mathrm{mol}, \Delta H_{298}^{\circ}=-105.49 \mathrm{KJ} / \mathrm{mol}$. Se tenía una base de datos experimentales cinéticos para el catalizador MoVTeNbO con los que se evaluó la influencia de la temperatura y espacio tiempo en la conversión de etano y selectividad de etileno de acuerdo a un estudio factorial $3^{2}$. El rango de selectividades a etileno y conversiones de etano fue de 81 a 95.7 y 16.5 a $86 \%$ respectivamente. Se analizó y extendió dicha base de datos para desarrollar un modelo cinético del tipo Mars van Krevelen que consideró la dinámica oxido reducción en la superficie del catalizador. El modelo cinético para la DHO- $\mathrm{C}_{2}$ ajustó adecuadamente los datos experimentales, obteniendo un valor de $\mathrm{F}$ de $1.581 X 10^{03}$ donde el valor de F tabulado correspondió a 2.59.

El modelo cinético se acopló al modelo de un reactor de lecho fluidizado pseudo heterogéneo, que consideró dos fases; emulsión y burbuja, para evaluar el comportamiento de la reacción de $\mathrm{DHO}-\mathrm{C}_{2}$ a escala industrial. Se simularon diferentes condiciones de operación incluyendo la temperatura de reacción $\left(400,440\right.$ y $\left.480^{\circ} \mathrm{C}\right)$, velocidad inicial de alimentación (3-11 veces $\left.u_{m f}\right)$, tasas de alimentación etano/oxígeno $\left(\mathrm{C}_{2} \mathrm{H}_{6} / \mathrm{O}_{2}\right)$ de 1 y 3 . Finalmente, para entender el efecto de la distribución de oxígeno en la reacción se modeló al reactor se consideraron dos casos: en el primero se alimenta $\mathrm{O}_{2}$ a determinadas distancias del reactor con el objetivo de mantener la tasa $\mathrm{DHO}-\mathrm{C}_{2} / \mathrm{O}_{2}$ de 1 a 4 , ya que en este rango tuvieron lugar los experimentos cinéticos; y en el segundo caso se consideró una alimentación de oxígeno equidistante a lo largo del reactor.

Los resultados mostraron que la temperatura de reacción influye directamente en la conversión y rendimiento de etano. Los mejores resultados se obtuvieron a una $\mathrm{T}$ de $480^{\circ} \mathrm{C}$ alcanzando $91 \%$ de conversión y un rendimiento de $89.9 \%$. Mientras que el efecto de la velocidad de alimentación se vio reflejado en el tiempo de residencia, para una velocidad inicial menor (3 veces $u_{m f}$ ) se obtuvieron la mejor conversión y rendimiento: 90 y $82 \%$ respectivamente. En tanto que el efecto de las tasas de alimentación sugiere que se alcanza una conversión de $86 \%$ y un rendimiento de $55 \%$ en el mejor de los casos cuando la concentración de etano es tres veces la concentración de oxígeno. Los casos de alimentación parcial de oxígeno mejoraron tanto la conversión como el rendimiento alcanzando 100 y $97 \%$ respectivamente en los mejores casos. Estos resultados obtenidos sugieren que el reactor de lecho fluidizado es una alternativa prometedora para llevar a cabo la reacción de $\mathrm{DHO}-\mathrm{C}_{2}$ a escala industrial. No obstante, es necesario continuar con la investigación en catalizadores altamente selectivos viables para implementarse en reactores de lecho fluidizado a escala industrial, así como los mecanismos de reacción. 


\section{Índice general}

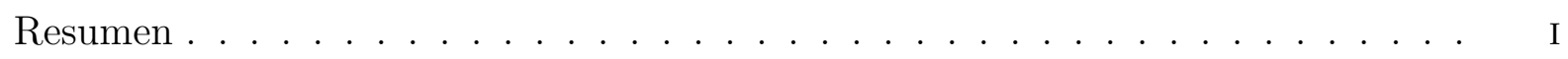

Índice general . . . . . . . . . . . . . . . . . . . . . . . . . . III

Índice de tablas . . . . . . . . . . . . . . . . . . . . . . . . . . VI

Nomenclatura . . . . . . . . . . . . . . . . . . . . V VII

\begin{tabular}{ll}
\hline 1. Introducción & 1
\end{tabular}

$\begin{array}{lr}2 . & \text { Estado del arte } \\ & 3\end{array}$

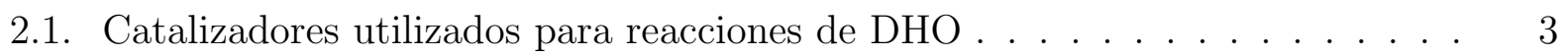

2.2. Estudios cinéticos y mecanismos de reacción $\ldots \ldots \ldots \ldots$

2.3. Reactores utilizados para DHO-C2 $\ldots \ldots \ldots \ldots 11$

\begin{tabular}{ll}
\hline 3. Planteamiento del problema & 14
\end{tabular}

3.1. Hipótesis . . . . . . . . . . . . . . . . . . . . . . . . . . . . . . . 15

\begin{tabular}{lr}
\hline 4. Objetivos & 16
\end{tabular}

\begin{tabular}{ll}
\hline 5. Metodología & 17
\end{tabular}

5.1. Experimentos: equipo, catalizador, diseño y manejo de datos. . . . . . . . . . 17

5.2. Modelo Cinético . . . . . . . . . . . . . . . . . . . . . . . . 19

$5.2 .1 . \quad$ Esquema y mecanismo de reacción $\ldots \ldots \ldots$. . . . . . 20 
5.3. Modelo del reactor y estimación de los parámetros cinéticos . . . . . . . . . 23

5.3.1. Modelo de estimación de parámetros . . . . . . . . . . . . . . . . 23

5.3.2. Algoritmo de estimación de parámetros . . . . . . . . . . . . . . . . . 24

5.4. Modelo de un reactor de lecho fluidizado a escala industrial . . . . . . . . . . 25

5.4.1. Model pseudo-heterogéneo de dos fases. . . . . . . . . . . . . . . . . 26

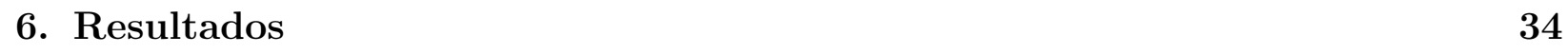

6.1. Evaluación del catalizador . . . . . . . . . . . . . . . . . . 34

6.1.1. Termodinámica . . . . . . . . . . . . . . . . . 34

6.1.2. Datos experimentales . . . . . . . . . . . . . . . 36

6.2. Modelo Cinético tipo MVK . . . . . . . . . . . . . . . . 41

6.3. Modelo del Reactor de Lecho Fluidizado . . . . . . . . . . . . . . . . . . . . 44

6.3.1. Modelado del reactor sin alimentación distribuída de oxígeno . . . . . 44

6.3.2. Modelado del reactor con alimentación distribuída de oxígeno . . . . 52

\begin{tabular}{ll}
\hline 7. Conclusiones & 55
\end{tabular}

\begin{tabular}{lr}
\hline Referencias & 57
\end{tabular}

\begin{tabular}{ll}
\hline A. Cálculos termodinámicos & 62
\end{tabular}

A.1. Criterios para determinar el modelo intrínseco . . . . . . . . . . . . . . 63 


\section{Índice de figuras}

2.1. Esquema del mecanismo de reacción de DHO propuesto por Yokoyama [23]. .7

2.2. Comparación de modos de operación de un reactor de membrana permeable: a) Modo membrana b) $\mathrm{O}_{2}$ y etano diluido con helio alimentado alternativamente y c) Modo de co-alimentación. . . . . . . . . . . . . . . . . . . 12

5.1. Esquema de reacción propuesto para la $\mathrm{DHO}_{-} \mathrm{C}_{2}$. . . . . . . . . . . . . . . 20

5.2. Representación de un reactor de lecho fluidizado . . . . . . . . . . . . . . . . 27

6.1. Datos experimentales de la selectividad de Etileno en términos de T y W/F . 36

6.2. Diagrama de superficie de la conversión de etano en función de T Y W/F . . 38

6.3. Diagrama de superficie de la selectividad de etileno en función de T Y W/F 39

6.4. Diagrama de superficie de la selectividad de CO en función de T Y W/F . . 40

6.5. Diagrama de superficie de la selectividad de $\mathrm{CO}_{x}$ en función de T Y W/F . . 40

6.6. Ajustes de los parámetros cinéticos estimados con los datos experimentales correspondientes a: a) $400{ }^{\circ} \mathrm{C}$ y b) $480{ }^{\circ} \mathrm{C}$ presenta los ajustes del modelo cinético a los datos experimentales a 400 y $480{ }^{\circ} \mathrm{C}$. . . . . . . . . . . . . . 42

6.7. Diagramas de paridad de los compuestos involucrados en la reacción. . . . . 43

6.8. Perfiles de concentración de los compuestos en la fase emulsión del reactor a

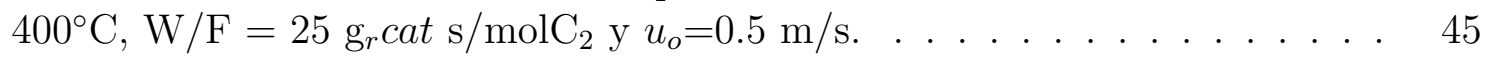

6.9. Perfiles de concentración de los compuestos en la fase burbuja del reactor a $400^{\circ} \mathrm{C}, \mathrm{W} / \mathrm{F}=25 \mathrm{~g}_{r} c a t \mathrm{~s} / \mathrm{molC}_{2} \mathrm{y}_{o}=0.5 \mathrm{~m} / \mathrm{s}$. . . . . . . . . . . . . 45

6.10. Perfiles de concentración de los compuestos en el reactor a $400^{\circ} \mathrm{C}$. . . . . . . 46 
6.11. Perfiles de concentración de $\mathrm{C}_{2} \mathrm{H}_{6}, \mathrm{C}_{2} \mathrm{H}_{4}$ y $\mathrm{CO}_{x}$ a 400 y $480^{\circ} \mathrm{C}$. . . . . . . 47

6.12. Conversiones de etano y rendimiento a etileno a 400 y $480^{\circ} \mathrm{C}$. . . . . . . . . . 47

6.13. Perfiles de concentración en el reactor a) $u_{o} / u_{m f}=3.0$ b) $u_{o} / u_{m f}=11.0$. . . $\quad 48$

6.14. Conversiones en función de la velocidad inicial 3-11 veces $u_{m f}$. . . . . . . . . 49

6.15. Conversión de etano y rendimiento a etileno a diferentes velocidades iniciales masa de catalizador constante. . . . . . . . . . . . . . . . . 50

6.16. Perfiles de concentración en el reactor con a) $\mathrm{C}_{2} \mathrm{H}_{6} / \mathrm{O}_{2}=1$ y b) $\mathrm{C}_{2} \mathrm{H}_{6} / \mathrm{O}_{2}=3$. . $\quad 51$

6.17. Conversiones de etano y rendimientos a etileno a diferentes tasas de alimen-

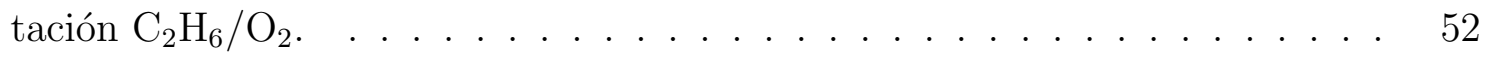

6.18. Perfiles de concentración en el reactor con distribución de oxígeno a lo largo

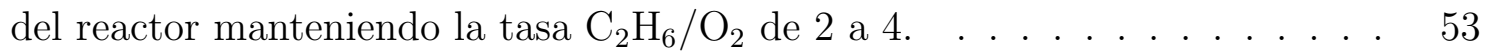

6.19. Comportamiento del reactor con alimentación distríbuda de oxígeno equidistante a lo largo del reactor. . . . . . . . . . . . . . . . 54

6.20. Conversión y rendimiento de los diferentes métodos de alimentación de oxígeno donde: $\mathrm{S} / \mathrm{Ap}=$ sin alimentación parcial, $\mathrm{C} / \mathrm{Ap}=$ con alimentación parcial y $\mathrm{C} / \mathrm{Ae}=$ con alimentación equidistante. . . . . . . . . . . . . . . . . . . . 54 


\section{Índice de tablas}

2.1. Reacciones, tasas de reacción y algunos parámetros óptimos del modelo cinético propuesto por Linke y col. $2002[20] . \ldots$. . . . . . . . . . . . . . . . . . 9

2.2. Modelos mecanísticos por el mecanismo MVK propuestos para la DHO de etano $[26] . \ldots \ldots \ldots \ldots \ldots$

5.1. Reacciones globales del modelo cinético . . . . . . . . . . . . . . . . . . 21

5.2. Reacciones elementales . . . . . . . . . . . . . . . . . . . 22

5.3. Parámetros y variables utilizadas en la simulación del reactor de lecho fluidizado 30

5.4. Parámetros y variables utilizadas en la simulación del reactor de lecho fluidizado 31

5.5. Condiciones de operación y valores de las variables estudiadas en la simulación del Reactor de Lecho Fluidizado a escala industrial. . . . . . . . . . . . . . . 33

6.1. Valores de entalpia y energía libre de Gibbs $25^{\circ} \mathrm{C}$. . . . . . . . . . . . . . 35

6.2. Entalpías de reacción a diferentes temperaturas $\mathrm{KJ} / \mathrm{mol}$. . . . . . . . . . . . 35

6.3. Análisis de varianza para el diseño factorial. . . . . . . . . . . . . . . . . . . 37

6.4. Parámetros termodinámicos estimados . . . . . . . . . . . . . . . . 41

A.1. Valores de Entalía y Energía libre de Gibss para los compuestos de las reacciones 62

A.2. Propiedades físicas del catalizador utilizado en los experimentos para las limitaciones de transporte . . . . . . . . . . . . . . . . 63

A.3. Condiciones iniciales de los ensayos de limitaciones de transporte . . . . . . . 64

A.4. Resultados de la evaluación del patrón de flujo, caída de presión y limitaciones al transporte de masa para lis dos experimentos representativos. . . . . . . . 64 


\section{Nomenclatura}

\begin{tabular}{|c|c|c|}
\hline$A_{i}$ & Factor pre-exponencial & \\
\hline$C_{i}^{\text {prod }}$ & Moles de $\mathrm{C}$ producidos en el compuesto i & $\mathrm{mmol} / \mathrm{m}^{3}$ \\
\hline$C_{C_{2}}^{c o n s}$ & Moles de $\mathrm{C}$ consumidos de etano & $\mathrm{mmol} / \mathrm{m}^{3}$ \\
\hline$C_{i, e}$ & Concentración del compuesto i en la fase emulsión & $\mathrm{mol} / \mathrm{m}_{e}^{3}$ \\
\hline$D_{i e}$ & Coeficiente de difusión & $m^{2} / s$ \\
\hline$d_{b}$ & Diámetro de partículas promedio & $m_{b}$ \\
\hline$d_{p}$ & Diámetro de partícula promedio & $m_{p}$ \\
\hline$E_{a}$ & Energía de activación & $K J / m o l$ \\
\hline$F_{H, a g u a}$ & Flujo molar de hidrógeno en agua & $\mathrm{mol}_{H} / \mathrm{h}$ \\
\hline$F_{H}^{\circ}$ & Flujo de entrada de hidrógeno en el etano & $\mathrm{mol}_{H} / h$ \\
\hline$\sum_{i=1}^{n} F_{H, i}$ & Flujo molar de hidrógeno contenido en productos & $\mathrm{mol}_{H} / h$ \\
\hline$F_{i}$ & Flujo molar del compuesto i & $\operatorname{mol}_{i} / h$ \\
\hline$G_{C_{2} H_{6}}^{\circ}$ & Flujo másico de etano en la entrada & $g r_{E t} / h$ \\
\hline$G_{C_{2} H_{6}}$ & Flujo de etano a la salida (grEt/h) & $g r_{E t} / h$ \\
\hline$g$ & Gravedad & $\mathrm{m} / \mathrm{s}^{2}$ \\
\hline$K_{b e}$ & Coeficiente de T. M. entre las fases emulsión y burbuja & $s^{-1}$ \\
\hline$k_{i}$ & Constante de reacción & $\mathrm{mol} / \mathrm{atm}^{\mathrm{m}} \mathrm{s}$ \\
\hline$M_{i}$ & Peso molecular del compuesto i & $\mathrm{gr} / \mathrm{mol}$ \\
\hline$P$ & Presión de alimentación total & atm \\
\hline$Q$ & Flujo volumétrico & $m^{2} / s$ \\
\hline$R$ & Constante de los gases ideales & atm. $\mathrm{m}^{3} / \mathrm{molK}$ \\
\hline$R_{i}$ & Tasas de reacción global para el elemento i & $\mathrm{mol} / \mathrm{gr}_{\text {cat }} \mathrm{s}$ \\
\hline$r_{i}$ & Tasas de reacción para el elemento i & $\mathrm{mol} / g r_{c a t}$ \\
\hline$S$ & Selectividad del C del compuesto i & \\
\hline$T$ & temperatura de reacción & $K$ \\
\hline$u_{0}$ & Velocidad de alimentación del gas & $\mathrm{m} / \mathrm{s}$ \\
\hline$u_{b}$ & Velocidad de burbujas & $m_{b} / s$ \\
\hline$u_{m f}$ & Velocidad mínima de fluidización & $m_{R} / s$ \\
\hline$W$ & Masa del catalizador & $g_{\text {cat }}$ \\
\hline$X_{C_{2} H_{6}}$ & Conversión de $\mathrm{C}$ de etano & \\
\hline$z$ & Distancia en el reactor & $m$ \\
\hline$\rho_{s}$ & Densidad de los sólidos en el lecho fluidizado & $g r_{\text {cat }} / m_{R}^{3}$ \\
\hline$f_{b}$ & Fracción del lecho correspondiente a la fase burbuja & $m_{b}^{3} / m_{L}^{3}$ \\
\hline$f_{e}$ & Fracción del lecho correspondiente a la fase emulsión & $m_{e}^{3} / m_{L}^{3}$ \\
\hline$\varepsilon_{b s}$ & Fracción de la fase burbuja correspondiente a los sólidos & $m_{s}^{3} / m_{b}^{3}$ \\
\hline$\varepsilon_{e s}$ & Fracción de la fase emulsión correspondiente a los sólidos & $m_{s}^{3} / m_{e}^{3}$ \\
\hline$\varepsilon_{m f}$ & Fracción vacía a la velocidad mínima de fluidización & \\
\hline$\mu$ & Viscosidad del gas & Pa.s \\
\hline$\rho_{g}$ & Densidad del gas & $\left.g_{\text {gas }} / m_{f}^{3}\right)$ \\
\hline$\rho_{p}$ & Densidad de partícula & $\left.g_{\text {cat }} / m_{f}^{3}\right)$ \\
\hline
\end{tabular}




\section{Capítulo 1}

\section{Introducción}

El etileno constituye por sí solo un importante producto del total de la producción de olefinas debido a su utilidad como materia prima para la producción de cloruros de etileno, etilbenceno, etiltolueno, algunos alcoholes y óxidos. La producción de etileno se da mediante el craqueo térmico y catalítico de naftas de etano, de propano y mezclas procedentes de la refinería, sin embargo, la naturaleza térmica de estas reacciones constituye una desventaja importante en el proceso. Debido a las restricciones termodinámicas como la energía de activación, la conversión y selectividad no se ven favorecidas, aunado a esto, los subproductos, la producción de coque y la desactivación del catalizador provocan que se tenga que detener el proceso repetidas veces para la limpieza de los equipos y que no se afecte el proceso en la transferencia de calor [1].

La des-hidrogenación oxidativa de etano a etileno $\left(\mathrm{DHO}-\mathrm{C}_{2}\right)$ representa una alternativa para sustituir los procesos convencionales de producción de olefinas ligeras tales como el etileno debido a las ventajas termodinámicas que estudios anteriores sugieren $[2,3]$. Sin embargo, hoy en día no se cuenta con un sistema que combine las propiedades de un catalizador selectivo a etileno capaz de operar a bajas temperaturas y la tecnología de un reactor que permita distribuir el calor producido durante la reacción para implementarse comercialmente. Por lo que en el presente trabajo se estudió el comportamiento de un catalizador multimetálico en un reactor de lecho fluidizado, para ello en el capítulo 2 se presenta el estado del arte donde se exponen los antecedentes de la DHO- $\mathrm{C}_{2}$ contemplando los estudios realizados en catalizadores multimetálicos selectivos al etileno así como las propuestas de los mecanismos de reacción y los reactores utilizados. Se consideraron los reactores de lecho fluidizado y una revisión de la participación de membranas de distribución y dosificación de reactivos en la selectividad.

En el capítulo 3 se presenta el planteamiento del problema considerando posible la mejora en el rendimiento de la reacción, el capítulo 4 plantea los objetivos general y específicos sobre los cuáles se desarrolla el trabajo. En el capítulo 5 se describe la metodología que 
se llevó a cabo para la realización del proyecto, se describen los experimentos cinéticos y el análisis de los parámetros en la respuesta de selectividad y conversión. Así también se presentan los modelos utilizados para la estimación de parámetros cinéticos y del reactor de lecho fluidizado, además las correlaciones utilizadas en el modelo del reactor así como las condiciones a las que se realizaron las simulaciones y las características que se evaluaron en la operación del reactor.

El capítulo 6 contiene el análisis de los resultados, este capítulo considera una sección para la discusión de las variables termodinámicas, los resultados de la estimación de los parámetros cinéticos y las predicciones del comportamiento del reactor a escala industrial así como una breve discusión de la participación del oxígeno en la selectividad del etileno a lo largo del reactor si este se alimenta parcialmente al sistema y finalmente en el capítulo 7 se presentan las conclusiones. 


\section{Capítulo 2}

\section{Estado del arte}

Una alternativa propuesta para sustituir los procesos de craqueo térmico y catalítico en la producción de etileno es la deshidrogenación oxidativa de etano $\left(\mathrm{DHO}-\mathrm{C}_{2}\right)$, dicha propuesta presenta diversas ventajas con respecto a los procesos convencionales: la principal es el ahorro energético debido a que la reacción es exotérmica lo que hace que el proceso se lleve a cabo a temperaturas menores a las del craqueo térmico y, además hace que el coque que se deposita en las paredes se produzca en menor cantidad haciendo que la transferencia de calor sea más eficiente lo que disminuye la desactivación del catalizador por sinterizado [3, 4]. A pesar de esto, la $\mathrm{DHO}-\mathrm{C}_{2}$ aún no es un proceso comerciable debido a que no se cuenta hoy en día con un catalizador que sea capaz de operar a estas condiciones y que sea rentable, y que además a nivel de reactor los problemas de control de temperatura originados por la exotermicidad de las reacciones hacen al proceso complejo y por lo tanto no se cuenta con la configuración de reactor para llevar a cabo esta reacción. Los estudios para mejorar y hacer rentable el proceso de $\mathrm{DHO}-\mathrm{C}_{2}$ se basan en la sinergia de dos aspectos generales, por un lado encontrar un catalizador lo suficientemente activo y selectivo a etileno y por otro lado, desarrollar la tecnología necesaria en cuanto al tipo y configuración de reactor se refiere, que garantice la producción de etileno para satisfacer su demanda.

\subsection{Catalizadores utilizados para reacciones de DHO}

Para las reacciones de oxidación catalítica es importante encontrar en el catalizador un balance entre la temperatura de activación y la selectividad, por lo que en las últimas décadas en la investigación de catalizadores para la DHO de olefinas ligeras se han propuesto una gran diversidad de catalizadores, que se pueden clasificar en tres grupos principales $[4,2]$ :

1. Los catalizadores basados en iones alcalinos, alcalinotérreos y óxidos. A este grupo pertenecen los catalizadores que contienen iones y óxidos de los grupos IA y IIA como 
el Li, Mg, ente otros, los cuales a pesar de ser selectivos al producto de interés sus temperaturas de activación superan los $600^{\circ} \mathrm{C}$ siendo un inconveniente para su implementación industrial. Por ejemplo, el catalizador de $\mathrm{BaF}_{2}$ que para alcanzar $89.7 \%$ de selectividad y $21 \%$ de conversión de etano requiere temperaturas de $700^{\circ} \mathrm{C}$ [5].

2. Los catalizadores basados en óxidos reducibles de metales de transición. A pesar de que este grupo de catalizadores aún no logran selectividades mejores a las del primer grupo, poseen la característica de que las temperaturas de activación son menores a los $600^{\circ} \mathrm{C}$ lo que representa una ventaja para su implementación. Los catalizadores más comunes se basan en una mezcla de mezcla de óxidos de Mo, V y Nb y constituyen un objetivo importante en la investigación de catalizadores para la DHO de etano a etileno [6,7] motivo por el cual ha atraído la atención de investigadores recientemente. Sin embargo, otros catalizadores se han propuesto de ese tipo de metales de transición como el caso del Ni-O combinado con W [8] y los basados en óxidos de vanadio [9].

3. Otros catalizadores: Este grupo de catalizadores contienen compuestos como $\mathrm{LaF}_{3^{-}}$ $\mathrm{CeO}_{2}$ [10], SAPO-34 [11], Pt,Sn/Mg(Al)O [12].

Debido a la importancia de los catalizadores basados en óxidos reducibles de metales de transición o de baja temperatura en la DHO de etano, a continuación se exponen algunos de los resultados de interés para este trabajo de investigaciones que han realizado diversos grupos de investigación de este tipo de catalizadores.

En 1978 Thorsteinson y col. publicaron un estudio para la producción de etileno a partir de etano utilizando un catalizador de óxidos de vanadio/molibdeno dopado con diferentes metales de transición ( $\mathrm{Ti}, \mathrm{Cr}, \mathrm{Mn}, \mathrm{Fe}, \mathrm{Co}, \mathrm{Ni}, \mathrm{Nb}$, Ta y Ce), en un rango de temperaturas de $280-550^{\circ} \mathrm{C}$. Los resultados indican que el $\mathrm{Nb}$ estabiliza la estructura del catalizador mejorando sus propiedades de óxido-reducción e incrementa su actividad alcanzando selectividades mayores al $80 \%$ y conversiones de etano de $10 \%$ [13]. Aunque otro tipo de catalizadores se han propuesto para la reacción de DHO de etano, los mejores resultados reportados se encuentraron en el uso de catalizadores de óxidos multimetálicos Mo-V-Nb presentado por Thorsteinson y col. (1978). Debido a esto la mayoría de las investigaciones se han enfocado a catalizadores cuya composición considere esta clase de metales $[6,7,14,15,16]$.

Ruth y col. (1998) estudiaron la estructura y las fases presentes del catalizador propuesto por Thorsteinson y col. Los resultados mostraron que la contribución a la actividad total del catalizador se controla por las propiedades fisicoquímicas del material más que la contribución en porcentaje peso del metal de transición presente [6]. La caracterización de las propiedades catalíticas de esta clase de materiales a diferentes condiciones de reacción que incluyen temperatura, tiempo de contacto y presión, sugieren una relación entre las propiedades del material y la actividad catalítica: la acidez del material favorece la adsorción y selectividad en la reacción de la molécula de etano, y la morfología microscópica juega un papel importante en la actividad y estabilidad del catalizador [17]. 
Ciambelli y col. (2000) presentan resultados del estudio de un catalizador de $\mathrm{VOPO}_{4} / \mathrm{TiO}_{2}$ para la $\mathrm{DHO}$ de etano a etileno en un rango de temperaturas de $450-550^{\circ} \mathrm{C}$ y W/F de 0.04 a $0.12 \mathrm{gsNcm}^{-3}$, encontraron que la selectividad a etileno disminuye con el tiempo de contacto pero incrementa con la temperatura. Así a $450^{\circ} \mathrm{C}$ la conversión de etano alcanza un $3 \%$ y la selectividad de etileno $65 \%$, mientras que a $550^{\circ} \mathrm{C}$ el etano tiene un $30 \%$ de conversión y un $60 \%$ selectividad ambas con el mismo tiempo de contacto [18].

Botella y col. (2003) presentan un estudio del comportamiento de un catalizador con la mezcla Mo-V-Nb-O para la $\mathrm{DHO}-\mathrm{C}_{2}$ en el que consideran diferentes fracciones de composición y condiciones de calcinación para obtener un catalizador selectivo a etileno. La composición del Mo se mantuvo constante para todas las muestras mientras que la de $\mathrm{V}$ se varió de $0.3,0.6$ y 0.9 y el Nb 0.12 y 0.24 . Los experimentos desarrollados en un reactor tubular trabajando a presión atmosférica en un rango de temperaturas de $340-400^{\circ} \mathrm{C}$ con tamaños de partículas para el catalizador de 0.3-0.5 mm alcanzan selectividades de hasta $75 \%$ para etileno cuando no hay $\mathrm{Nb}$ presente y 0.6 de $\mathrm{V}$, y conversión superior a $20 \%$ con la misma cantidad de $\mathrm{V}$ y un porcentaje de 0.12 de Nb: La alimentación fue de 30/10/60 de etano/oxígeno/helio. Sin embargo, la selectividad de etileno decrece conforme aumenta la conversión de etano [14].

López Nieto y col. (2004) incorporan Telurio a la mezcla Mo-V-Nb-O por diferentes métodos para la DHO de etano y propano, teniendo selectividades a etileno mayores a $80 \%$, este comportamiento se explica por la formación de fases altamente selectivas a temperaturas de reacción de $340-400^{\circ} \mathrm{C}$. [16]. Botella y col. (2004) evalúan este tipo de materiales propuestos por López Nieto en un reactor tubular de lecho fijo a presión atmosférica, con tasas de alimentación de 25-100 ml min ${ }^{-1}$ y tamaños de partículas de 0.3-0.5 mm en cantidades que variaron de 0.5-2.0 g del catalizador. La alimentación consistió en una mezcla de etano/oxígeno/helio en un rango de temperaturas de $325-425^{\circ} \mathrm{C}$ para la DHO de etano a etileno para el mejor catalizador $(1 / 0.14 / 0.17 / 0.19$ de $\mathrm{Mo} / \mathrm{V} / \mathrm{Nb} / \mathrm{Te})$ la selectividad y conversión superaron el $80 \%[7]$.

\subsection{Estudios cinéticos y mecanismos de reacción}

Los modelos más utilizados para la descripción cinética de la DHO de alcanos ligeros son: Langmuir-Hinshelwood y Mars van Krevelen. En el modelo cinético de LangmuirHinshelwood se considera que todas las especies son adsorbidas antes de que reaccionen. Una variación de este mecanismo es el mecanismo de Eley-Rideal en el que se considera que una de las especies es adsorbida antes de reaccionar y las demás toman parte en la reacción desde la fase gas. Esquemáticamente los pasos de reacción con dos reactivos se representan así:

$$
A_{g}+* \longleftrightarrow A_{a d s}
$$




$$
\begin{gathered}
B_{g}+* \longleftrightarrow B_{a d s} \\
A_{a d s}+B_{a d s} \longleftrightarrow C_{a d s} \\
C_{a d s} \longleftrightarrow C_{g}+*
\end{gathered}
$$

Así los diferentes pasos de la reacción en este mecanismo son: la adsorción de los reactivos (1) y (2), su reacción superficial (3) y la desorción del producto (4) donde * representa los sitios activos del catalizador disponibles para que se lleve a cabo la reacción. Cualquiera de los pasos expuestos puede ser el paso limitante de la reacción. El mecanismo de tipo Mars Van Krevelen o modelo del tipo redox considera la participación del oxígeno desde la estructura o lattice del catalizador, el catalizador es reducido para la formación de productos y es re-oxidado por el oxígeno presente en la fase gas. Este mecanismo es característico en los catalizadores multimetálicos utilizados para la reacción de deshidrogenación oxidativa de olefinas $[4,19]$.

$$
\begin{gathered}
C_{2} H_{n+2}+\text { cat }_{o x} \longleftrightarrow C_{2} H_{n}+\text { cat }_{r e d} \\
\text { cat }_{r e d}+\mathrm{O}_{2} \longleftrightarrow \text { cat }_{o x}
\end{gathered}
$$

Estudios realizados a catalizadores multimetálicos de NiVMo han aportado información acerca de su estructura, que permite identificar los sitios activos y el posible mecanismo de reacción de la DHO de etano a etileno. Sin embargo, no se ha definido un mecanismo totalmente aceptado. A pesar de ello de las diversas propuestas se puede resumir que el mecanismo de reacción para DHO de etano a etileno involucra cuatro pasos característicos en la superficie catalítica de algunos materiales [4]:

1. La interacción del etano con la superficie del catalizador.

2. Una ruptura del enlace $\mathrm{C}-\mathrm{H}$ formando especies alkyl.

3. La reacción de estas especies alkil con un oxígeno de la superficie del catalizador $\beta$ eliminación y la formación del etileno, en menor medida un intermediario como el caso del ácido acético comercial [20,21, 17, 13, 22, 13].

4. La reoxidación del catalizador reducido. 
Varias son las investigaciones enfocadas a desarrollar un mecanismo cinético para la DHO, algunos de los reportes que se revisaron consideran diferentes rutas de reacción y la participación de subproductos de diferente tipo por lo que la discusión acerca de cuál es el mecanismo de reacción continua.

Canavi y Trifiró (1995) presentan un resumen de los mecanismos propuestos en la literatura de la oxi hidrogenación de etano. Dependiendo de la temperatura esta reacción puede llevarse a cabo en la fase gaseosa o en la superficie del catalizador $<600^{\circ} \mathrm{C}$, cuando la reacción se lleva a cabo en el catalizador se resalta como paso controlante la adsorción del etano y su interacción con la superficie catalítica oxidada que da lugar a la liberación de un hidrógeno para formar especies $\mathrm{C}_{2} \mathrm{H}_{5} \mathrm{O}^{-}$y $\mathrm{OH}^{-}$como precursores para la formación de $\mathrm{C}_{2} \mathrm{H}_{4}, \mathrm{CO}_{2}$ y $\mathrm{H}_{2} \mathrm{O}[2]$.

Por su parte Yokoyama (1996) estudió la adición de varios metales monolitos cubierto de Pt para la deshidrogenación oxidativa de etano a etileno, este trabajo discute el mecanismo de reacción propuesto por Huff y Schmidt en 1993 en el que se considera la disociación de etano a $\mathrm{C}_{2} \mathrm{H}_{5}(\mathrm{ad})$ y $\mathrm{OH}(\mathrm{ad})$ en la superficie oxidada del medio, para dar paso a dos rutas diferentes de reacción. Por un lado directamente a la $\beta$-eliminación de hidrógeno que produce $\mathrm{C}_{2} \mathrm{H}_{4}(\mathrm{ad})$ el cuál se desorbe para formar etileno y por otro lado la eliminación hidrógeno del $\mathrm{C}_{2} \mathrm{H}_{5}(\mathrm{ad})$ que produce $\mathrm{C}_{2} \mathrm{H}_{4} \mathrm{y} /$ o $\mathrm{CO}_{x}[23,24]$.

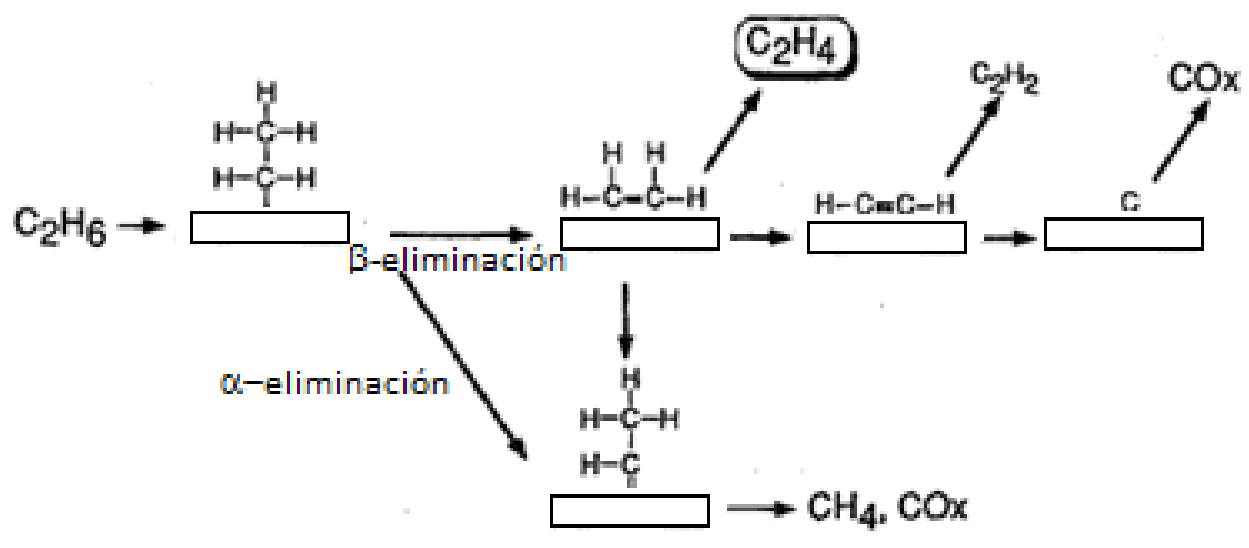

Figura 2.1: Esquema del mecanismo de reacción de DHO propuesto por Yokoyama [23].

Ruth y col. (1998) estudiaron las propiedades químicas y catalíticas del óxido de Mo-V$\mathrm{Nb}$ como catalizador para la $\left(\mathrm{DHO}-\mathrm{C}_{2}\right)$, ellos sugieren un resumen de los mecanismos para esta reacción, en el que consideran que la molécula de etano es adsorbida en la superficie del catalizador como un etóxido tal como lo sugiere para el $\mathrm{Mo}^{V I}$ Thornsteinson y col en 1978, siendo este compuesto el que se transforma en etileno por una $\beta$-eliminación [17]. 
Linke y col. (2002) describen un modelo cinético que considera dos sitios activos diferentes $\mathrm{Z}$ y X para un catalizador de $\mathrm{Mo}_{1} \mathrm{~V}_{0} .25 \mathrm{Nb}_{0} .12 \mathrm{Pd}_{0} .0005 O \mathrm{x}$. El primero representa un sitio donde ocurre la reacción de DHO de etano, la oxidación total o parcial de etileno a ácido acético. Mientras, que el segundo, es un sitio del catalizador que se activa en presencia de agua, con la activación de este sitio lleva a cabo la conversión del etileno a ácido acético por un mecanismo tipo Wacker. Contrario a lo que se esperaba el catalizador es selectivo a etileno a temperaturas mayores de $520^{\circ} \mathrm{C}$ lo que sugiere la oxidación parcial a etileno absorbido en sitios Z. La Tabla 2.1 resume los datos de reacciones, tasas de reacción y parámetros óptimos de este modelo cinético [20, 22].

En 2002 se destaca la publicación de Morris y col. quienes utilizan catalizadores de óxidos de vanadio en dos soportes diferentes, $\mathrm{VO}_{x} / \mathrm{Al}_{2} \mathrm{O}_{3}$ y $\mathrm{VO}_{x} / \mathrm{ZrO}_{2}$ para la $\mathrm{DHO}$ de etano a etileno. El esquema de reacción propuesto considera de una serie de pasos elementales en los que el oxígeno de la lattice representado como $\mathrm{O}^{*}$ en las ecuaciones siguientes, se puede encontrar en tres maneras diferentes $(\mathrm{O}=\mathrm{V}, \mathrm{V}-\mathrm{O}-\mathrm{V}$ o $\mathrm{V}-\mathrm{O}-\mathrm{M}$ donde $\mathrm{V}$ es el Vanadio, $\mathrm{O}$ es oxígeno y $\mathrm{M}$ es el soporte), la formación de $\mathrm{C}_{2} \mathrm{H}_{5} \mathrm{O}^{*}$ en el segundo paso es una especie etóxido adherido al catión $\mathrm{V}\left(\mathrm{C}_{2} \mathrm{H}_{5}-\mathrm{O}-\mathrm{V}\right)$ y solo es relevante cuando el $\mathrm{O}^{*}$ es el reactivo más abundante (MARI por sus siglas en inglés). El grupo hidroxil $\mathrm{OH}^{*}$ está unido a $\mathrm{V}$ o M y el sitio reducido es representado por ${ }^{*}$, mismo que se re-oxida en el paso cinco del esquema con $\mathrm{O}_{2}[3]$.

$$
\begin{gathered}
\mathrm{C}_{2} \mathrm{H}_{6}+\mathrm{O}^{*} \leftrightarrows \mathrm{C}_{2} \mathrm{H}_{6} \mathrm{O}^{*} \\
\mathrm{C}_{2} \mathrm{H}_{6} \mathrm{O}^{*}+\mathrm{O}^{*} \stackrel{k_{2}}{\longrightarrow} \mathrm{C}_{2} \mathrm{H}_{5}^{*}+O H^{*} \\
\mathrm{C}_{2} \mathrm{H}_{5} \mathrm{O}^{*}+\mathrm{O}^{*} \stackrel{k_{3}}{\longrightarrow} \mathrm{C}_{2} \mathrm{H}_{4}+O H^{*} \\
O H^{*}+O H^{*} \stackrel{k_{4}}{\longrightarrow} \mathrm{H}_{2} \mathrm{O}+\mathrm{O}^{*}+^{*} \\
\mathrm{O}_{2}+^{*}+{ }^{*} \stackrel{k_{5}}{\longrightarrow} \mathrm{O}^{*}+^{*}
\end{gathered}
$$

Heracleous y Lemonidou (2006) realizaron experimentos cinéticos para estudiar la naturaleza de los compuestos de oxígeno que participan en la reacción de DHO de etano a etileno con el objetivo de elucidar el mecanismo de reacción en catalizadores basados en Ni.

Para un catalizador Ni-Nb-O con $46 \%$ de alimentación de etano a $400^{\circ} \mathrm{C}$, estos investigadores sugieren la participación de aniones de oxígeno de la lattice como en un mecanismo del tipo Mars Van Krevelen en donde se tienen una disociación rápida de oxígeno dando como 
Tabla 2.1: Reacciones, tasas de reacción y algunos parámetros óptimos del modelo cinético propuesto por Linke y col. 2002 [20].

\begin{tabular}{|c|c|c|c|}
\hline j Reacción & Ecuación & $\begin{array}{c}\mathrm{k} \text { a } 539 \mathrm{~K} \\
\operatorname{mol}(\operatorname{skgPa})^{-1}\end{array}$ & $\begin{array}{c}E a \text { o } \Delta H_{a d s} \\
\left(k J m o l^{-1}\right)\end{array}$ \\
\hline $\begin{array}{l}\text { Activación de etano } \\
\mathrm{C}_{2} \mathrm{H}_{6}+\mathrm{Z}-\mathrm{O} \rightarrow \mathrm{Z}-\mathrm{C}_{2} \mathrm{H}_{4}+\mathrm{H}_{2} \mathrm{O}\end{array}$ & $r_{1}=K_{1} P_{C_{2} H_{6}} \theta_{Z-O}$ & $K_{1}=1.67 x 10^{-9}$ & 99.7 \\
\hline $\begin{array}{l}\text { Formación de ácido acético } \\
\mathrm{Z}-\mathrm{C}_{2} \mathrm{H}_{4}+\mathrm{O}_{2} \rightarrow \mathrm{Z}+\mathrm{CH}_{3} \mathrm{COOH}\end{array}$ & $r_{2}=K_{2} P_{O_{2}} \theta_{Z-C_{2} H_{4}}$ & $K_{2}=1.25 x 10^{-9}$ & 92.6 \\
\hline $\begin{array}{l}\mathrm{C}_{2} \mathrm{H}_{4}+\mathrm{X}-\mathrm{OHOH}+0.5 \mathrm{O}_{2} \\
\rightarrow \mathrm{CH}_{3} \mathrm{COOH}+\mathrm{X}+\mathrm{H}_{2} \mathrm{O}\end{array}$ & $r_{3}=K_{3} P_{C_{2} H_{4}} \theta_{X-2 O H}$ & $K_{3}=1.25 x 10^{-5}$ & 144 \\
\hline $\begin{array}{l}\text { Reoxidación del catalizador } \\
0.5 \mathrm{O}_{2}+Z \rightarrow Z-O\end{array}$ & $r_{4}=K_{2} P_{O_{2}} \theta_{Z}$ & $K_{4}=1.71 \times 10^{-8}$ & 123 \\
\hline $0.5 O_{2}+X \rightarrow X-O$ & $r_{5}=K_{5} P_{O_{2}} \theta_{X}$ & $K_{5}=4.45 \times 10^{-9}$ & 85.2 \\
\hline
\end{tabular}

Adsorción/desorción de etano y agua

$$
\begin{aligned}
& \mathrm{C}_{2} \mathrm{H}_{4}+\mathrm{Z} \leftrightarrows Z-\mathrm{C}_{2} \mathrm{H}_{4} \quad r_{6}=\frac{K_{6} P_{C_{2} H_{4}} \theta_{Z}-K_{6}}{K_{6} \theta_{Z-C 2 H 4}} \quad K_{6}=6.23 \times 10^{-8} \\
& K_{6}=\frac{2.48 \times 10^{-4}}{P a} \\
& \mathrm{H}_{2} \mathrm{O}+\mathrm{Z} \leftrightarrows \mathrm{Z}-\mathrm{H}_{2} \mathrm{O} \quad r_{7}=\frac{K_{7} P_{\mathrm{H}_{2} O} \theta_{Z}-K_{7}}{K_{7} \theta_{Z-H_{2} O}} \quad K_{7}=1.36 \times 10^{-1}
\end{aligned}
$$

Formación del centro Wacker

$$
\begin{array}{rr}
X-\mathrm{O}+\mathrm{H}_{2} \mathrm{O} \rightarrow \mathrm{X}-\mathrm{OHOH} \quad r_{8}=\frac{K_{8} P_{\mathrm{H}_{2} \mathrm{O}} \theta_{X-\mathrm{O}}}{K_{8} \theta_{X-\mathrm{OHOH}}}-K_{8} \quad K_{8}=2.63 \times 10^{-9} \\
K_{8}=\frac{5.4 x 10^{-6}}{P a}
\end{array}
$$

Pasos no selectivos de la reacción

$$
\begin{array}{lcc}
C_{2} H_{6}+Z-O \rightarrow Z-C_{2} H_{4}+H_{2} O & r_{9}=K_{9} P_{C_{2} H_{6}} \theta_{Z-O} & K_{9}=3.36 x 10^{-10} \\
C_{2} H_{6}+Z-O \rightarrow Z-C_{2} H_{4}+H_{2} O & r_{1} O=K_{10} P_{C_{2} H_{6}} \theta_{Z-O} & K_{1} 0=2.02 \times 10^{-8}
\end{array}
$$


Tabla 2.2: Modelos mecanísticos por el mecanismo MVK propuestos para la DHO de etano [26].

\section{Modelo B}

DHO Etano en sitios M

1. $\mathrm{C}_{2} \mathrm{H}_{6}+[\mathrm{M}-\mathrm{O}] \rightarrow \mathrm{C}_{2} \mathrm{H}_{4}+\mathrm{H}_{2} \mathrm{O}+[\mathrm{M}]$

$$
r_{1}=K_{1} P_{C_{2} H_{6}} \theta_{[M-O]}^{1}
$$

Oxidación total primaria y secundaria en sitios $\mathrm{T}$

2. $\mathrm{C}_{2} \mathrm{H}_{6}+[\mathrm{T}-\mathrm{O}]+3 \mathrm{O}_{2} \rightarrow 2 \mathrm{CO}_{2}+3 \mathrm{H}_{2} \mathrm{O}+[\mathrm{T}]$

$$
\begin{aligned}
& r_{2}=K_{2} P_{C_{2} H_{6}} \theta_{[T-O]}^{2} \\
& r_{3}=K_{3} P_{C_{2} H_{4}} \theta_{[T-O]}^{1}
\end{aligned}
$$

3. $\mathrm{C}_{2} \mathrm{H}_{4}+[\mathrm{T}-\mathrm{O}]+2.5 \mathrm{O}_{2} \rightarrow 2 \mathrm{CO}_{2}+2 \mathrm{H}_{2} \mathrm{O}+[\mathrm{T}]$

Ad/desorción de agua en los sitios M
4. $\mathrm{H}_{2} \mathrm{O}+[\mathrm{M}]+[\mathrm{M}-\mathrm{O}] \rightarrow 2[\mathrm{M}-\mathrm{OH}]$
$r_{4}=K_{4} P_{H_{2} O} \theta_{[M-O]}^{1} \theta_{[M]}+\frac{k_{4} \theta_{[M-O H]}^{2}}{K_{4}}$

Re-oxidación del catalizador

5. $5 \mathrm{O}_{2}+[M] \rightarrow[M-O]$

$$
\begin{aligned}
& r_{5}=K_{5} P_{O_{2}} \theta_{[M]}^{1 / 2 o 1} \\
& r_{6}=K_{6} P_{O_{2}}^{1 / 2} \theta_{[T]}^{1 / 2}
\end{aligned}
$$$$
\text { 6. } 5 \mathrm{O}_{2}+[M] \rightarrow[M-O]
$$

\section{Modelo $\mathbf{C}$}

DHO Etano en sitios M
1. $\mathrm{C}_{2} \mathrm{H}_{6}+[\mathrm{M}-\mathrm{O}] \rightarrow \mathrm{C}_{2} \mathrm{H}_{4}+\mathrm{H}_{2} \mathrm{O}+[\mathrm{M}]$
$r_{1}=K_{1} P_{C_{2} H_{6}} \theta_{[M-O]}^{1 o 2}$

Oxidación total primaria y secundaria en sitios $\mathrm{T}$

2. $\mathrm{C}_{2} \mathrm{H}_{6}+[\mathrm{T}-\mathrm{O}]+3 \mathrm{O}_{2} \rightarrow 2 \mathrm{CO}_{2}+3 \mathrm{H}_{2} \mathrm{O}+[\mathrm{T}]$

$$
\begin{aligned}
& r_{2}=K_{2} P_{C_{2} H_{6}} \theta_{[T-O]}^{2} \\
& r_{3}=K_{3} P_{C_{2} H_{4}} \theta_{[T-O]}^{1}
\end{aligned}
$$

3. $\mathrm{C}_{2} \mathrm{H}_{4}+[\mathrm{T}-\mathrm{O}]+2.5 \mathrm{O}_{2} \rightarrow 2 \mathrm{CO}_{2}+2 \mathrm{H}_{2} \mathrm{O}+[\mathrm{T}]$

Ad/desorción de agua en los sitios M

4. $\mathrm{H}_{2} \mathrm{O}+[\mathrm{M}]+[\mathrm{M}-\mathrm{O}] \rightarrow 2[\mathrm{M}-\mathrm{OH}]$

$$
r_{4}=K_{4} P_{H_{2} O} \theta_{[M-O]}^{1} \theta_{[M]}+\frac{k_{4} \theta_{[M-O H]}^{2}}{K_{4}}
$$

Re-oxidación del catalizador
5. $5 \mathrm{O}_{2}+[M] \rightarrow[M-O]$
$r_{5}=K_{5} P_{O_{2}} \theta_{[M]}^{1 / 2}$
6. $5 \mathrm{O}_{2}+[M] \rightarrow[M-O]$
$r_{6}=K_{6} P_{O_{2}} \theta_{[T]}^{1}$ 
resultado la formación de especies de oxígeno electrofílicas cuya activación es responsable de la oxidación total del etano.

La reacción DHO sobre el Ni involucra reacciones paralelas que considera la formación del $\mathrm{CO}_{2}$ la activación irreversible del etano por especies $\mathrm{O}^{-}$para la formación de etileno. Los autores proponen cuatro modelos diferentes; el esquema general de reacciones lo forman tres pasos: (1) la DHO de etano a etileno, (2) la oxidación total del etano a dióxido de carbono y (3) la oxidación consecutiva del eteno a dióxido de carbono, con una tasa de reacción para cada una expresada como: $r i=k i\left(P_{\mathrm{HC}_{\mathrm{C}}}\right)^{a}\left(P_{\mathrm{O}_{2}}\right)^{b}$.

La Tabla 2.2 presenta dos de los cuatro modelos propuestos que resumen las suposiciones consideradas, en todos los modelos se considera la re-oxidación de sitios activos por $\mathrm{O}_{2}$ gas irreversible y dos tipos de sitios para las diferentes reacciones [25].

\subsection{Reactores utilizados para DHO-C2}

Siendo los reactores la parte esencial en el diseño y optimización de un proceso, su configuración y parámetros de operación han sido objetivo de muchos estudios de investigación por parte de la industria y la academia para diversos procesos. Para el caso de la reacción de deshidrogenación oxidativa de compuestos como el propano y etano, actualmente no se tiene en operación un reactor a escala industrial. En la literatura se ha propuesto para esta reacción, reactores de lecho fijo y lecho fluidizado estudiando mediante el modelado su posible comportamiento [27, 28, 29, 30].

Recientemente la atención se ha enfocado en estudiar el comportamiento de estos reactores asistidos por membranas como una herramienta para mejor la selectividad hacia las olefinas de interés. Para reacciones de DHO de etano, propano y butano se ha demostrado que a escala banco la implementación de membranas en los reactores resulta favorable [31]. El caso particular de DHO de etano a etileno no ha sido muy investigado en estos aspectos, sin embargo resultados obtenidos para reacciones de oxidación catalítica o similares [32, 33] permiten suponer un comportamiento similar en el que las membranas jueguen un papel importante en la selectividad del etileno.

En 1995 se publicó un estudio desarrollado por Coronas y col. de un reactor con membrana de cerámica para $\mathrm{DHO}$ de etano a etileno en un reactor de lecho fijo con $\mathrm{Li} / \mathrm{MgO}$ como catalizador, el oxígeno se alimentó a través de la membrana mientras el etano se alimentó axialmente. El reactor de membrana porosa consistió de un tubo de alúmina porosa cuya permeabilidad fue adaptada para distribuir el oxígeno necesario para la reacción de DHO de etano. El lecho de catalizador consistió en una longitud de $14 \mathrm{~cm}$ de largo y un diámetro interno del tubo de $6.6 \mathrm{~mm}$. Las temperaturas de reacción se variaron entre 590 y $740^{\circ} \mathrm{C}$ con relaciones de etano/oxígeno desde 4:1 a 4:3. El reactor de membrana permitió un funcionamiento estable térmicamente incluso con relaciones de $\mathrm{C}_{2} \mathrm{H}_{6} / \mathrm{O}_{2}$ bastante bajos. El 
comportamiento de este reactor se comparó con su operación sin membrana y se observó que la selectividad a etileno es similar en ambos reactores, no obstante se observó que el papel de la membrana es reducir la presencia de los puntos calientes [34].

Wang y col. (2002) estudiaron la posibilidad de suministrar continuamente el óxido de la lattice para controlar la reacción de $\mathrm{DHO}$ de etano a etileno en un reactor de membrana permeable de oxígeno de $\mathrm{Ba}_{0.5} \mathrm{Sr}_{0.5} \mathrm{Co}_{0.8} \mathrm{Fe}_{0.2} \mathrm{O}_{x}$ misma que funciona como catalizador. Los resultados a $650^{\circ} \mathrm{C}$ y $6.1 \mathrm{ml} / \mathrm{min}$ de alimentación de etano alcanzan selectividades de $90.6 \mathrm{con}$ $18 \%$ de conversión; aunque para diversos modos de operación (ver Figura 2.1) del sistema la selectividad no cambia mucho la conversión de etano varió desde 3.4 a $23 \%$ [35].

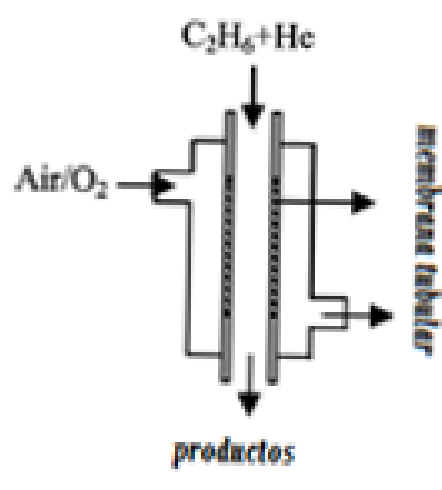

(a)

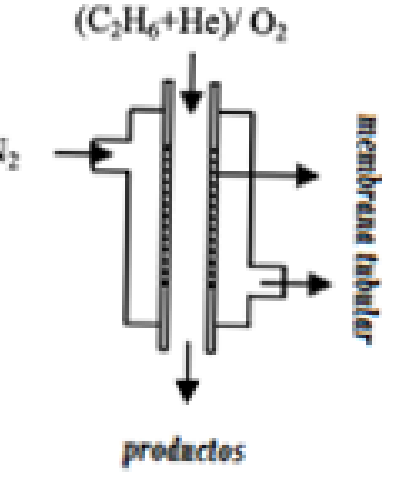

(b)

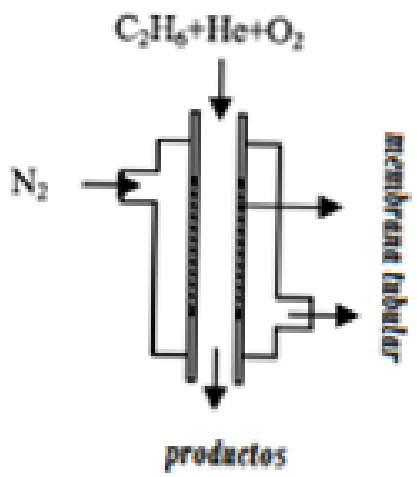

(c)

Figura 2.2: Comparación de modos de operación de un reactor de membrana permeable: a) Modo membrana b) $\mathrm{O}_{2}$ y etano diluido con helio alimentado alternativamente y c) Modo de co-alimentación.

Klose y col. (2004) realizaron la comparación de reactores a escala laboratorio de lecho empacado con y sin membrana PBMR y PBR respectivamente, para la oxidación catalítica de etano sobre $\mathrm{VO}_{X} / \alpha-\mathrm{Al}_{2} \mathrm{O}_{3}$. Pellets de $1.8 \mathrm{~mm}$ de diámetro fueron empacados en un reactor de lecho fijo de diámetro interno de $15 \mathrm{~mm}$ y $30 \mathrm{~mm}$ de longitud para 3.1 gramos de catalizador. El reactor empacado con membrana consistió de una cerámica inerte con un diámetro de poro de $10 \mathrm{~nm}$. Se estudiaron tres modos de operación para el reactor con membrana; el primero se caracterizó por alimentar un exceso de hidrocarburo y tener tiempos de contacto largos este favoreció la formación de etileno, el segundo implica exceso de oxígeno, tiempos de contacto cortos y temperaturas menores a $600^{\circ} \mathrm{C}$ en el que la formación de $\mathrm{CO}$ se favorece, en el tercer caso el PBMR es operado a con un exceso de oxígeno, tiempos de contacto largos y temperaturas superiores a los $550^{\circ} \mathrm{C}$ la selectividad tanto de los intermediarios como del etileno y $\mathrm{CO}$ fue significativamente más baja en PBMR comparado con PMR, en este caso se favorece la producción de $\mathrm{CO}_{2}$. En este como en el caso anterior son 
modos en los que el tiempo de contacto es más importante en los perfiles de concentración para mejorar la selectividad, de acuerdo a los resultados que obtuvieron, tiempos de contacto prolongados mejoran la conversión y la selectividad a etileno en un reactor con membrana PBR [33].

Achieva y col. (2005) comparan experimentalmente el comportamiento de un reactor de lecho fluidizado sin membrana (FLBR) y uno con membrana (FLBMR) a escala piloto para la DHO de etano usando un catalizador de $\mathrm{VO}_{X} / \gamma-\mathrm{Al}_{2} \mathrm{O}_{3}$. Se estudiaron los efectos de temperatura en un rango de $500-680^{\circ} \mathrm{C}$, el suministro de oxígeno de $0.4-4.2 \%$ y W/F de $150-230 \mathrm{~kg} / \mathrm{m} 3$. Ambas configuraciones se operaron a presión atmosférica a $500^{\circ} \mathrm{C}$ con una velocidad mínima de fluidización de las partículas del catalizador de $0.48 \mathrm{~m} / \mathrm{s}$. Los resultados mostraron una mejora en la selectividad del etileno en el FBLMR (superior $20 \%$ ) a pesar de que la conversión de etano fue $6 \%$ mayor en FLBR. Comparando las producciones máximas se obtuvo $36.6 \%$ en el FBLMR contra un $23.3 \%$ en FBLR.

Por otro lado, la selectividad del oxígeno se ve menos afectada en el reactor con membrana cuando este se alimenta en exceso, es decir, la producción de etileno es mayor en un FLBR comparado con FLBMR a bajas proporciones de oxígeno-hidrocarburo, en tanto que un exceso de oxígeno en las condiciones de alimentación favorece la selectividad en un FLBMR la cuál puede atribuirse a la baja concentración axial promedio de oxígeno [15].

Rodríguez y col. (2010) publican los resultados de un estudio de un reactor multi-tubular de lecho empacado con membrana para la DHO de etano a etileno sobre un catalizador de Ni$\mathrm{Nb-O}$, tomando en cuenta la composición radial y perfiles de temperatura con un modelo de dos dimensiones pseudo-homogéneo. El reactor se asumió aislado con pérdidas despreciables de calor al ambiente, con longitud de $4 \mathrm{~m}, d_{t} 2.66 \mathrm{~cm}$ en un rango de temperaturas de $370-$ $430^{\circ} \mathrm{C}$ las partículas de catalizador se consideraron como cilindros del tipo Rasching de $6 \mathrm{~mm}$ x $6 \mathrm{~mm}$ x $2 \mathrm{~mm}$ para disminuir las caídas de presión con fracción vacía de 0.48 , la membrana inerte distribuye el reactivo a lo largo de los tubos, reduciendo las presiones parciales de oxígeno dentro del reactor permitiendo que la selectividad del etileno aumente y mejore la transferencia de calor [31]. 


\section{Capítulo 3}

\section{Planteamiento del problema}

Los procesos actuales de craqueo térmico o catalítico para la producción de olefinas ligeras tales como el etileno han mostrado desventajas en el consumo energético debido a la naturaleza endotérmica de las reacciones. Por otro lado, se espera que en los próximos años la demanda de etileno aumente y que los procesos actuales sean insuficientes para satisfacer dicha demanda. Recientemente, la deshidrogenación oxidativa de etano a etileno $\left(\mathrm{DHO}-\mathrm{C}_{2}\right)$ representa una alternativa capaz de minimizar las desventajas energéticas de los procesos actuales que puede ayudar a incrementar los niveles de producción de etileno.

La investigación de catalizadores altamente selectivos para el etileno en una reacción de DHO- $\mathrm{C}_{2}$ que puedan implementarse industrialmente El catalizador es uno de los dos aspectos más importantes que se consideran para poder sustituir o complementar los procesos de craqueo actuales. Actualmente, un catalizador multimetálico compuesto por MoVTeNbO promete buenos resultados para la conversión de etano y selectividad de etileno a temperaturas menores a los $480^{\circ} \mathrm{C}$. Dicho catalizador está siendo investigado como una opción para implementarse en un proceso a escala industrial para a DHO de etano por su elevada conversión y principalmente por su alta selectividad.

Además, la búsqueda de la tecnología en la que pueda llevarse a cabo la reacción de DHO$\mathrm{C}_{2}$ es otro aspecto de interés para la implementación industrial de este proceso. Actualmente esta reacción se ha indagado en el uso de reactores de lecho fijo y lecho fluidizado, este último elimina la desventaja de la generación de puntos calientes y caídas de presión que se tienen en reactores de lecho fijo, por lo que sugieren una alternativa para que la producción de etileno se lleve a cabo a nivel industrial.

Actualmente esta reacción se ha evaluado mediante la simulación en reactores de lecho fijo y lecho fluidizado, estos últimos se sugieren una alternativa capaz de aumentar la producción de etileno a nivel industrial mejorando su selectividad sobre otros productos presentes en la reacción. En ese sentido es necesario estudiar las condiciones de reacción y operación de 
un reactor de lecho fluidizado con un catalizador altamente selectivo para llevar a cabo la reacción.

\subsection{Hipótesis}

El uso de un reactor de lecho fluidizado es una alternativa viable para llevar a cabo la reacción de $\mathrm{DHO}-\mathrm{C}_{2}$ por las ventajas que tiene con respecto a los reactores de lecho fijo, principalmente, no hay presencia de puntos calientes que puedan afectar la selectividad del catalizador así como su desactivación por el fenómeno de sinterizado. 


\section{Capítulo 4}

\section{Objetivos}

\section{General}

Modelar el comportamiento de un reactor de lecho fluidizado a escala industrial utilizando un catalizador multi-metálico (MoTeNbVO) para una reacción de deshidrogenación catalítica de etano a etileno con y sin distribuidor de oxígeno.

\section{Específicos}

- Desarrollar el modelo cinético para la DHO de etano a etileno por el mecanismo de MVK en un catalizador MoTeNbVO altamente selectivo a etileno.

- Desarrollar el modelo de un reactor de lecho fluidizado que acople el comportamiento catalítico del catalizador con los fenómenos de transporte de masa a nivel del reactor. 


\section{Capítulo 5}

\section{Metodología}

En esta sección se presenta la metodología que se desarrolló para cumplir los objetivos del proyecto. Primero se presenta el equipo donde se llevaron a cabo los experimentos cinéticos. Se describe el diseño experimental y la estrategia estadística desarrollada para ampliar la base de datos experimentales que se utilizaron para el desarrollo del modelo cinético. Segundo, se presenta el planteamiento del modelo cinético del tipo Mars van Krevelen y el algoritmo de solución del modelo y de Levenberg-Maquart para la estimación de los parámetros cinéticos correspondientes. Finalmente se presenta el planteamiento del modelo de un reactor de lecho fluidizado a escala industrial y de las simulaciones que se realizaron con una sola alimentación y considerando una alimentación distribuida de oxígeno.

\subsection{Experimentos: equipo, catalizador, diseño y ma- nejo de datos.}

Los experimentos para observar el efecto de la temperatura y el W/F en la selectividad de etileno, $\mathrm{CO}$ y $\mathrm{CO}_{2}$ y en la conversión de etano y oxígeno fueron realizaron por el grupo de trabajo en colaboración con el IMP mismos que están reportados [27] basándose en un diseño factorial $3^{2}$ en una unidad de micro-reacción. La unidad de reacción que comprende el reactor de cuarzo de tipo tubular empacado con catalizador y un horno de calentamiento fue operado en modo isotérmico, un alimentación constante.

La reacción tuvo lugar en un lecho catalítico de $0.6 \mathrm{~g}$ de catalizador multi-metálico compuesto de MoVTeNbO sintetizado por el IMP a tres temperaturas diferentes (400, $440 \mathrm{y}$ $480{ }^{\circ} \mathrm{C}$ ) con valores de $\mathrm{W} / \mathrm{F}$ de $23,46.5$ y $70 \mathrm{~g}_{\text {cat }} \mathrm{h} / \mathrm{molC}_{2}$. El catalizador fue tamizado para tener un tamaño de partícula promedio de 150 micrones para despreciar las resistencias a la transferencia de masa intrapartícula. La fracción vacía del lecho fue de 0.3. El reactor se 
operó en régimen integral y se registraron la conversión de etano y oxígeno $\left(X_{\mathrm{O}_{2}} \mathrm{y} X_{C_{2}}\right)$ y las selectividades de $\mathrm{C}_{2} \mathrm{H}_{4}, \mathrm{CO}$ y $\mathrm{CO}_{2}\left(S_{C_{2}}, S_{C_{2}}\right.$ y $\left.S_{C O}\right)$ en estado estacionario.

La selectividad y conversión están definidas por:

$$
\begin{gathered}
S_{i}=\frac{C_{i}^{\text {prod }}}{C_{C_{2}}^{\text {cons }}} \\
X_{C_{2} H_{6}}=\frac{F_{C_{2} H_{6}}^{\circ}-F_{C_{2} H_{6}}}{F_{C_{2} H_{6}}^{\circ}}
\end{gathered}
$$

Dónde:

$S=$ Selectividad del C del compuesto i

$C_{i}^{\text {prod }}=$ Moles de C producidos en el compuesto i $\left(\mathrm{mmol} / \mathrm{m}^{3}\right)$

$C_{C_{2}}^{\text {cons }}=$ Moles de $\mathrm{C}$ consumidos de etano $\left(\mathrm{mmol} / \mathrm{m}^{3}\right)$

$X_{C_{2} H_{6}}=$ Conversión de $\mathrm{C}$ de etano

$M_{i}=$ Peso molecular del compuesto i (gmol)

El flujo molar del sistema se calculó con los datos de la composición de entrada y presión del gas con la ley de gases ideales para cada compuesto.

$$
F_{i}=\frac{Y_{i} P Q}{R T}
$$

Dónde:

$P=$ Presión de alimentación total en atmosferas

$Q=$ Flujo volumétrico $\left(\mathrm{m}^{3} / \mathrm{s}\right)$

$R=$ Constante de los gases ideales $\left(\right.$ atm. $\left.\mathrm{m}^{3} / \mathrm{mol} . K\right)$

$T=$ Temperatura de reacción $(\mathrm{K})$

Las respuestas de conversión y selectividad se utilizaron para calcular los moles generados de $\mathrm{C}_{2} \mathrm{H}_{4}$, $\mathrm{CO}$ y $\mathrm{CO}_{2}$ necesarios para estimar los parámetros cinéticos de la reacción por medio de un balance de moles. Se obtuvo también la cantidad de agua generada considerando del etano consumido en la reacción, la cantidad de hidrógeno que reacciona de la siguiente 
manera:

$$
F_{H, \text { agua }}=F_{H}^{\circ}-\sum_{i=1}^{n} F_{H, i}
$$

Dónde:

$F_{H, \text { agua }}=$ Flujo molar de hidrógeno en agua $\left(\operatorname{mol}_{H} / \mathrm{h}\right)$

$F_{H}^{\circ}=$ Flujo de entrada de hidrógeno en el etano $\left(\mathrm{mol}_{H} / \mathrm{h}\right)$

$\sum_{i=1}^{n} F_{H, i}=$ Flujo molar de hidrógeno contenido en los compuestos generados.

Considerando que para la estimación de parámetros el número de observaciones debe ser siempre mayor al número de parámetros a estimar para minimizar la incertidumbre de los resultados, como aproximación en este estudio fue necesario ampliar la base de datos de las respuestas y esto se hizo estadísticamente con ayuda del programa JMP8.

El procedimiento consistió en que a partir de los datos experimentales obtenidos del diseño factorial se hizo una regresión lineal con la que se obtuvo una expresión para la selectividad y conversión de cada uno de los compuestos. Con dicha expresión se calcularon las respuestas para valores diferentes de $\mathrm{T}$ y W/F. Los valores propuestos fueron para temperaturas $420 \mathrm{y}$ $460{ }^{\circ} \mathrm{C}$ y para $\mathrm{W} / \mathrm{F}$ de 35 y 52 , con estos valores se obtuvieron 45 datos que minimizaron la incertidumbre al estimar los parámetros del modelo cinético que se presentan a continuación.

\subsection{Modelo Cinético}

Si bien es cierto que para la optimización del diseño de un catalizador se necesitan modelos cinéticos que consideren los pasos elementales de la reacción, para fines de diseño de procesos es suficiente con un modelo que considere los procesos mecanísticos a nivel macroscópico en la superficie del catalizador como los modelos del tipo LHHW o MVK. Es importante que el modelo propuesto ajuste las observaciones experimentales y que las consideraciones incluyan que este modelo puede ser utilizado únicamente a las condiciones de operación a las que fueron obtenidas.

En este estudio se considera que el mecanismo de reacción de la $\mathrm{DHO}-\mathrm{C}_{2}$ en un catalizador multimetálico de MoVTeNbO es del tipo Mars van Krevelen. Esto porque se encontró en varios estudios hechos a este tipo de catalizadores los cuales sugieren que es el mecanismo por el que operan, ya que no hay estudios cinéticos para el catalizador que se utiliza en esta investigación $[2,20]$. 


\subsubsection{Esquema y mecanismo de reacción}

La Figura 5.1 muestra el esquema de reacción propuesto para la $\mathrm{DHO}-\mathrm{C}_{2}$ que incluye seis reacciones que se desarrollan en la superficie del catalizador. Tres de estas reacciones se consideran primarias por ser donde participa directamente el etano para la formación de etileno, monóxido y dióxido de carbono. Las tres restantes donde tiene lugar la participación como reactivo del etileno y monóxido de carbono se consideran como secundarias. En estas reacciones se considera la oxidación total a monóxido y dióxido de carbono de etano y etileno y la oxidación de monóxido de carbono a dióxido de carbono.

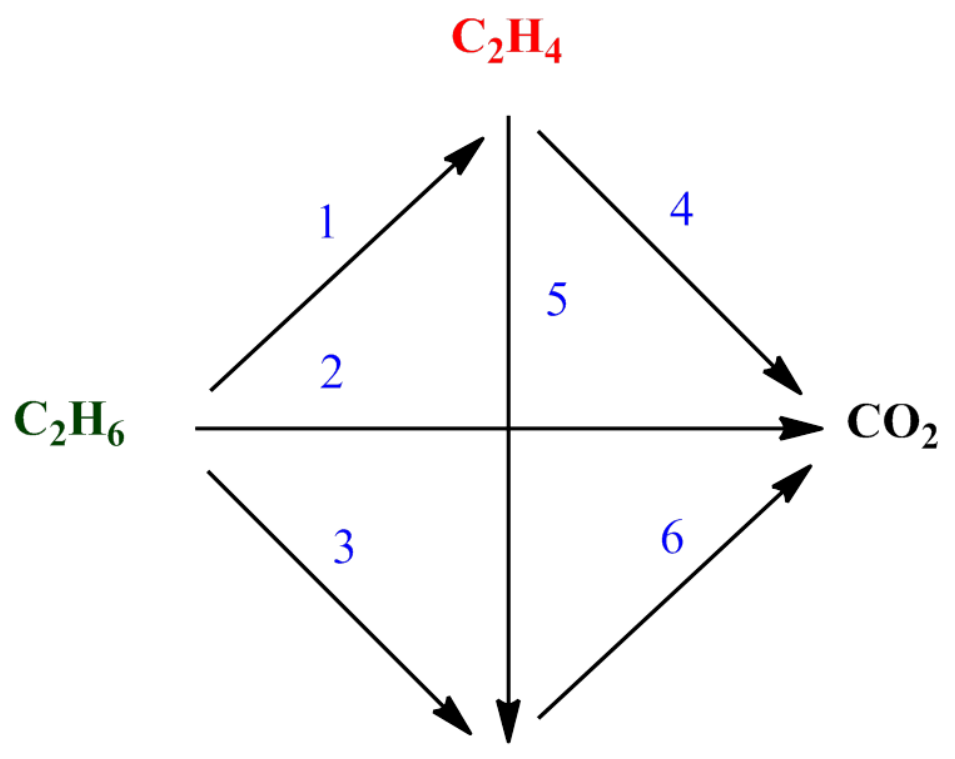

CO

Figura 5.1: Esquema de reacción propuesto para la $\mathrm{DHO}-\mathrm{C}_{2}$

En la Tabla 5.1 se presentan las reacciones globales de acuerdo al esquema de reacción propuesto en la Figura 5.1. Esquema de reacción propuesto para la DHO-C2 los coeficientes estequiométricos de las reacciones globales balanceadas servirán para conocer la participación de los distintos compuestos y sitios catalíticos en las reacciones del mecanismo cinético que se propone.

La Tabla 5.2 presenta el mecanismo de reacción, este mecanismo, del tipo Mars van Krevelen se desarrolla bajo el supuesto que de que se tienen sitios oxidados activos en la estructura del catalizador responsables de la oxidación parcial y total de los diferentes compuestos involucrados en la reacción. Una vez que los sitios oxidados se reducen por la reacción, son re-oxidados con el oxígeno alimentado al sistema en la fase gas. Se presentan además las 
Tabla 5.1: Reacciones globales del modelo cinético

\begin{tabular}{lc}
\hline Reacción global & Paso \\
$\mathrm{C}_{2} \mathrm{H}_{6}+0.5 \mathrm{O}_{2} \rightarrow \mathrm{C}_{2} \mathrm{H}_{4}+\mathrm{H}_{2} \mathrm{O}$ & 1 \\
$\mathrm{C}_{2} \mathrm{H}_{6}+3.5 \mathrm{O}_{2} \rightarrow 2 \mathrm{CO}_{2}+3 \mathrm{H}_{2} \mathrm{O}$ & 2 \\
$\mathrm{C}_{2} \mathrm{H}_{6}+2.5 \mathrm{O}_{2} \rightarrow 2 \mathrm{CO}+3 \mathrm{H}_{2} \mathrm{O}$ & 3 \\
$\mathrm{C}_{2} \mathrm{H}_{4}+3 \mathrm{O}_{2} \rightarrow 2 \mathrm{CO}_{2}+2 \mathrm{H}_{2} \mathrm{O}$ & 4 \\
$\mathrm{C}_{2} \mathrm{H}_{4}+2 \mathrm{O}_{2} \rightarrow 2 \mathrm{CO}_{2}+2 \mathrm{H}_{2} \mathrm{O}$ & 5 \\
$\mathrm{CO}+0.5 \mathrm{O}_{2} \rightarrow \mathrm{CO}_{2}$ & 6 \\
\hline
\end{tabular}

velocidades de reacción $r_{j}$ de cada uno de los pasos considerados en el mecanismo, dicha velocidad de reacción se expresa en función de las presiones parciales de los compuestos que participan en cada reacción y de los sitios activos disponibles para que se lleve a cabo.

La re-oxidación del catalizador descrita en el paso 7 depende de la presión parcial de oxígeno, en este punto es importante mencionar que la re-oxidación del catalizador es parte fundamental en el mecanismo cinético de la reacción debido a que se relaciona directamente con la disponibilidad de sitios activos. Una vez definidas todas las velocidades de reacción se realizó el balance de sitios oxidados y reducidos que participan en la $\mathrm{DHO}-\mathrm{C}_{2}$, este balance de sitios consideró la velocidad con la que el catalizador se re-oxida menos el consumo o participación de los sitios en todas las reacciones. La suma de todas las fracciones corresponde al total de sitios disponibles.

$$
\frac{d \theta_{o x}}{d t}=r_{r e-o x}-\sum V_{i} k_{i} \theta_{o x} P_{i, j}
$$

Dónde:

$$
\theta_{o x}+\theta_{\text {red }}=1
$$

Sustituyendo las tasas de las reacciones elementales para obtener el valor de sitios activos 
Tabla 5.2: Reacciones elementales

\begin{tabular}{|c|c|c|}
\hline Paso & Reacción & Velocidad de reacción \\
\hline 1 & $\mathrm{C}_{2} \mathrm{H}_{6}+\theta_{\text {ox }} \rightarrow \mathrm{C}_{2} \mathrm{H}_{4}+\mathrm{H}_{2} \mathrm{O}+\theta_{\text {red }}$ & $r_{1}=k_{1} P_{C_{2} H_{6}} \theta_{o x}$ \\
\hline 2 & $\mathrm{C}_{2} \mathrm{H}_{6}+\theta_{\text {ox }} \rightarrow \mathrm{CO}_{2}+\mathrm{H}_{2} \mathrm{O}+\theta_{\text {red }}$ & $r_{2}=k_{2} P_{C_{2} H_{6}} \theta_{o x}$ \\
\hline 3 & $\mathrm{C}_{2} \mathrm{H}_{6}+\theta_{\text {ox }} \rightarrow \mathrm{CO}+3 \mathrm{H}_{2} \mathrm{O}+\theta_{\text {red }}$ & $r_{3}=k_{3} P_{C_{2} H_{6}} \theta_{o x}$ \\
\hline 4 & $\mathrm{C}_{2} \mathrm{H}_{4}+\theta_{\text {ox }} \rightarrow \mathrm{CO}_{2}+2 \mathrm{H}_{2} \mathrm{O}+\theta_{\text {red }}$ & $r_{4}=k_{4} P_{C_{2} H_{6}} \theta_{o x}$ \\
\hline 5 & $\mathrm{C}_{2} \mathrm{H}_{4}+\theta_{\text {ox }} \rightarrow \mathrm{CO}_{2}+\mathrm{H}_{2} \mathrm{O}+\theta_{\text {red }}$ & $r_{5}=k_{5} P_{C_{2} H_{4}} \theta_{o x}$ \\
\hline 6 & $\mathrm{CO}+\theta_{\text {ox }} \rightarrow \mathrm{CO}_{2}+\theta_{\text {red }}$ & $r_{6}=k_{6} P_{C O} \theta_{o x}$ \\
\hline 7 & $\theta_{\text {red }}+n \mathrm{O}_{2} \rightarrow \theta_{o x}$ & $r_{r e-o x}=k_{o} \theta_{r e d} P_{O_{2}}^{m}$ \\
\hline
\end{tabular}

se obtiene la siguiente expresión:

$$
\frac{d \theta_{o x}}{d t}=k_{o} \theta_{r e d} P_{O_{2}}^{m}-\left[\left(k_{1}+k_{2}+k_{3}\right) P_{C_{2} H_{6}}+\left(k_{4}+k_{5}\right) P_{C_{2} H_{6}}+k_{6} P_{C O}\right] \theta_{o x}
$$

Suponiendo un pseudo-estado estacionario, se obtiene lo siguiente:

$$
\begin{gathered}
k_{o} P_{O_{2}}^{m}\left(1-\theta_{o x}\right)=-\left[\left(0.5 k_{1}+3.5 k_{2}+2.5 k_{3}\right) P_{C_{2} H_{6}}+\left(3 k_{4}+2 k_{5}\right) P_{C_{2} H_{6}}+k_{6} P_{C O}\right] \theta_{o x} \\
k_{o} P_{O_{2}}^{m}=-\left[\left(0.5 k_{1}+3.5 k_{2}+2.5 k_{3}\right) P_{C_{2} H_{6}}+\left(3 k_{4}+2 k_{5}\right) P_{C_{2} H_{6}}+k_{6} P_{C O}\right] \theta_{o x}+k_{o} P_{O_{2}}^{m} \theta_{o x}
\end{gathered}
$$

Finalmente la expresión resultante para los sitios oxidados disponibles presentes en el catalizador es:

$$
\theta_{o x}=\frac{k_{o} P_{O_{2}}^{m}}{k_{o} P_{O_{2}}^{m}+\left[\left(0.5 k_{1}+3.5 k_{2}+2.5 k_{3}\right) P_{C_{2} H_{6}}+\left(3 k_{4}+2 k_{5}\right) P_{C_{2} H_{6}}+k_{6} P_{C O}\right]}
$$


En esta expresión el número de sitios oxidados disponibles está relacionado directamente con la presión parcial de oxígeno, y la presión parcial de etano, etileno y CO disponibles y se considera para cada velocidad de reacción antes establecida.

\subsection{Modelo del reactor y estimación de los parámetros cinéticos}

\subsubsection{Modelo de estimación de parámetros}

El modelo pseudo-homogéneo unidimensional del reactor de laboratorio que se utilizó en los experimentos cinéticos considera las siguientes suposiciones:

- Reactor de lecho empacado que se operó en modo isotérmico

- Se desprecian las resistencias a las transferencias de masa y energía (ver Tabla A.4), teniendo un estudio cinético intrínseco.

- Flujo unidimensional

- Estado estacionario

- Régimen integral

Este modelo está dado por la siguiente ecuación:

$$
\frac{d F_{i}}{d W}=R_{i}
$$

Con CI: $W=0$ y $F_{i}=F_{i 0}$ es decir al inicio del reactor el flujo molar de los compuestos es igual al flujo molar alimentado.

Dónde:

$F_{i}=$ Flujo molar del compuesto $i$

$W=$ Masa del catalizador

$R_{i}=$ Tasas de reacción globales para el elemento $i$

Las tasas de reacción para cada elemento están dadas por las siguientes ecuaciones:

$$
R_{C_{2} H_{6}}=-\left(r_{1}+r_{2}+r_{3}\right)
$$




$$
\begin{gathered}
R_{C_{2} \mathrm{H}_{4}}=r_{1}-r_{4}-r_{5} \\
R_{C O_{2}}=2\left(r_{2}+r_{4}\right)+r_{6} \\
R_{C O}=2\left(r_{3}+r_{5}\right)-r_{6} \\
R_{O_{2}}=-\left[0.5\left(r_{1}+r_{6}\right)+3.5 r_{2}+2.5 r_{3}+3 r_{4}+2 r_{5}\right]
\end{gathered}
$$

Las velocidades de reacción $r_{i}$ están están dadas en la Tabla Reacciones elementales, mientras que las constantes cinéticas están en función de la temperatura de acuerdo a la ecuación de Arrhenius:

$$
k_{i}=A_{i}\left[\exp \frac{E_{a}}{R T}\right]
$$

Dónde:

$$
\begin{aligned}
& A_{i}=\text { factor pre-exponencial } \\
& k_{i}=\text { constante de reacción }(\mathrm{mol} / \mathrm{atms}) \\
& E_{a}=\text { Energía de activación }(\mathrm{KJ} / \mathrm{mol})
\end{aligned}
$$

El modelo resultante, un sistema de ecuaciones diferenciales ordinarias se resolvió por el método de Runge-Kutta Felberg.

\subsubsection{Algoritmo de estimación de parámetros}

Los parámetros a estimar corresponden a la energía de activación y el factor pre-exponencialde la ecuación (. De tal forma que los parámetros a estimar suman catorce más el orden de reacción del oxígeno para la re-oxidación de los sitios. La función objetivo a minimizar mediante el algoritmo de Levenverg-Maquart que se utilizó para llevar a cabo la estimación de parámetros se representa por la siguiente ecuación:

$$
\sum_{j}^{n_{\text {resp }}} \sum_{k}^{n_{\text {resp }}} W_{j k} \sum_{i=1}^{n_{\text {exp }}}\left(y_{i j}-\hat{\mathrm{y}}_{j i}\right)\left(y_{i k}-\hat{\mathrm{y}}_{i k}\right) \stackrel{\beta_{1}, \beta_{1}, \beta_{2}, \ldots \beta_{n}}{\longrightarrow} \min
$$


En donde el número de observaciones experimentales y el número de respuestas del modelo se denotan por $n_{\text {obs }}$ y $n_{\text {resp }}$ respectivamente, se refiere a la respuesta experimental "j" del experimento "i" de igual forma $\hat{y}_{i, j}$ se refiere a la misma respuesta calculada "j" del experimento "i", es importante mencionar que para poder tener confianza en los resultados es necesario tener al menos un datos experimental más que el número de parámetros que se requiera estimar. El peso asignado a cada respuesta, es decir la importancia o influencia en la respuesta se representa por $V^{i j}$ y el vector de parámetros se representa por la letra $\beta$.

La evaluación de los valores obtenidos se realizó viendo los ajustes estimados con los datos experimentales y por medio de diagramas de paridad, además se utilizó las pruebas $\mathrm{F}$. La prueba $\mathrm{F}$ es utilizada para determinar la significancia global de la regresión con la que se estimaron los parámetros, para obtener este valor se utiliza la suma de los cuadrados de la regresión y la suma del residual dividido por su respectivo grado de libertad representado en la ecuación siguiente:

$$
F-\text { value }=\frac{\sum_{j}^{n_{\text {resp }}} \sum_{k}^{n_{\text {resp }}} W_{j k} \sum_{i=1}^{n_{\text {resp }}}\left(y_{i k} \hat{\mathrm{y}}_{i k}\right) / n_{\text {par }}}{\sum_{j}^{n_{\text {resp }}} \sum_{k}^{n_{\text {resp }}} W_{j k} \sum_{i=1}^{n_{\text {resp }}}\left(y_{i j}-\hat{\mathrm{y}}_{j i}\right)\left(y_{i k}-\hat{\mathrm{y}}_{i k}\right) /\left(n_{\text {exp }} n_{\text {resp }}-n_{\text {par }}\right)}
$$

La regresión se considera significativa si el valor es mayor que el tabulado a un valor dado de la distribución F.

Donde $\beta_{i}$ y $\beta_{\text {iref }}$ son los valores estimados y de referencia respectivamente y $V\left(\beta_{i}\right)_{i i}$ es el elemento i-ésimo de la diagonal de la matriz de covarianza de los parámetros estimados, definida por:

$$
V\left(\beta_{i}\right)_{i i}=\left[\sum_{j=1}^{n_{\text {resp }}} \sum_{k=1}^{n_{\text {resp }}} W_{i k} J_{j}^{T} J_{k}\right]
$$

Dónde $J_{j}$ es la matriz de Jacobianos de la respuesta $y_{i}$ con respecto al parámetro $\beta_{i}$ :

$$
J_{j}=\left[\frac{\partial y_{i}(\beta)}{\partial \beta_{i}}\right]
$$

\subsection{Modelo de un reactor de lecho fluidizado a escala industrial}

En reacciones altamente exotérmicas como la DHO de etano se requiere del diseño de equipos capaces de transferir eficientemente el calor generado, un reactor de lecho fluidizado 
es una opción viable para implementar la reacción debido a que sus características permiten la operación con control de temperatura.

El desarrollo de un proceso escala comercial en un reactor de lecho fluidizado involucra hacer muchas simplificaciones, al respecto el secreto para un escalamiento exitoso no radica en la exactitud y sofisticación de simulaciones de modelos experimentales si no en el reconocimiento y manejo de las incertidumbres asociadas. Bajo el requisito de que la cinética de reacción se conoce, el proceso de escalamiento considera:

1. Selección de un régimen de fluidización apropiado.

2. Modelado del lecho fluidizado para tener el primer dimensionamiento ya sea a escala, piloto o industrial.

3. Construcción de un reactor escala banco (Diametro $0.2 \mathrm{~m}$ ) que sea capaz de capturar la respuesta de atrición, alimentación de sólidos, carga y descarga, efecto de la distribución de partícula y problemas de separación.

4. Retroalimentar el modelo del lecho fluidizado y proponer el dimensionamiento de un reactor a escala piloto.

5. Construir una unidad escala piloto (Diámetro $\sim 0.5 \mathrm{~m}$ )

6. Retroalimentar al modelo del lecho fluidizado con la información experimental a escala piloto y dimensionar un reactor a nivel industrial.

7. Construir un reactor a nivel industrial.

8. Retroalimentar el modelo del lecho fluidizado con el objetivo de optimizar la unidad industrial.

Este trabajo se desarrolla en el contexto del punto 2 citado para lo que se propuso un modelo cinético y se estimaron los parámetros implicados para el ajuste de los datos experimentales. Además se propone un modelo de reactor de lecho fluidizado con el que se pretende describir el comportamiento del catalizador a escala industrial. La información obtenida, servirá para mejorar el diseño de experimentos para la evaluación de este catalizador a diferentes condiciones y tener la primera inferencia sobre el diseño de un reactor de lecho fluidizado que permita tener mayor certidumbre acerca del comportamiento de este sistema.

\subsubsection{Model pseudo-heterogéneo de dos fases.}

Durante el proceso de fluidizado estrictamente se forman tres fases: la fase burbuja, la fase sólida, y la fase gas. Bajo ciertas condiciones de operación se pueden suponer algunas 
simplificaciones para que los modelos que se utilizan para describir el comportamiento de este tipo de reactores sean pseudo-homogéneos que consideran una fase, pseudo-heterogéneos que consideran dos o tres fases. La Figura 5.2 representa la configuración y componentes de este tipo de reactores, a escala industrial, los sólidos mezclados están en constantes cambios de circulación por lo cual los modelos de lecho fluidizado pseudo-homogéneos tienen gran éxito para describir el comportamiento a gran escala.

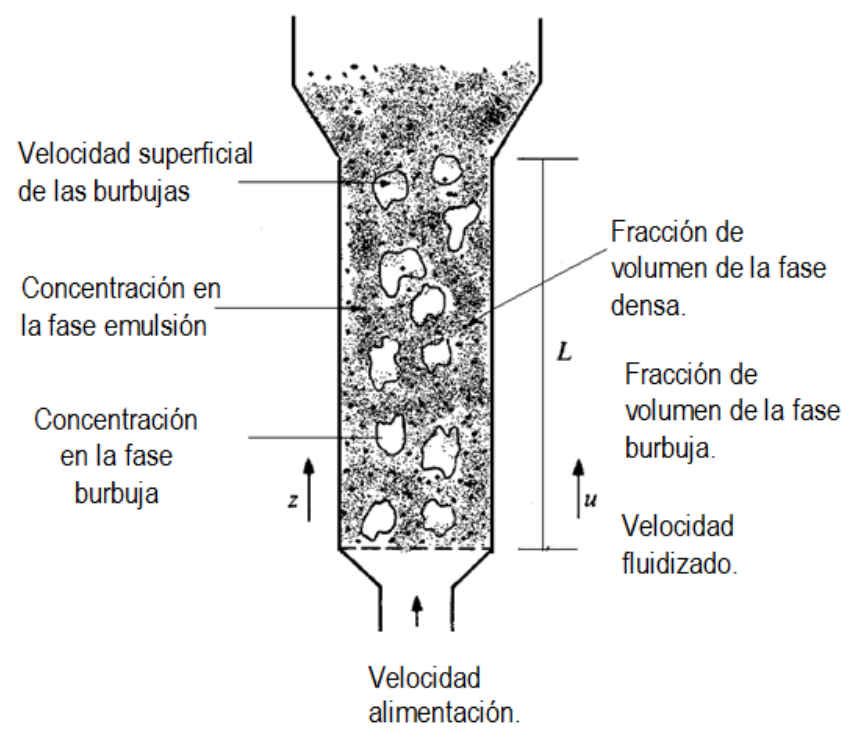

Figura 5.2: Representación de un reactor de lecho fluidizado

El reactor a modelar es uno de lecho fluidizado del tipo tamaño industrial con un diámetro de $2 \mathrm{~m}$ y altura de $10 \mathrm{~m}$ que considera dos fases: la fase emulsión compuesta por las partículas de catalizador y el gas y la fase burbuja. Las partículas del catalizador mantendrán la misma densidad que las que se usaron en el laboratorio y será de $1285.714 \mathrm{Kg} / \mathrm{m}^{3}$ se considera un diámetro promedio de $0.5 \mathrm{~cm}$. La temperatura de reacción considera las mismas a las que se desarrollaron los experimentos cinéticos, un rango de 400 a $480^{\circ} \mathrm{C}$ con una presión de alimentación de 1 atm y la velocidad de alimentación será de 3-11 mayor que la velocidad mínima de fluidización $u_{m f}$.

El modelo del reactor que se utilizó para simular el comportamiento del catalizador multimétalico en un lecho fluidizado considera las siguientes suposiciones:

- El reactor opera en estado estacionario, es decir que se desprecian los fenómenos de desactivación en la superficie del catalizador o que las condiciones de operación se modifiquen en función del tiempo. 
- El reactor se encuentra en estado isotérmico, lo anterior considerando que la transferencia de calor es eficiente y el catalizador altamente selectivo.

- El flujo del gas en ambas fases se considera del tipo pistón lo que permite despreciar los efectos dispersivos de transporte, esto debido a los flujos de alimentación altos a escala industrial, la longitud del reactor y que se minimizan los fenómenos de retromezclado por la dispersión del catalizador en el lecho.

- Se consideran dos fases y además la presencia de partículas catalíticas en las burbujas, de tal forma que la reacción puede llevarse a cabo en las dos fases. En la fase emulsión se considera que no hay resistencia a la transferencia de masa inter e intra partícula y del flujo de alimentación alto.

- Se consideran los efectos de atrición despreciables, esta es la suposición con mayor incertidumbre en el modelo y que implica efectos importantes en la evaluación del catalizador en el reactor.

Esta última suposición deberá evaluarse en trabajos posteriores a partir de experimentos a nivel laboratorio y/o piloto con un catalizador que cumpla las características adecuadas para un reactor de lecho fluidizado para minimizar la incertidumbre.

El modelo del reactor de lecho fluidizado queda definido para la fase emulsión por:

$$
f_{e} u_{0} \frac{d C_{i, e}}{d z}=\varepsilon_{e s} \rho_{s} R_{i} f_{e}-K_{b e}\left(C_{i, e}-C_{i, b}\right)
$$

y la fase burbuja:

$$
f_{b} u_{0} \frac{d C_{i, b}}{d z}=\varepsilon_{b s} \rho_{s} R_{i} f_{b}+K_{b e}\left(C_{i, e}-C_{i, b}\right)
$$

Las condiciones de frontera a la entrada del reactor están dadas por:

$$
z=0 \quad C_{i, 0}=C_{i, b 0}=C_{i, e 0}
$$

Dónde:

$C_{i, e}=$ Concentración del compuesto i en la fase emulsión $\left(\mathrm{mol} / \mathrm{m}_{e}^{3}\right)$

$u_{0}=$ Velocidad de alimentación del gas $(\mathrm{m} / \mathrm{s})$

$\rho_{s}=$ Densidad de los sólidos en el lecho fluidizado $\left(\mathrm{g}_{r} c a t / \mathrm{m}_{R}^{3}\right)$ 
$f_{e}=$ Fracción del lecho correspondiente a la fase emulsión $\left(\mathrm{m}_{e}^{3} / \mathrm{m}_{L}^{3}\right)$

$K_{b e}=$ Coeficiente de transferencia entre las fases emulsión y burbuja $\left(\mathrm{s}^{-1}\right)$

$\varepsilon_{e s}=$ Fracción de la fase emulsión correspondiente a los sólidos $\left(\mathrm{m}_{s}^{3} / \mathrm{m}_{e}^{3}\right)$

$C_{i, b}=$ Concentración del compuesto i en la fase burbuja $\left(\mathrm{mol} / \mathrm{m}_{b}^{3}\right)$

$f_{b}=$ Fracción del lecho correspondiente a la fase burbuja $\left(\mathrm{m}_{b}^{3} / \mathrm{m}_{L}^{3}\right)$

$\varepsilon_{b s}=$ Fracción de la fase burbuja correspondiente a los sólidos $\left(\mathrm{m}^{3}{ }_{s} / \mathrm{m}^{3}{ }_{b}\right)$

$z=$ altura o longitud del reactor $\left(\mathrm{m}_{R}\right)$

En reactores de lecho fluidizado se presentan tres comportamientos característicos una vez que la velocidad inicial supere la velocidad mínima de fluidización; burbujero, slugging y turbulento. El número de Froude así como el número de Reynolds son dos variables importantes para determinar el tipo de fluidizado que se tiene dadas las condiciones de diámetro de partícula, velocidad mínima de fluidización.

$$
\begin{aligned}
& F r_{m f}=\frac{u_{m f}^{2}}{d_{p} g} \\
& R e=\frac{d_{p} u_{0} \rho_{g}}{\mu}
\end{aligned}
$$

Dónde:

$u_{m f}=$ Velocidad mínima de fluidización $\left(\mathrm{m}_{R} / \mathrm{s}\right)$

$d_{p}=$ Diámetro de partícula $\left(\mathrm{m}_{p}\right)$

$g=\operatorname{gravedad}\left(\mathrm{m} / \mathrm{s}^{2}\right)$

$u_{0}=$ Velocidad inicial $\left(\mathrm{m}_{R} / \mathrm{s}\right)$

$\rho_{g}=$ densidad del gas $\left(\mathrm{g}_{\text {gas }} / \mathrm{m}^{3} \mathrm{f}\right)$

$\mu=$ viscosidad del gas (Pa.s)

Debido a que $F r_{m f}>1.3$ y que $R e<20$ se considera un fluidizado por burbujeo y las correlaciones correspondientes se eligieron de acuerdo a estos criterios [36]. Para conocer las fracciones de volumen del reactor correspondientes a cada fase se hizo uso de las correlaciones reportadas por Mostoufi y col. [37], obteniendo dichas fracciones de burbujas presentes en el reactor de lecho fluidizado se relaciona con el volumen ocupado por la emulsión considerando que la suma de estos representa el volumen total del reactor. El modelo 
propuesto se resolvió por el método de Runge-Kutta-Felberg programado en un compilador de FORTRAN.

A continuación se presentan las correlaciones que se utilizaron para obtener los valores de cada uno de los parámetros utilizados resumidos en la Tabla 5.3, mismas que se eligieron por ser aplicables en para el número de Reynolds calculado.

Tabla 5.3: Parámetros y variables utilizadas en la simulación del reactor de lecho fluidizado

\begin{tabular}{lcc}
\hline Variable & Valor & Referencia \\
\hline$F_{m f}$ & $>1.3$ & {$[36]$} \\
$f_{b}$ & $0.17-0.49$ & {$[38-39]$} \\
$f_{e}$ & $0.83-0.51$ & {$[38-39]$} \\
$\varepsilon_{e s}$ & 0.29 & {$[38]$} \\
$\varepsilon_{m f}$ & 0.52 & {$[36,39]$} \\
$\varepsilon_{b s}$ & 0.12 & {$[38]$} \\
$D_{A B}$ & 0.051 & {$[40,41]$} \\
$d_{b}$ & 0.024 & {$[36]$} \\
$u_{0}$ & 0.5 & -- \\
$u_{m f}$ & 0.06 & {$[36]$} \\
& & \\
\hline
\end{tabular}

a) Fracción del lecho compuesto por burbujas:

$$
f_{b}=1-\exp \left(\frac{u_{0}-u_{m f}}{-0.62}\right)
$$

b) Fracción de sólidos presentes en la fase emulsión:

$$
\varepsilon_{e s}=\varepsilon_{m f}+0.00061 \exp \left(\frac{u_{0}-u_{m f}}{0.262}\right)
$$

c) Fracción de sólidos presentes en la fase burbuja

$$
\varepsilon_{b s}=0.784-0.139 \exp \left(\frac{u_{0}-u_{m f}}{-0.272}\right)
$$


d) Coeficiente de transferencia de masa entre las fases burbuja-emulsión [39]

$$
K_{b e}=\frac{6}{d_{b}}\left[\frac{u_{m f}}{3}+\left(\frac{4 D_{i e} \varepsilon_{m f} u_{b}}{\pi d_{b}}\right)^{1 / 2}\right]
$$

Dónde:

$D_{i e}=$ Coeficiente de difusión $\left(\mathrm{m}^{2} / \mathrm{s}\right)$

$U_{b}=$ Velocidad de burbujas $\left(\mathrm{m}_{b} / \mathrm{s}\right)$

$d_{b}=$ Diámetro de partículas promedio $\left(\mathrm{m}_{b} / \mathrm{s}\right)$

e) Coeficiente de difusión para mezclas:

$$
D_{A B}=\frac{0.00266 T^{2 / 3}}{P M_{A B}^{1 / 2} \sigma_{A B} \Omega_{D}}
$$

Dónde $\sigma_{A B}=0.5\left(\sigma_{A}+\sigma_{B}\right)$

El valor de $\Omega_{D}$ que corresponde a la colisión integral para la difusión es dimensionalmente y depende de la temperatura con $T^{*}=k T / \varepsilon_{A B}$ donde $\varepsilon_{A B}$ se puede relacionar con $\varepsilon_{A B}=$ $\left(\varepsilon_{B} \varepsilon_{B}\right)^{1 / 2}$.

$$
\Omega_{D}=\frac{A}{\left(T^{*}\right)^{B}}+\frac{C}{\exp \left(D T^{*}\right)}+\frac{E}{\exp \left(F T^{*}\right)}+\frac{G}{\exp \left(H T^{*}\right)}
$$

Los valores para las constantes se presentan en la ecuación se presentan en la tabla 5.4.1 [41]:

Tabla 5.4: Parámetros y variables utilizadas en la simulación del reactor de lecho fluidizado

\begin{tabular}{lccccccc}
\hline $\mathrm{A}$ & $\mathrm{B}$ & $\mathrm{C}$ & $\mathrm{D}$ & $\mathrm{E}$ & $\mathrm{F}$ & $\mathrm{G}$ & $\mathrm{H}$ \\
\hline 1.06036 & 0.1561 & 0.193 & 0.47635 & 1.03587 & 1.52996 & 1.76474 & 3.89411 \\
\hline
\end{tabular}

Finalmente el coeficiente de difusión para una mezcla se obtuvo por [40]:

$$
D_{A}^{\prime}=\frac{1}{\left(\frac{Y_{B}}{D_{A B}}\right)+\left(\frac{Y_{C}}{D_{A C}}\right)+\left(\frac{Y_{D}}{D_{A D}}\right)}
$$


f) Velocidad mínima de fluidización. Esta se calculó con la correlación propuesta por Kunii y Levenspiel [36, 39] debido a que cumple con dos criterios importantes:

$$
R e=\frac{d_{p} u_{m f} \rho_{g}}{\mu}<20
$$

y

$$
u_{0}>(3-11) U_{m f}
$$

De tal forma que:

$$
u_{0}=\left(1-f_{b}-\alpha f_{b}\right) \varepsilon_{m f} u_{e}+\left(f_{b}+\alpha \varepsilon_{m f} f_{b}\right) u_{b}
$$

La expresión está dada por:

$$
u_{m f}=\frac{d_{p}^{2}\left(\rho_{p}-\rho_{g}\right)}{1650 \mu} g
$$

Dónde:

$u_{m f}=$ Velocidad mínima de fluidización $(\mathrm{m} / \mathrm{s})$

$\rho_{p}=$ densidad de partícula $\left(\mathrm{g}_{c a t} / m_{p}^{3}\right)$

$\mu=$ viscosidad del gas (Pa.s)

$g=\operatorname{gravedad}\left(\mathrm{m} / \mathrm{s}^{2}\right)$

$d_{p}=$ diámetro de partícula promedio $\left(m_{p}\right)$

g) La velocidad de la burbuja descrita en función del diámetro de partícula, la velocidad mínima de fluidizado y la velocidad inicial o de alimentación:

$$
u_{b}=u_{0}-u_{m f}+0.711\left(g d_{b}\right)^{1 / 2}
$$

h) La velocidad de la emulsión en función de la velocidad mínima de fluidización, la fracción de burbujas del lecho y la velocidad de burbujas.

$$
u_{e}=\frac{u_{m f}}{\varepsilon_{m f}}-\frac{\alpha f_{b} u_{b}}{1-f_{b}-\alpha f_{b}}
$$


i) El diámetro de burbuja se calculó de acuerdo a la correlación:

$$
d_{b}=\frac{0.54}{g^{1 / 5}}\left(u_{0}-u_{m f}\right)
$$

Finalmente en la Tabla 5.5 se presentan las condiciones de operación y los valores de las variables de estudio con las que se realizaron las simulaciones para estudiar el comportamiento del reactor de lecho fluidizado en función de la conversión de etano definida en la ecuación 12 y el rendimiento del etileno definido como:

$$
Y=\frac{m_{C_{C_{2} H_{4}}}}{m o l_{C_{2} H_{6}}^{\circ}}
$$

Tabla 5.5: Condiciones de operación y valores de las variables estudiadas en la simulación del Reactor de Lecho Fluidizado a escala industrial.

\begin{tabular}{|c|c|c|c|}
\hline & Parámetro & Condiciones & Valores evaluados \\
\hline $\begin{array}{c}\text { Evaluación sin } \\
\text { distribución parcial } \\
\text { de reactivo }\end{array}$ & $T\left({ }^{\circ} \mathrm{C}\right)$ & 400 & $400 \mathrm{y} 480$ \\
$u_{0}(\mathrm{~m} / \mathrm{s})$ & 0.5 & $(3 \mathrm{y} 11) u_{m f}$ \\
& $C_{2} H_{6} / \mathrm{O}_{2}$ & 1.28 & $1 \mathrm{y} 3$ \\
\hline $\begin{array}{c}\text { Evaluación de la distribución parcial } \\
\text { del } \mathrm{O}_{2}\end{array}$ & $C_{2} H_{6} / \mathrm{O}_{2 i n i}$ & 3 & $0-5$ \\
& $C_{2} H_{6} / O_{2 i n i}$ & 5 & Equidistante $(10 \mathrm{~cm})$ \\
\hline
\end{tabular}




\section{Capítulo 6}

\section{Resultados}

Este capítulo aborda la descripción y discusión de los resultados y comprende: de manera sintetizada la termodinámica de la reacción en función de las entalpias de reacción y energías libres de Gibbs, la evaluación del catalizador en términos del estudio del efecto de T y W/F en las selectividades y conversiones. Se presenta el ajuste del modelo cinético a los datos experimentales, finalmente se aborda las respuestas del reactor de lecho fluidizado a nivel industrial que tuvieron como objetivo evaluar el comportamiento del catalizador y la participación del oxígeno en la selectividad de etileno y conversión de etano mediante la comparación de la respuesta de la alimentación de oxígeno.

\subsection{Evaluación del catalizador}

\subsubsection{Termodinámica}

Las variables termodinámicas; la energía libre de Gibbs $(\Delta G)$ y entalpía de reacción $(\Delta H)$ para la reacción de $\mathrm{DHO}-\mathrm{C}_{2}$ se presentan en la Tabla 6.1 estos valores corresponden a la temperatura ambiente. Para las reacciones globales, dichos valores muestran que la naturaleza de las reacciones es exotérmica y que son posibles termodinámicamente. De acuerdo a estos resultados, las oxidaciones totales se favorecen además son las que liberan mayor cantidad de energía, lo que sugiere que el diseño tanto del catalizador como del reactor deben ser los óptimos para controlar la liberación de calor y evitar problemas en la selectividad hacia el etileno y desactivación irreversible del catalizador por el efecto de la temperatura.

Se calculó la constante de equilibrio para la reacción de deshidrogenación oxidativa de etano a etileno a $25^{\circ} \mathrm{C}$ or ser la reacción que presentó el valor mínimo en cuanto a la energía libre de Gibbs. La constate de equilibrio $\mathrm{Ka}=1.7607 \times 10^{15}$ es grande, con este se puede 
Tabla 6.1: Valores de entalpia y energía libre de Gibbs $25^{\circ} \mathrm{C}$

\begin{tabular}{lcc}
\hline Reacción & $\Delta \mathrm{H}(\mathrm{KJ} / \mathrm{mol})$ & $\Delta G(\mathrm{KJ} / \mathrm{mol})$ \\
\hline $\mathrm{C}_{2} \mathrm{H}_{6}+0.5 \mathrm{O}_{2} \leftrightarrows \mathrm{C}_{2} \mathrm{H}_{4}+\mathrm{H}_{2} \mathrm{O}$ & -105.49 & -128.08 \\
$\mathrm{C}_{2} \mathrm{H}_{6}+3.5 \mathrm{O}_{2} \leftrightarrows 2 \mathrm{CO}_{2}+3 \mathrm{H}_{2} \mathrm{O}$ & -1428.63 & -144.16 \\
$\mathrm{C}_{2} \mathrm{H}_{6}+2.5 \mathrm{O}_{2} \leftrightarrows 2 \mathrm{CO}+3 \mathrm{H}_{2} \mathrm{O}$ & -862.67 & -927.72 \\
$\mathrm{C}_{2} \mathrm{H}_{4}+3 \mathrm{O}_{2} \leftrightarrows 2 \mathrm{CO}_{2}+2 \mathrm{H}_{2} \mathrm{O}$ & -282.92 & -257.22 \\
$\mathrm{C}_{2} \mathrm{H}_{4}+2 \mathrm{O}_{2} \leftrightarrows 2 \mathrm{CO}_{2}+2 \mathrm{H}_{2} \mathrm{O}$ & -1323.14 & -1314.08 \\
$\mathrm{CO}+0.5 \mathrm{O}_{2} \leftrightarrows \mathrm{CO}_{2}$ & -757.18 & -799.64 \\
\hline
\end{tabular}

comprobar que las reacciones de $\mathrm{DHO}-\mathrm{C}_{2}$ no están limitadas por el equilibrio. Además se evaluaron las entalpias de reacción para las reacciones a las temperaturas de reacción que se utilizaron para la evaluación del catalizador $\left(400,440\right.$ y $\left.480^{\circ} \mathrm{C}\right)$. En la Tabla 6.2 se muestran los resultados que indican que al igual que sucede a $25^{\circ} \mathrm{C}$ no se tendrán limitaciones para la reacción a otras temperaturas.

Tabla 6.2: Entalpías de reacción a diferentes temperaturas KJ/mol

\begin{tabular}{lrrrr} 
Reacción & $400^{\circ} \mathrm{C}$ & $440^{\circ} \mathrm{C}$ & $480^{\circ} \mathrm{C}$ & $500^{\circ} \mathrm{C}$ \\
\hline $\mathrm{C}_{2} \mathrm{H}_{6}+0.5 \mathrm{O}_{2} \leftrightarrows \mathrm{C}_{2} \mathrm{H}_{4}+\mathrm{H}_{2} \mathrm{O}$ & -103.9057 & -103.3394 & -102.7137 & -99.508 \\
$\mathrm{C}_{2} \mathrm{H}_{6}+3.5 \mathrm{O}_{2} \leftrightarrows 2 \mathrm{CO}_{2}+3 \mathrm{H}_{2} \mathrm{O}$ & -1425.7248 & -1425.2913 & -1424.7323 & -1424.799 \\
$\mathrm{C}_{2} \mathrm{H}_{6}+2.5 \mathrm{O}_{2} \leftrightarrows 2 \mathrm{CO}+3 \mathrm{H}_{2} \mathrm{O}$ & -860.9220 & -860.3608 & -859.7577 & -858.176 \\
$\mathrm{C}_{2} \mathrm{H}_{4}+3 \mathrm{O}_{2} \leftrightarrows 2 \mathrm{CO}_{2}+2 \mathrm{H}_{2} \mathrm{O}$ & -280.2668 & -280.0243 & -279.6743 & -287.077 \\
$\mathrm{C}_{2} \mathrm{H}_{4}+2 \mathrm{O}_{2} \leftrightarrows 2 \mathrm{CO}_{2}+2 \mathrm{H}_{2} \mathrm{O}$ & -1320.2356 & -1319.8177 & -1319.2814 & -1326.921 \\
$\mathrm{CO}+0.5 \mathrm{O}_{2} \leftrightarrows \mathrm{CO}_{2}$ & -755.4328 & -754.8872 & -754.3068 & -759.985 \\
& & & & \\
\hline
\end{tabular}




\subsubsection{Datos experimentales}

Los valores de conversión y selectividad a las diferentes condiciones de $\mathrm{T}$ y $\mathrm{W} / \mathrm{F}$ se registraron, estos valores se calcularon de acuerdo a las ecuaciones 12 y 13 . A cada temperatura se varió el flujo de alimentación en un rango de 50 a 150 a intervalos de $25 \mathrm{ml} / \mathrm{min}$ con relaciones de $\mathrm{W} / \mathrm{F}$ de 70 a $23 \mathrm{~g}_{r} c a t / \mathrm{molC}_{2}$. Los resultados, representados gráficamente en la Figura 6.1 indican que los dos parámetros juegan un papel importante en la producción de etileno, con selectividades que van desde 76 a $95.7 \%$.

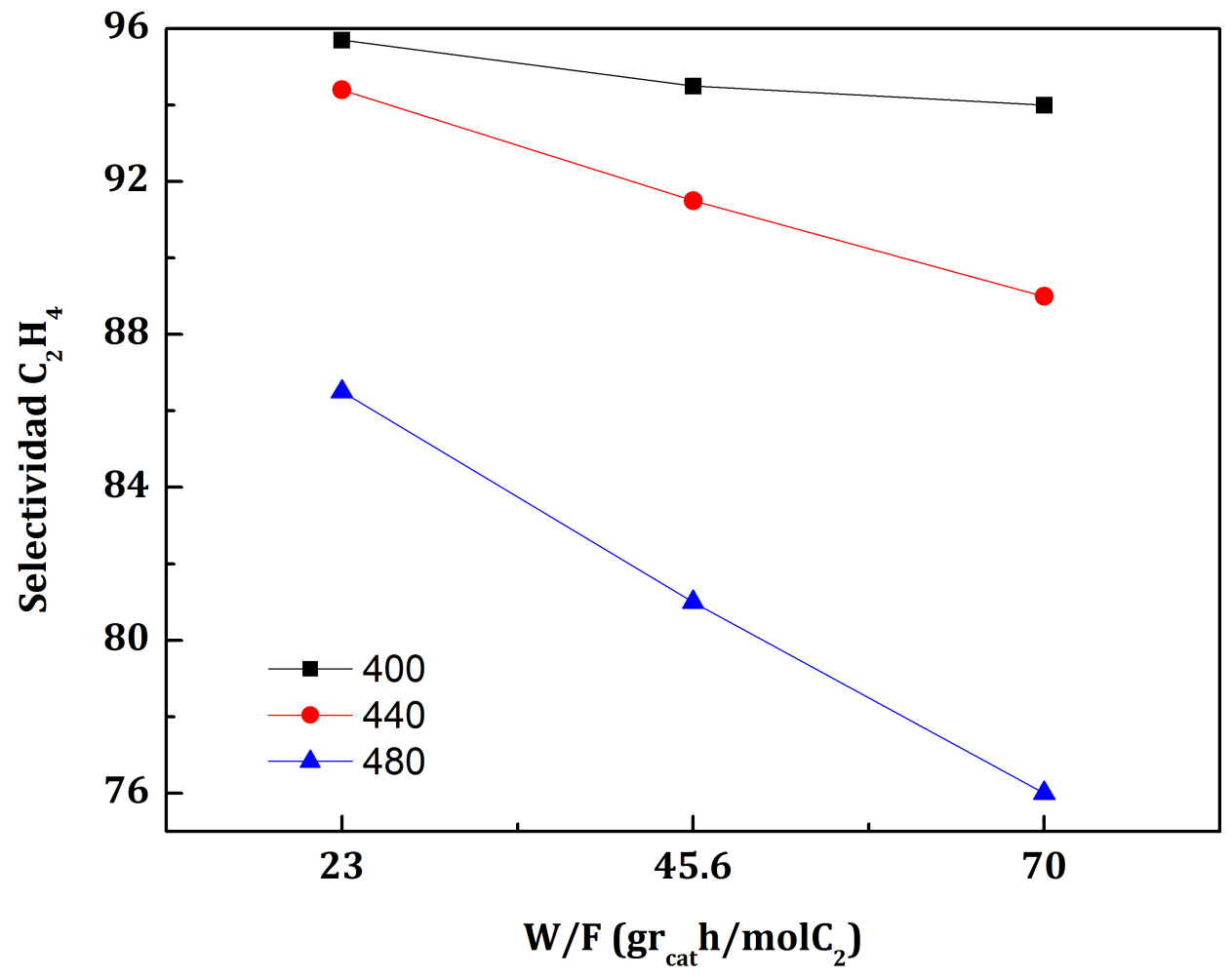

Figura 6.1: Datos experimentales de la selectividad de Etileno en términos de $\mathrm{T}$ y W/F

Para ampliar el análisis del efecto de los factores en las variables se obtuvieron correlaciones para cada variable de respuesta a partir del análisis hecho en el programa JMP8. Las correlaciones que toman la forma de la ecuación xx51 fueron útiles para ampliar el estudio de la influencia de las variables mediante la predicción de respuestas basadas en un análisis estadístico de los datos experimentales.

$$
Y=a_{0}+a_{1} x_{1}+a_{2} x_{2}+a_{12} x_{1} x_{2}+a_{11} x_{1}^{2} \ldots
$$

Las correlaciones para cada respuesta en donde representa $\mathrm{T}$ y representa la variable $\mathrm{W} / \mathrm{F}$ se presentan a continuación para cada variable de respuesta: 
- Selectividad de Etileno:

$$
Y=170.182-0.1708 x_{1}-0.1248 x_{2}-0.0023\left(x_{1}-440\right)\left(x_{2}-46.2\right)
$$

- Selectividad de CO:

$$
Y=-50.646+0.1225 x_{1}+0.0843 x_{2}+\left(x_{1}-440\right)(x 2-46.2)
$$

- Selectividad de $\mathrm{CO}_{2}$ :

$$
Y=-19.507+0.0479 x_{1}+0.0404 x_{2}+\left(x_{1}-440\right)\left(x_{2}-46.2\right)
$$

- Conversión de Etano:

$$
Y=-253.40+0.6425 x_{1}+0.4432 x_{2}+\left(x_{1}-440\right)\left(x_{2}-46.2\right)
$$

- Conversión de oxígeno:

$$
Y=-303.229+0.7433 x_{1}+0.4751 x_{2}+\left(x_{1}-440\right)\left(x_{2}-46.2\right)
$$

Se realizó un análisis ANOVA de los datos experimentales el cual se resume en la Tabla Análisis de varianza para el diseño factorial para el caso de selectividad de etileno. Los valores de t calculados son mayores a la t tabulado (3.182) para $\mathrm{T}$ y $\mathrm{W} / \mathrm{F}$ lo que indica que la participación de los parámetros influyen en la selectividad de etileno, sin embargo la combinación de ambos factores no juega un papel tan importante como cada factor por sí mismo. Por su parte la respuesta $\mathrm{F}$ con un valor tabulado de 5.94 sugiere que la regresión del modelo es significativa.

Tabla 6.3: Análisis de varianza para el diseño factorial

\begin{tabular}{lccccc}
\hline $\begin{array}{l}\text { Parámetro } \\
\text { de variación }\end{array}$ & $\begin{array}{c}\text { Grados de } \\
\text { libertad }\end{array}$ & $\begin{array}{c}\text { Suma de } \\
\text { cuadrados }\end{array}$ & $|t|$ & $\mathrm{F}$ & $P>F$ \\
\hline Temperatura & 1 & 280.166 & 1.91 & 52.59 & $0.0008^{*}$ \\
$\mathrm{~W} / \mathrm{F}$ & 1 & 51.626 & $3.11^{*}$ & 9.69 & $0.0265^{*}$ \\
Temperatura* W/F & 1 & 19.360 & $7.25^{*}$ & 3.63 & 0.1149 \\
\hline
\end{tabular}

A fin de elucidar más claramente el papel de los parámetros $\mathrm{T}$ y W/F y sus cambios simultáneos en las selectividades y conversiones, se construyeron los diagramas de superficie utilizando los datos del diseño experimental obtenidos por el programa JMP8 variando la temperatura de 400 a $480^{\circ} \mathrm{C} \mathrm{W} / \mathrm{F}$ de 23 a 70 grcath $/ \mathrm{molC}_{2}$ con alimentación constante de $\mathrm{C}_{2} / \mathrm{O}_{2} / \mathrm{N}_{2}=9 / 7 / 84$. Estos diagramas además de demostrar la influencia de los parámetros en las variables elegidas como respuesta, nos permiten tener una idea de las regiones en donde se encuentran las condiciones ideales de operación. 
La Figura 6.2 representa el diagrama de superficie de la conversión de etano, en esta se puede observar que la región donde se ve favorecida la conversión es donde valores de temperatura y W/F son grandes, teniendo conversiones que alcanzan el $85 \%$. Este comportamiento es proporcional a la conversión de oxigeno mostrada en la Figura Diagrama de superficie de la conversión de oxígeno en función de T Y W/F, sin embargo en esta última la pendiente formada a lo largo de los valores de $\mathrm{W} / \mathrm{F}$ a temperaturas altas es mayor alcanzando conversiones de $97 \%$ lo que nos sugiere que la temperatura juega un papel muy importante en la conversión de oxígeno que finalmente se traducirá en la selectividad de los compuestos.

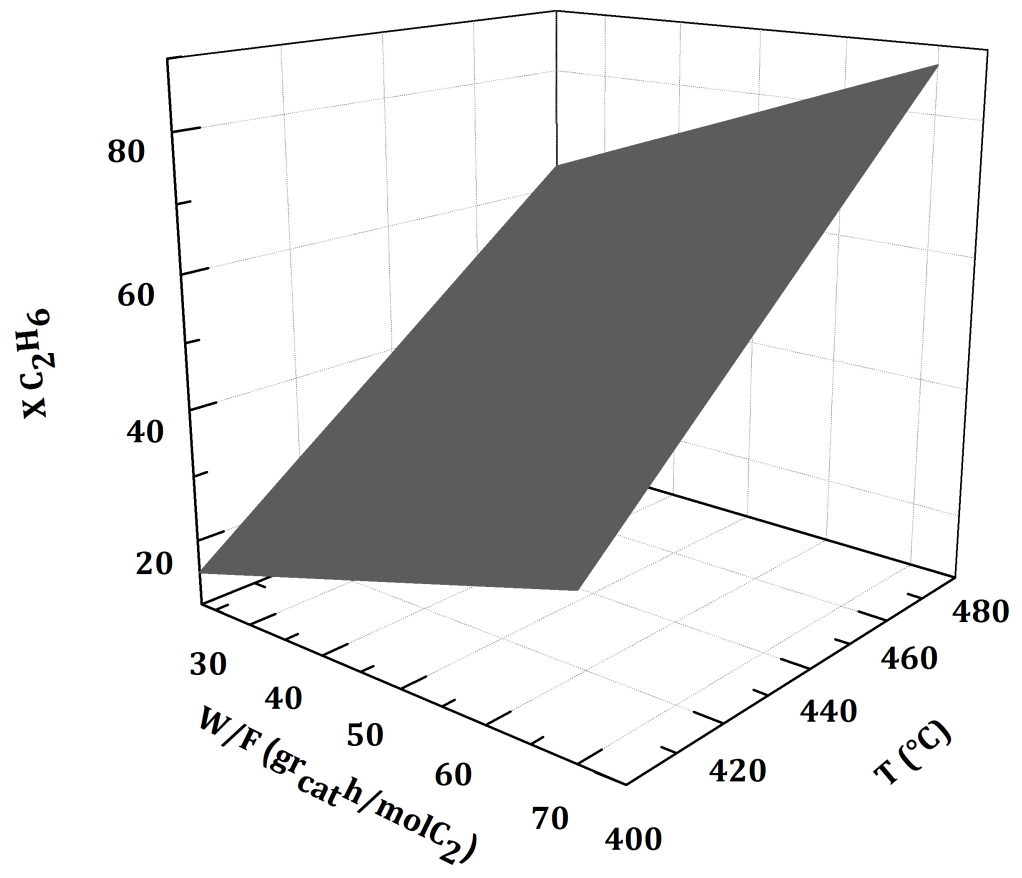

Figura 6.2: Diagrama de superficie de la conversión de etano en función de T Y W/F

La influencia de los parámetros en selectividad de etileno se representa en la Figura 6.3 nos muestra que en esta variable ambos parámetros son importantes y que la región en la que la selectividad del etileno sobre los otros productos se favorece es donde tanto los valores de $\mathrm{T}$ como los de W/F son bajos superando el $95 \%$. Mientras que para una temperatura menor y un espacio tiempo bajo la selectividad alcanza un $86 \%$, cuando el espacio tiempo aumenta esta se ve disminuida significativamente. Lo anterior se explica debido a la formación de otros compuestos producto de la oxidación total del etano o del mismo etileno. 


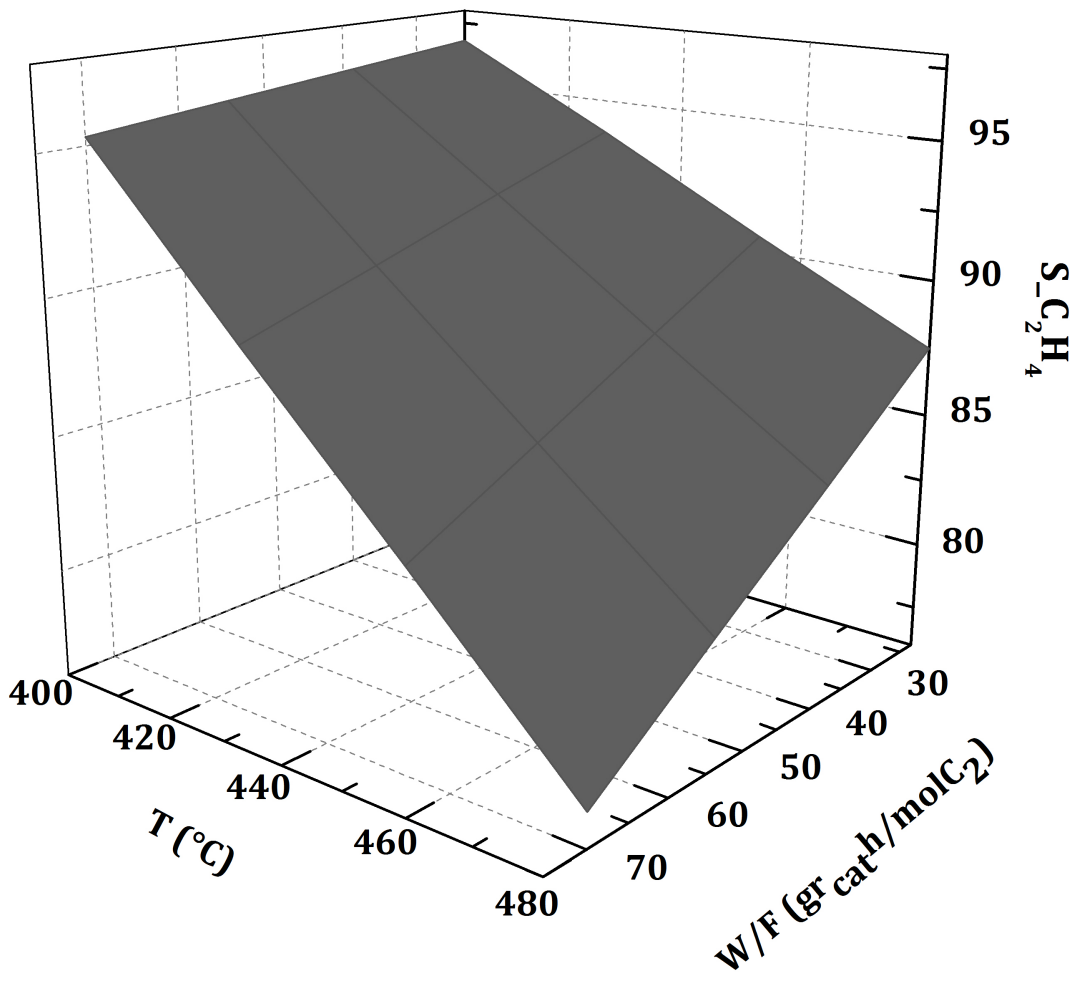

Figura 6.3: Diagrama de superficie de la selectividad de etileno en función de T Y W/F

Las figuras 6.4 y 6.5 presentan los diagramas de superficie para las selectividades de CO y $\mathrm{CO}_{2}$ donde un aumento en la temperatura favorece claramente la formación de $\mathrm{CO}$ en primer lugar y $\mathrm{CO}_{2}$ en segundo lugar. El comportamiento de estos diagramas es muy similar al de las conversiones de etano y oxígeno, lo que sugiere que esta selectividad está relacionada directamente la temperatura a valores altos. 


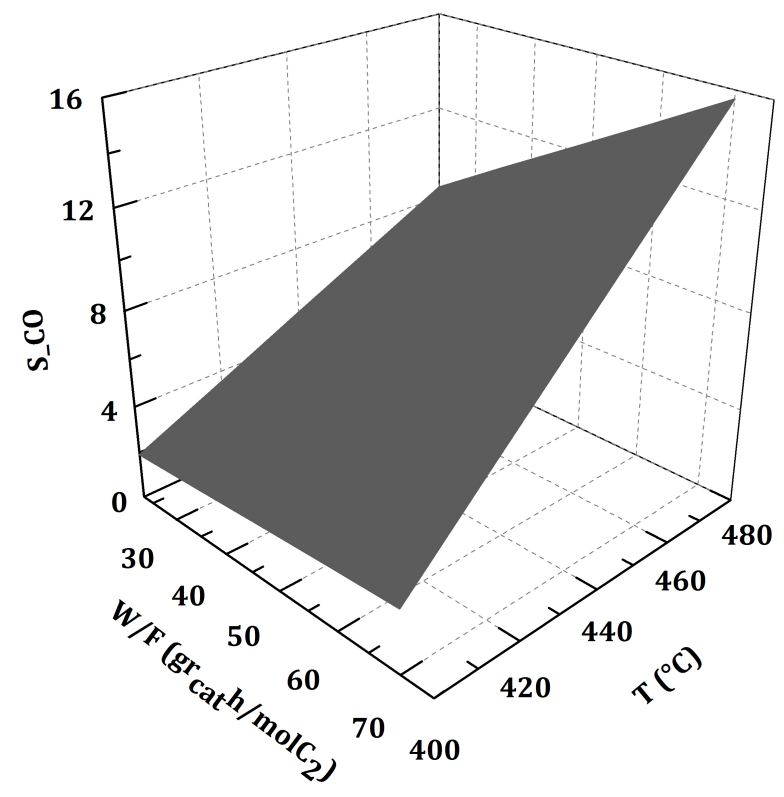

Figura 6.4: Diagrama de superficie de la selectividad de CO en función de T Y W/F

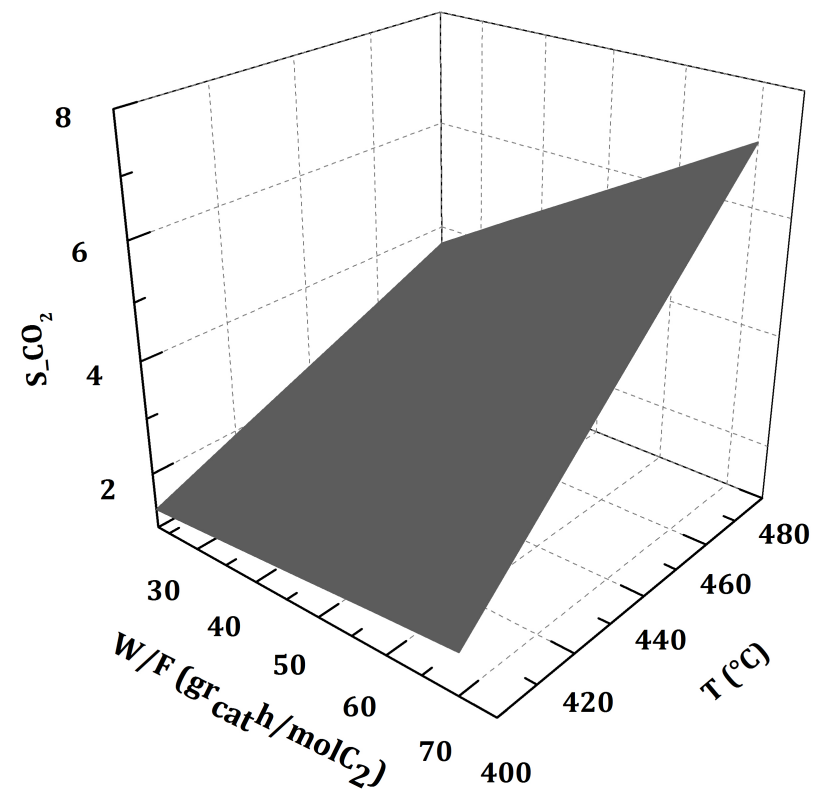

Figura 6.5: Diagrama de superficie de la selectividad de $\mathrm{CO}_{x}$ en función de T Y W/F 


\subsection{Modelo Cinético tipo MVK}

Se estimaron los parámetros cinéticos; energías de activación y factores pre-exponenciales para cada reacción y el valor de la presión parcial de oxígeno en la reacción. Los valores estimados se resumen en la Tabla 6.4 y el valor de $\mathrm{m}$ fue de $4.477 \times 10^{-01}$. Los valores obtenidos se encuentran dentro de los rangos reportados por otros trabajos con mecanismos cinéticos similares, y muestran que la reacción 1 es favorecida con las condiciones establecidas en el capítulo anterior. Las oxidaciones totales requieren de una energía de activación mayor para poder llevarse a cabo lo que tienen que ver directamente con la temperatura de reacción.

Tabla 6.4: Parámetros termodinámicos estimados

\begin{tabular}{lcc}
\hline Reacción & $A_{0}$ & $\mathrm{EA}(\mathrm{kJ} / \mathrm{mol})$ \\
\hline & & \\
1 & $2.985 \times 10^{07}$ & $7.503 \times 10^{01}$ \\
3 & $7.921 \times 10^{06}$ & $8.699 \times 10^{01}$ \\
4 & $2.229 \times 10^{07}$ & $9.000 \times 10^{01}$ \\
5 & $3.020 \times 10^{00}$ & $1.000 \times 10^{02}$ \\
6 & $1.527 \times 10^{-06}$ & $1.221 \times 10^{02}$ \\
7 & $3.515 \times 10^{02}$ & $1.757 \times 10^{01}$ \\
\hline
\end{tabular}

Como se puede observar en la Tabla 6.4, la energía activación requerida para la reacción número siete que representa la oxidación del catalizador es muy pequeña respecto a las otras consideradas en el mecanismo, esto aunado al valor encontrado para m sugiere que existirán sitios disponibles en los que se pueda llevar a cabo la reacción en todo momento.

La Figura 6.6 representa los ajestes del modelo a los datos experimentales a dos temperaturas, en ambos casos el modelo fue capaz de describir el comportamiento de la reacción de DHO- $\mathrm{C}_{2}$ a estas condiciones. Sin embargo el mejor ajuste se presenta a $400^{\circ} \mathrm{C}$ y disminuye conforme la temperatura aumenta como se demuestra en la figura a $480^{\circ} \mathrm{C}$. Los $\mathrm{CO}_{x}$ presentan los ajustes menos favorables para ambos casos, esto puede generar incertidumbre en los valores obtenidos, sin embargo para fines de simulación de un reactor a escala industrial es suficiente con que el modelo cinético describa de manera general el comportamiento de la reacción a evaluar. 

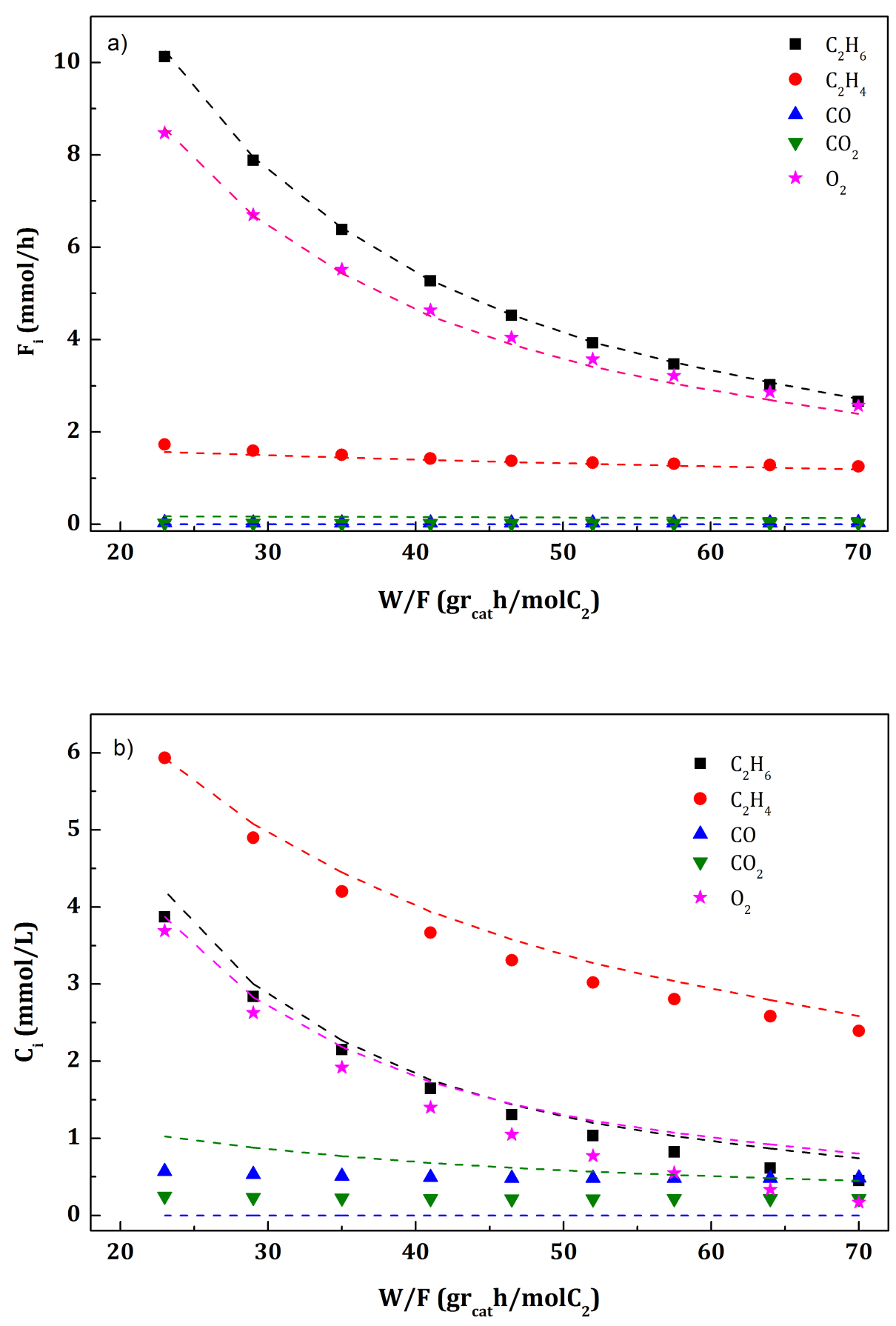

Figura 6.6: Ajustes de los parámetros cinéticos estimados con los datos experimentales correspondientes a: a) $400{ }^{\circ} \mathrm{C} \mathrm{y} \mathrm{b)} 480{ }^{\circ} \mathrm{C}$ presenta los ajustes del modelo cinético a los datos experimentales a 400 y $480^{\circ} \mathrm{C}$ 
Los resultados obtenidos fueron evaluados por parámetros estadísticos en un intervalo de confianza de $95 \%$. El valor de F obtenido fue de $1.581 \times 10^{03}$ en tanto que el valor tabulado corresponde a 2.79 lo que nos permite decir que el modelo de ajuste de los parámetros es estadísticamente confiable. En la Figura 6.7, se presenta el diagrama de paridad de los flujos molares de los compuestos involucrados en la reacción de DHO- $\mathrm{C}_{2}$ dicho diagrama compara los datos experimentales contra los datos predichos por el modelo cinético. Los resultados comprueban que las predicciones tienen buenos ajustes, donde las lineas azules representan un rango de error de $10 \%$.

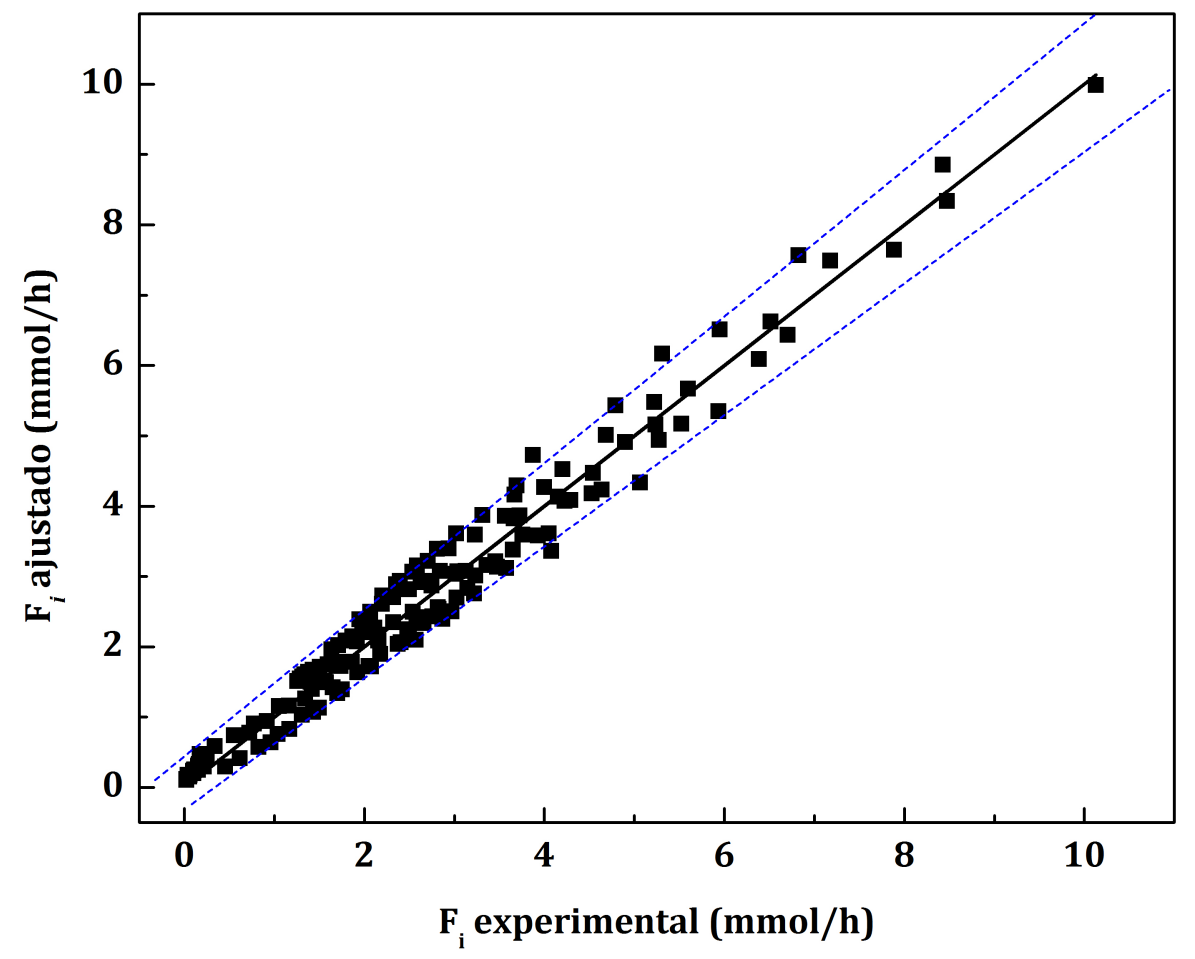

Figura 6.7: Diagramas de paridad de los compuestos involucrados en la reacción. 


\subsection{Modelo del Reactor de Lecho Fluidizado}

\subsubsection{Modelado del reactor sin alimentación distribuída de oxígeno}

En esta sección se presentan los resultados obtenidos de las simulaciones del modelo del reactor de lecho fluidizado. Se estudió la influencia de la temperatura considerando los valores de las temperaturas de reacción y concentraciones de entrada al reactor utilizadas para el modelo cinético, procurando tener certidumbre en los resultados. Se evaluó la velocidad inicial de entrada al reactor considerando los límites establecidos en la bibliografía, tres a once veces la velocidad mínima de fluidización para el régimen de burbujeo y finalmente se varió la relación entre la relación molar etano/oxígeno manteniendo esta siempre en el rango al que se realizaron los experimentos 1 a 6 veces etano por oxígeno.

\subsubsection{Perfiles de concentración en cada fase componente del reactor.}

Para empezar se presentan los perfiles de concentración en cada una de las fases en el reactor: fase emulsión y fase burbuja, esto se realizó para ejemplificar como son los perfiles de ambas fases ya que por cuestiones de análisis en las secciones posteriores sólo se presentarán valores de concentración promediados de estas dos fases, de acuerdo a lo expuesto en la sección 5.4. Estos perfiles se obtuvieron a una temperatura constante de $400^{\circ} \mathrm{C}, u_{o}$ de 0.5 $\mathrm{m} / \mathrm{s}, \mathrm{y} \mathrm{W} / \mathrm{F}$ de $25 \mathrm{~g}_{r}$ cat $\mathrm{s} / \mathrm{molC}_{2}$ y serán similares para cada uno de los casos de estudio que se abordaron, estos perfiles, sugieren que la participación de ambas fases son importantes en la reacción, sin embargo la fase emulsión contribuye en mayor medida.

Este resultado se debe particularmente al caso en donde la velocidad inicial es varias veces mayor a la velocidad mínima de fluidizado, ya que las fracciones de emulsión y burbuja están relacionados directamente con la velocidad inicial. La fase burbuja es más importante conforme la velocidad inicial aumenta, es decir, para los casos en los que la velocidad inicial no sea muchas veces mayor la velocidad mínima de fluidización esta fase puede no considerarse en la reacción [42]. Debido a que tanto la longitud como la fracción de la fase burbuja a las condiciones de operación utilizadas son significativas es esencial considerarla en el modelado del reactor. 


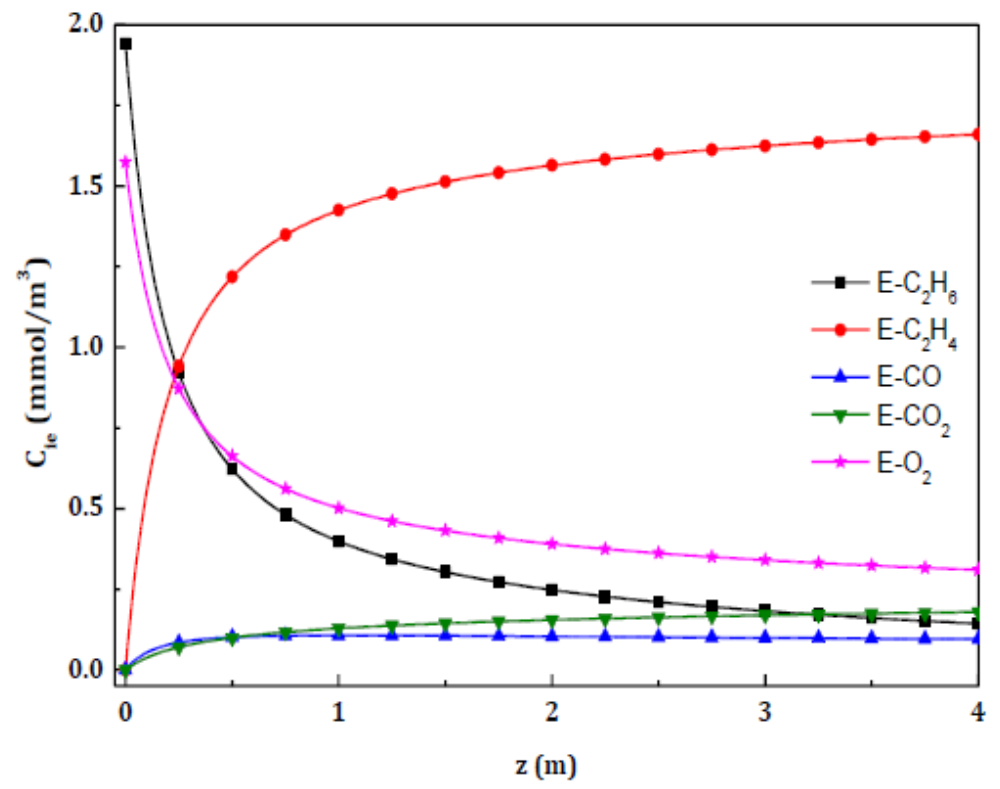

Figura 6.8: Perfiles de concentración de los compuestos en la fase emulsión del reactor a $400^{\circ} \mathrm{C}, \mathrm{W} / \mathrm{F}=25 \mathrm{~g}_{r}$ cat $\mathrm{s} / \mathrm{molC}_{2}$ y $u_{o}=0.5 \mathrm{~m} / \mathrm{s}$.

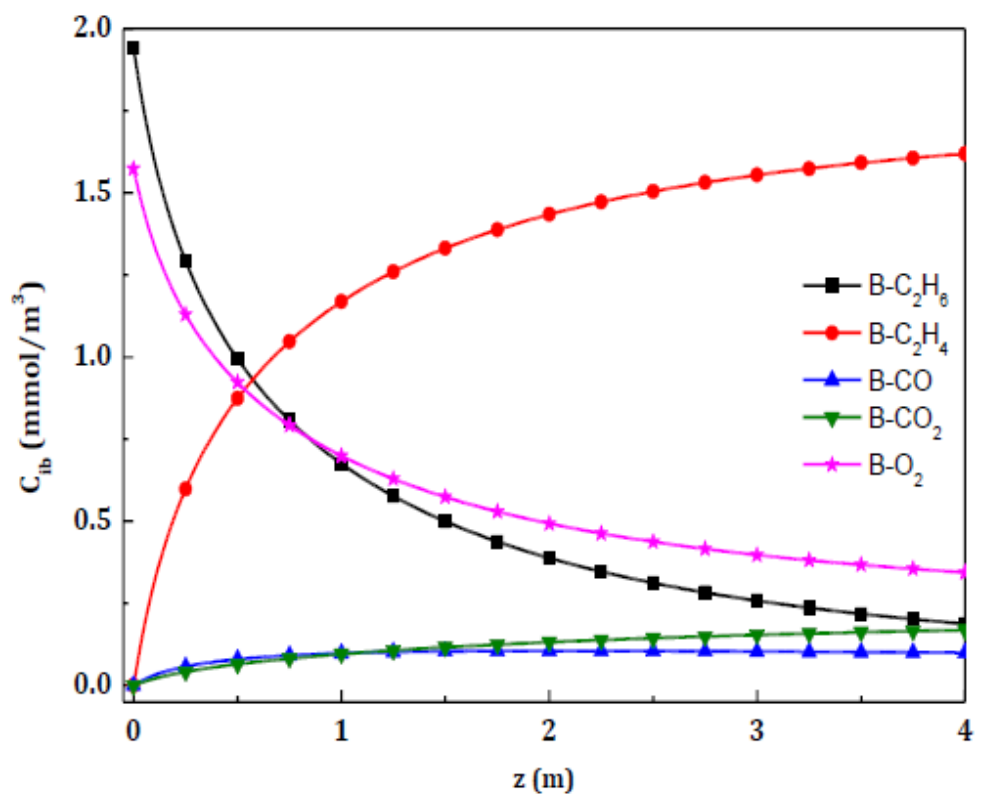

Figura 6.9: Perfiles de concentración de los compuestos en la fase burbuja del reactor a $400^{\circ} \mathrm{C}$, $\mathrm{W} / \mathrm{F}=25 \mathrm{~g}_{r}$ cat $\mathrm{s} / \mathrm{molC}_{2}$ y $u_{o}=0.5 \mathrm{~m} / \mathrm{s}$. 


\subsubsection{Influencia de la temperatura de reacción}

Como se expuso en secciones anteriores, el papel de la temperatura en la reacción juega un papel importante en la selectividad y producción de etileno, la influencia de esta variable en la conversión y selectividad se espera que sea similar en el reactor de lecho fluidizado que se modela. La Figura 6.10 presenta la respuesta del reactor en términos de concentración a lo largo del reactor a $400^{\circ} \mathrm{C}$ manteniendo $u_{o}=0.5 \mathrm{~m} / \mathrm{s}, \mathrm{W} / \mathrm{F}=25 \mathrm{gr}_{c a t} \mathrm{~s} / \mathrm{molC}_{2}$ constantes mientras, la Figura 6.11 muestra los perfiles de concentración de $\mathrm{C}_{2} \mathrm{H}_{6}, \mathrm{C}_{2} \mathrm{H}_{4}$ y $\mathrm{CO}_{x}$ a 400 y $480^{\circ} \mathrm{C}$. Ambas figuras muestran que la reacción tiene lugar en los primeros 8 metros del reactor, siendo los primeros 4 donde se presenta mayor actividad alcanzando en esta distancia una conversión de etano de $91 \%$ y de $79 \%$ de oxígeno para $400^{\circ} \mathrm{C}$.

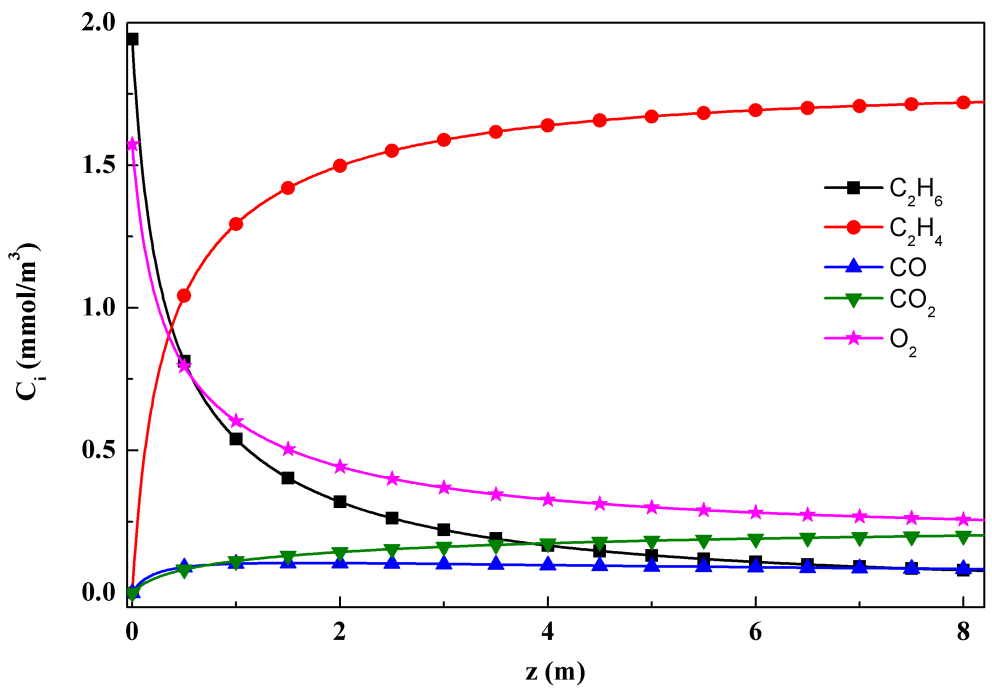

Figura 6.10: Perfiles de concentración de los compuestos en el reactor a $400^{\circ} \mathrm{C}$.

La diferencia de las conversiones y remdimientos se puede apreciar en las Figura 6.12 donde se muestra la conversión y rendimiento de etano con respecto a la distancia. La temperatura tuvo una influencia en la conversión, principalmente en los primeros metros del reactor. La conversión resultó mayor a temperaturas altas como $480^{\circ} \mathrm{C}$ en los primeros cuatro metros, después de esta distancia la conversión no varía mucho. Sin embargo, a pesar de que las producciones serían mejores a estas temperaturas no significa que sean las condiciones óptimas de operación ya que en términos de selectividad del etileno a $400^{\circ} \mathrm{C}$ se alcanzan un $92 \%$ de selectividad mejorando $1 \%$ comparación a $480^{\circ} \mathrm{C}$.

A pesar de que el rendimiento es mejor para etano, no significa que la producción de etileno sea mejor, hay que considerar la selectividad y que además temperaturas altas pueden 


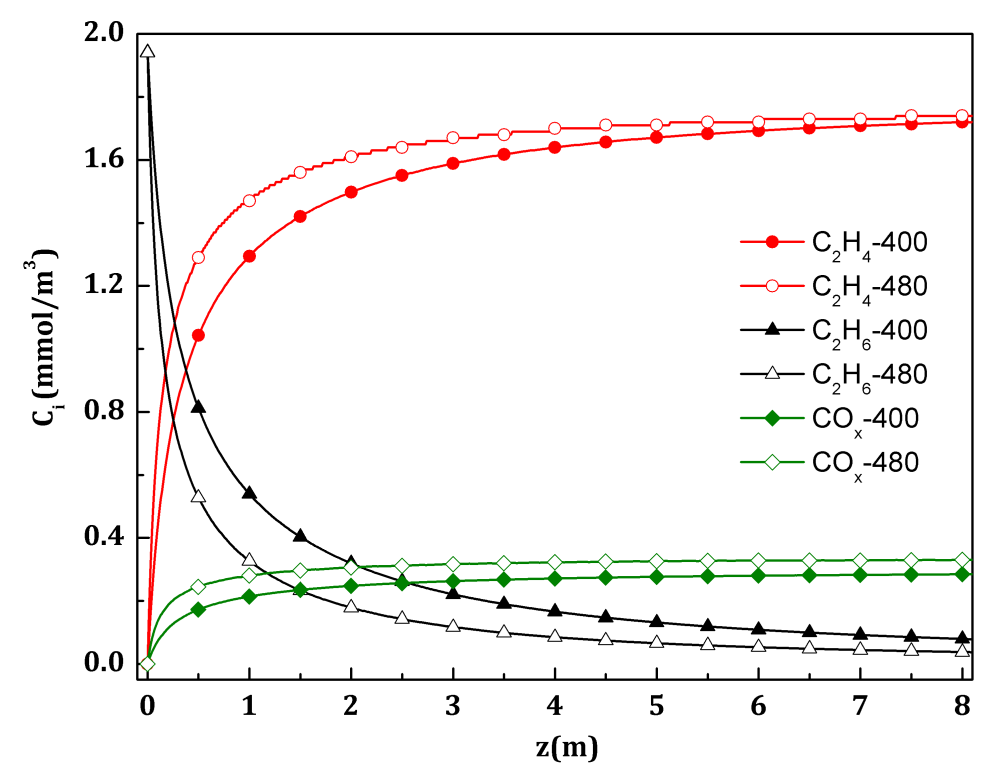

Figura 6.11: Perfiles de concentración de $\mathrm{C}_{2} \mathrm{H}_{6}, \mathrm{C}_{2} \mathrm{H}_{4}$ y $\mathrm{CO}_{x}$ a 400 y $480^{\circ} \mathrm{C}$.

provocar problemas en la actividad del catalizador ya que pueden provocar sinterizado [3, 43] lo que se reflejaría en una disminución de la selectividad y disminución de producción de etileno a través del tiempo.

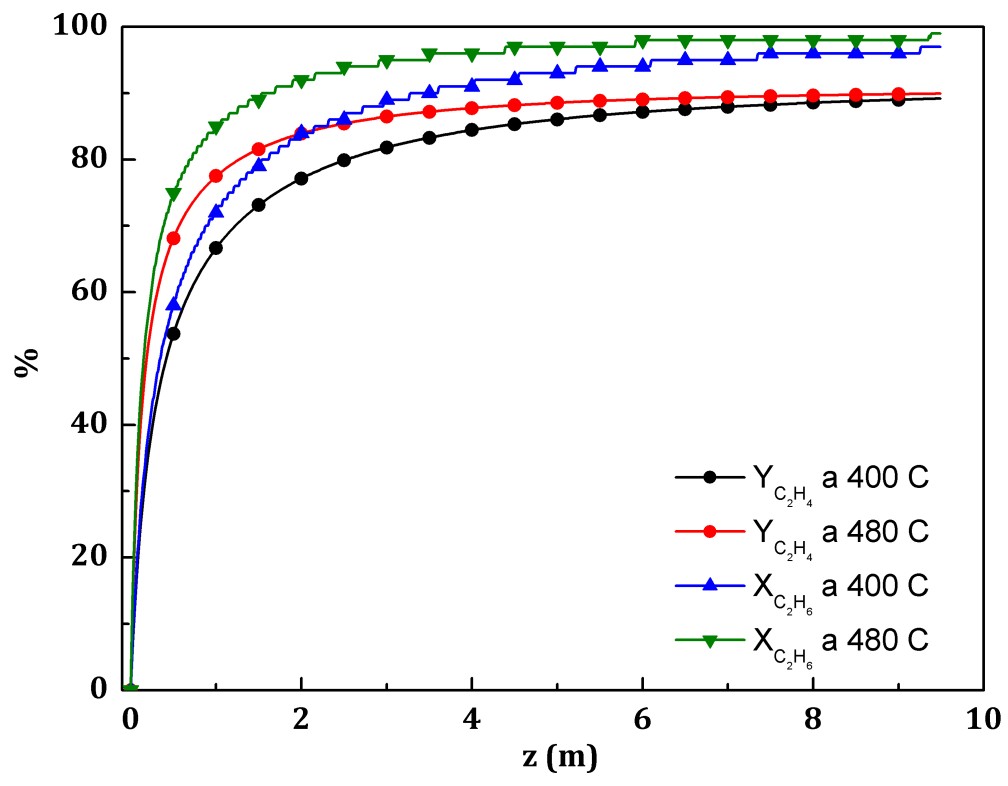

Figura 6.12: Conversiones de etano y rendimiento a etileno a 400 y $480^{\circ} \mathrm{C}$. 


\subsubsection{Influencia de la velocidad inicial}

Para observar la respuesta de la velocidad inicial de alimentación al reactor se mantuvo contante los valores de temperatura a $400^{\circ} \mathrm{C}$, alimentación inicial a $1 \mathrm{~atm}$ de presión y un $\mathrm{W} / \mathrm{F}$ de $25 \operatorname{gr}_{c a t} \mathrm{~s} / \mathrm{molC}_{2}$. Los valores de la velocidad inicial se modificaron de tal manera que el mínimo 3 y máximo 11 veces la velocidad mínima de fluidización debido a que estos son los límites establecidos para la operación de reactores de este tipo en la bibliografía consultada [44].
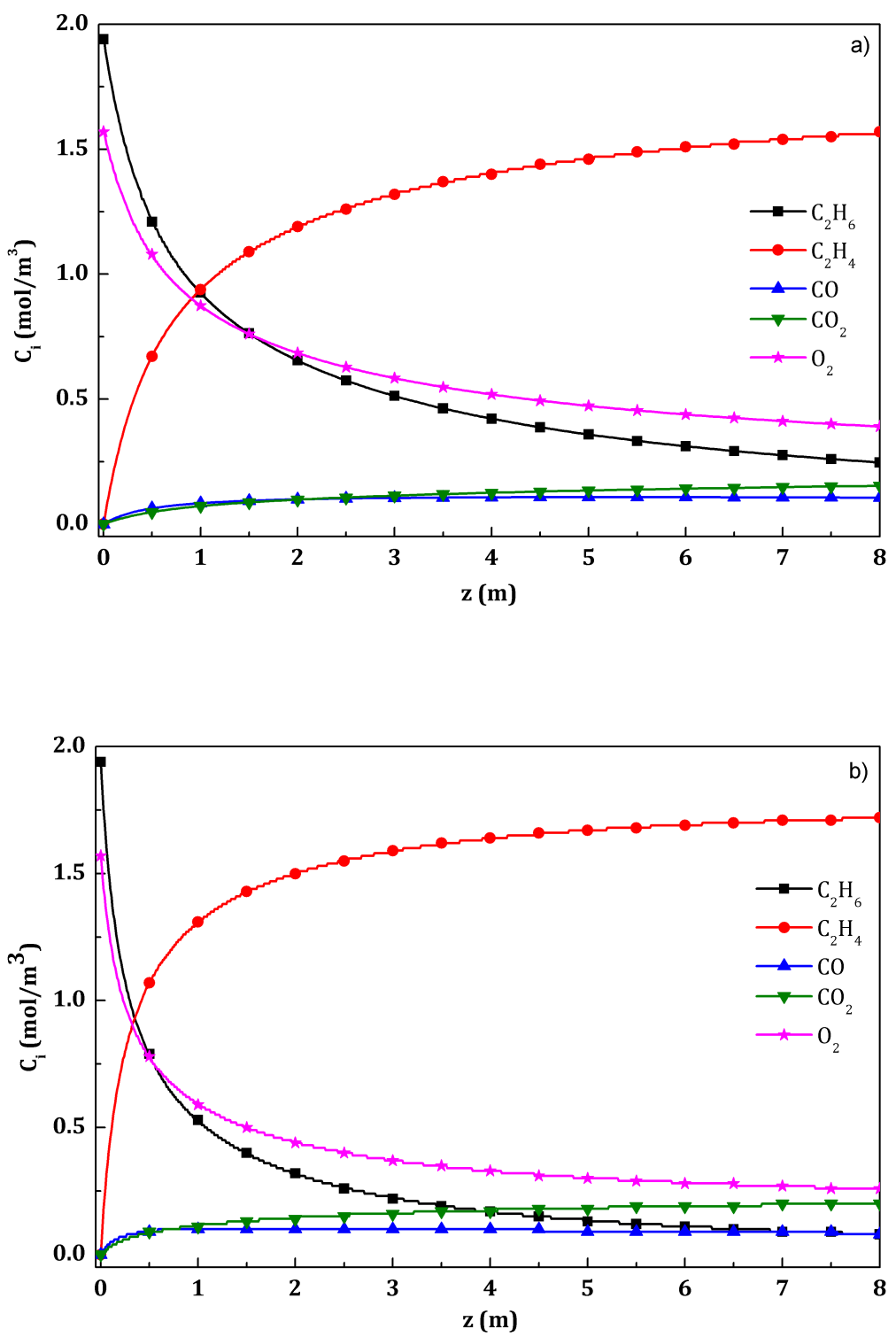

Figura 6.13: Perfiles de concentración en el reactor a) $u_{o} / u_{m f}=3.0$ b) $u_{o} / u_{m f}=11.0$. 
En la Figura 6.13 se presentan los perfiles de concentración de los diferentes compuestos que participan en la reacción a dos valores de $u_{o} 0.183$ y $0.671 \mathrm{~m} / \mathrm{s}$ con los que se cumplió los criterios definidos. Los perfiles indican que la velocidad de reacción es mayor cuando se trabaja el límite superior, esto se relaciona con la cantidad de catalizador suministrada para la operación del reactor que se estimó en función del flujo molar alimentado al reactor. La diferencia de los rendimientos se puede observar manteniendo la misma cantidad del catalizador para ambos casos, de ser así, se puede dilucidar de mejor manera la participación de este parámetro en la reacción propuesta.

Por otro lado, en la Figura 6.14 se presentan las conversiones del etano a lo largo del reactor para los dos valores de velocidad inicial. La conversión se favorece significativamente a $u_{o}=0.671 \mathrm{~m} / \mathrm{s}$ alcanzando un conversión del $90 \%$ contra un $70 \%$ alcanzado en $u_{o}=0.183$ $\mathrm{m} / \mathrm{s}$, este efecto se atribuye a que la misma cantidad de etano está siendo alimentada a un reactor con mayor carga de catalizador por lo que se espera que entre mayor sea el flujo molar alimentado mayor sea la cantidad de catalizador y por lo tanto las conversiones mayores.

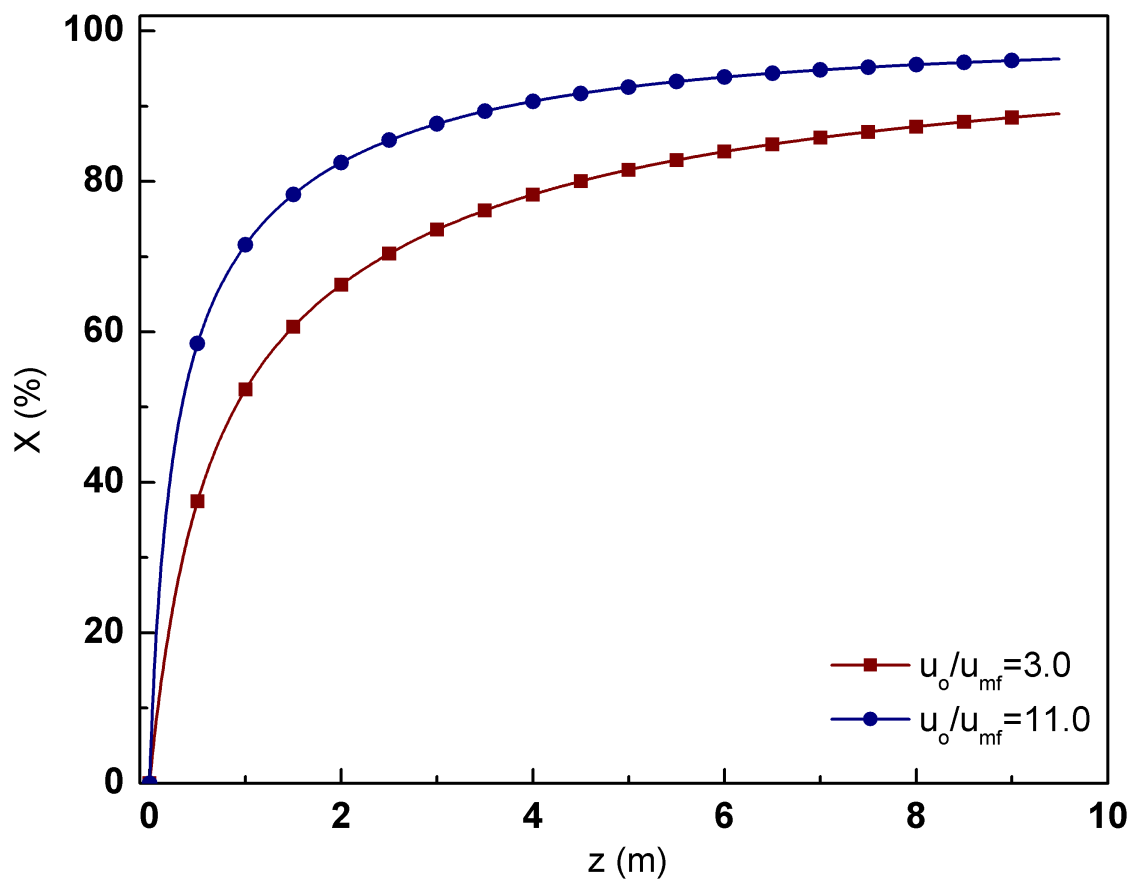

Figura 6.14: Conversiones en función de la velocidad inicial 3-11 veces $u_{m f}$.

El efecto contrario sucede al mantener la masa del catalizador constante en ambos casos, la Figura 6.15 presenta las conversiones y rendimiento a velocidades iniciales de 3 y 11 veces la velocidad mínima de fluidización, en estas simulaciones se considera la misma cantidad de masa del catalizador para ambos casos y los resultados sugieren conversiones menores con respecto a las velocidades de alimentación mínimas, estos últimos resultados coinciden con los reportados por Farag y col. [45]. Esta respuesta se debe al tiempo de residencia de los 
reactivos dentro del reactor.

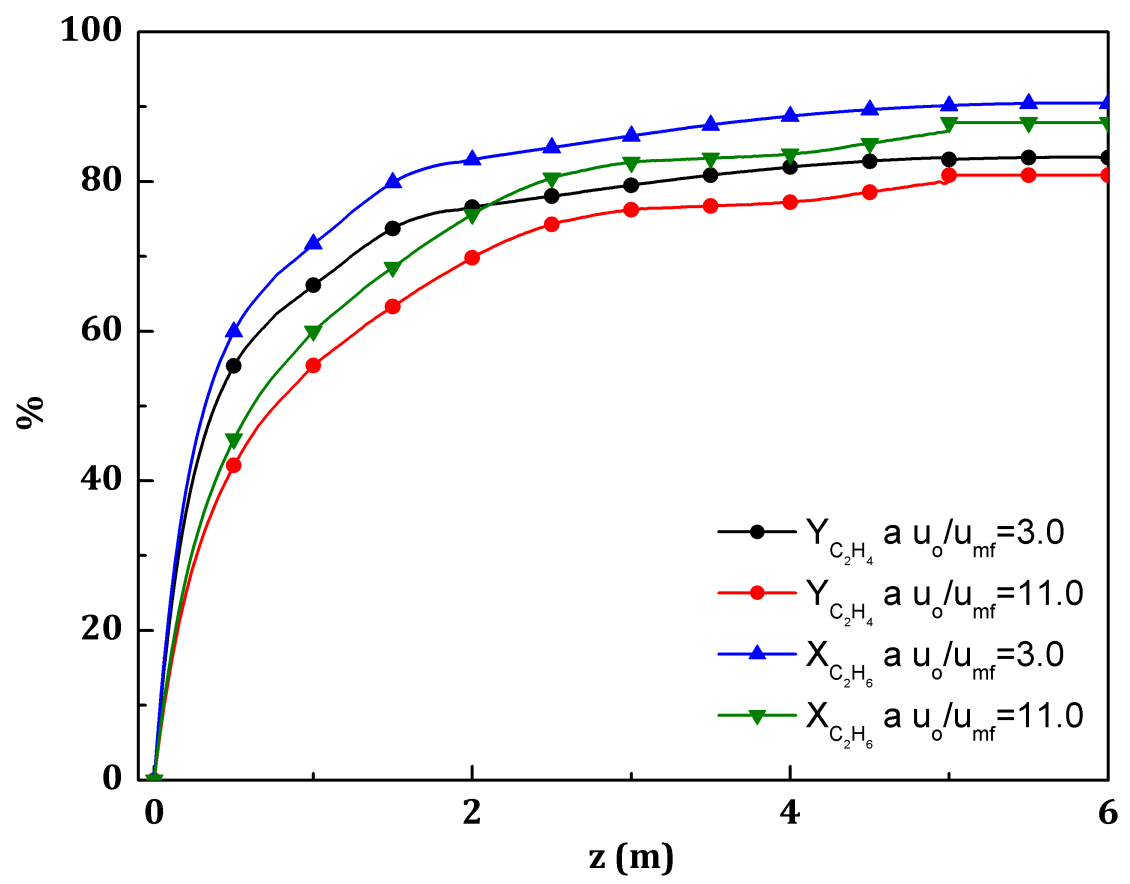

Figura 6.15: Conversión de etano y rendimiento a etileno a diferentes velocidades iniciales masa de catalizador constante.

\subsubsection{Influencia de tasas de alimentación $\mathrm{C}_{2} \mathrm{H}_{6} / \mathrm{O}_{2}$}

Finalmente se consideró la influencia de las tasas de alimentación de $\mathrm{C}_{2} \mathrm{H}_{6} / \mathrm{O}_{2}$ en la conversión del etano, manteniendo constantes la $\mathrm{T}=400^{\circ} \mathrm{C}, u_{o}=0.5 \mathrm{~m} / \mathrm{s}$. Los perfiles de concentración a $\mathrm{C}_{2} \mathrm{H}_{6} / \mathrm{O}_{2}=3$ se presentan en la Figura 6.16 , a estas condiciones la reacción es muy rápida ocupando apenas $50 \mathrm{~cm}$ y alcanzando un $50 \%$ de conversión debido a que la cantidad de oxígeno no es suficiente para que el etano siga reaccionando. Para el caso de alimentación $\mathrm{C}_{2} \mathrm{H}_{6} / \mathrm{O}_{2}=1$ los perfiles de concentración se distribuyen a lo largo del reactor, debido a que tanto el etano como el oxígeno están disponibles para que la reacción se lleve a cabo, sin embargo en este caso se tiene una gran acumulación de oxígeno. La conversión alcanzada para este último caso se puede ver en Figura 6.17, siendo esta del $90 \%$.

Comparando los primeros centímetros del reactor, se tienen una mejora de $1 \%$ para el caso en el que se limita la presencia de oxígeno, sin embargo, este caso como se mencionó solo se dispone del reactivo en los primeros metros, lo que puede afectar en la producción de etileno además en los siguientes centímetros del reactor la selectividad solo se supera en 
$0.5 \%$. Debido a que limitar el oxígeno en la reacción sugiere resultados positivos para la selectividad se propuso estudiar el efecto de este cuando se dosifica para lo que se propuso una distribución parcial a lo largo del reactor, esto se aborda en la diguiente sección.
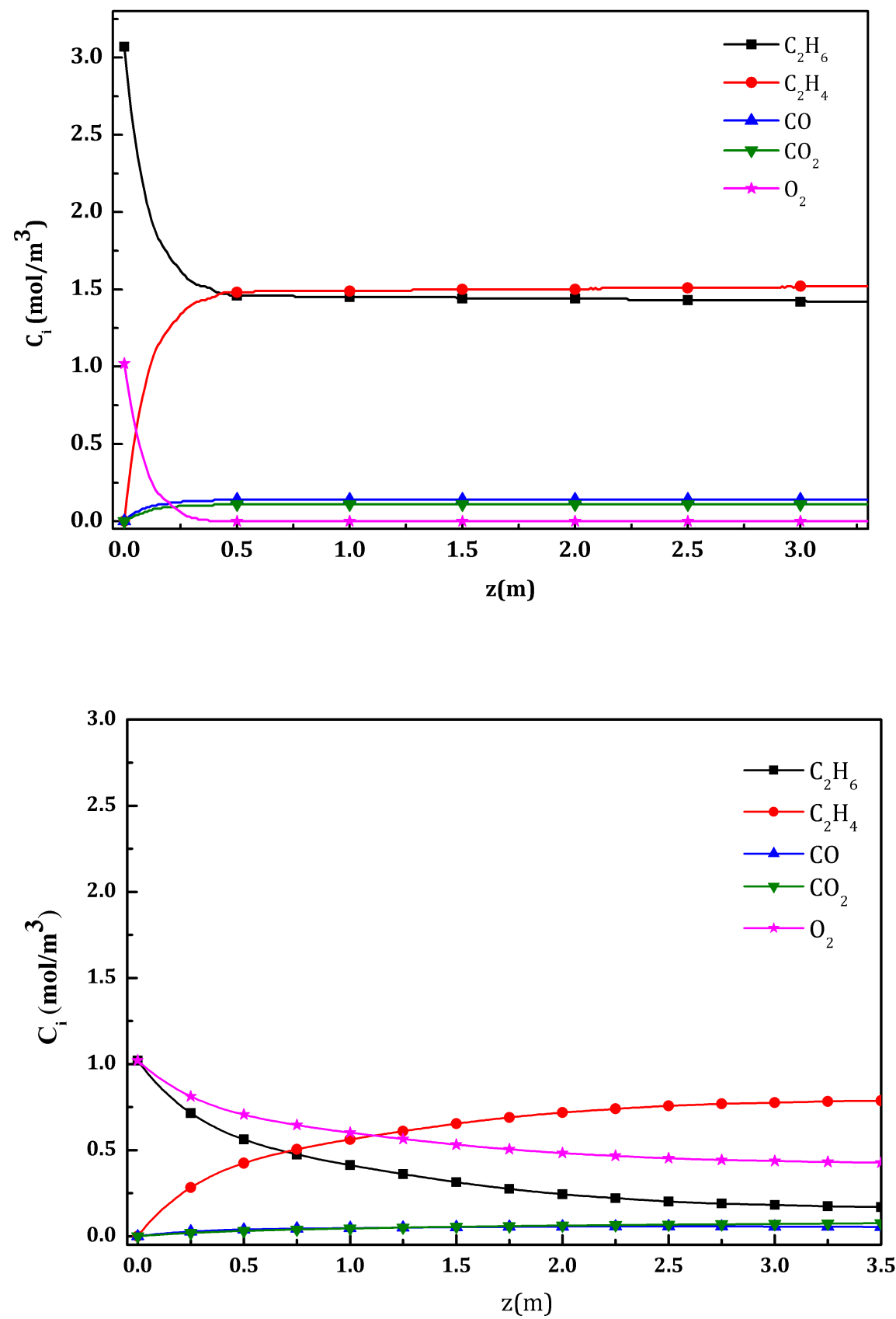

Figura 6.16: Perfiles de concentración en el reactor con a) $\mathrm{C}_{2} \mathrm{H}_{6} / \mathrm{O}_{2}=1$ y b) $\mathrm{C}_{2} \mathrm{H}_{6} / \mathrm{O}_{2}=3$. 


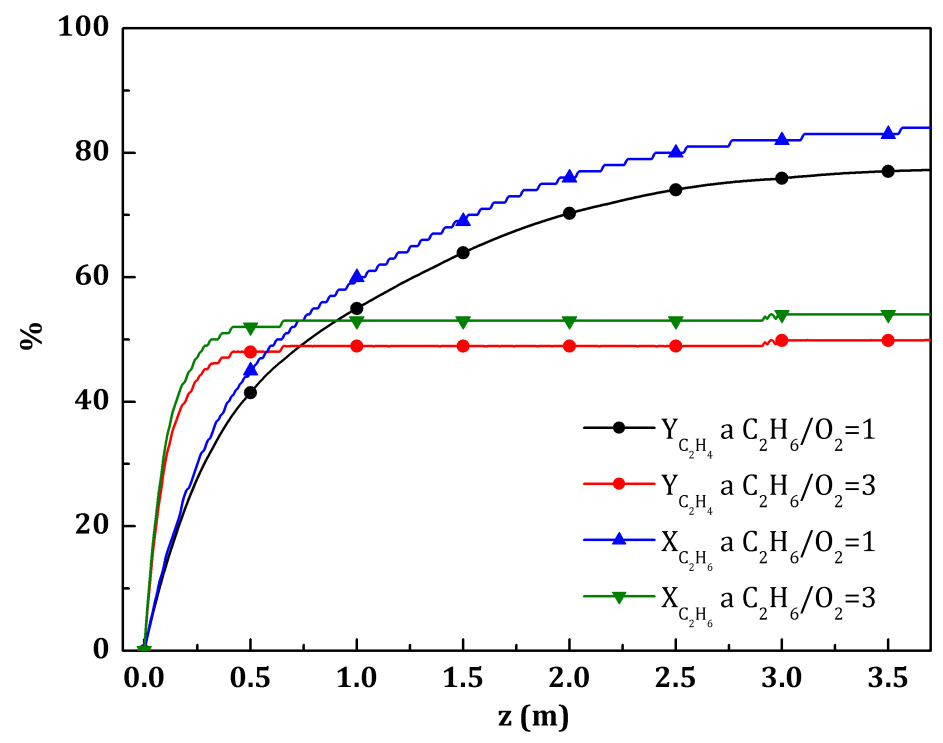

Figura 6.17: Conversiones de etano y rendimientos a etileno a diferentes tasas de alimentación $\mathrm{C}_{2} \mathrm{H}_{6} / \mathrm{O}_{2}$.

\subsubsection{Modelado del reactor con alimentación distribuída de oxígeno}

Para observar el efecto de la disponibilidad de oxígeno en la reacción se consideran dos casos de estudio, el primero considera distribución parcial de oxígeno a lo largo del reactor manteniendo la tasa $\mathrm{C}_{2} \mathrm{H}_{6} / \mathrm{O}_{2}$ en un rango de 1 a 4 . El segundo caso sugiere la alimentación del oxígeno cada determinada distancia. Los resultados de dichas simulaciones en términos de concentración en el reactor, la conversión y selectividad para cada caso serán presentados.

\subsubsection{Alimentación distribuída de oxígeno en función de la tasa $\mathrm{C}_{2} \mathrm{H}_{6} / \mathrm{O}_{2}$ en el reactor.}

La primera simulación referente a la distribución parcial de oxígeno se realizó manteniendo las condiciones de operación de $\mathrm{P}_{o}=1 \mathrm{~atm}, \mathrm{~W} / \mathrm{F}=25 \mathrm{gr}_{\text {cat }} \mathrm{s} / \mathrm{molC}_{2}$ y $u_{o}=0.5 \mathrm{~m} / \mathrm{s}$ a una temperatura constante de $400^{\circ} \mathrm{C}$ con una proporción $\mathrm{C}_{2} \mathrm{H}_{6} / \mathrm{O}_{2}$ inicial de dos a uno. Un aspecto importante que se cuidó fue que las tasas de alimentación se encontraran dentro de los valores reportados experimentalmente, para poder dar certidumbre a los resultados. De esta manera se mantuvo la cantidad de etano de en un rango de 1 a 6 veces sobre oxígeno.

La Figura 6.18 presenta los perfiles de concentración obtenidos a lo largo del reactor, la alimentación de oxígeno se realizó cada vez que la concentración de etano fuera mayor o igual a 2 pero menor o igual a 4 . Bajo estas condiciones el etano reacciona con el oxígeno 
presente y este último no se acumula en el reactor por lo que la selectividad hacia el etileno se mejora al dosificar uno de los reactivos. La selectividad para este caso alcanzó $97 \%$.

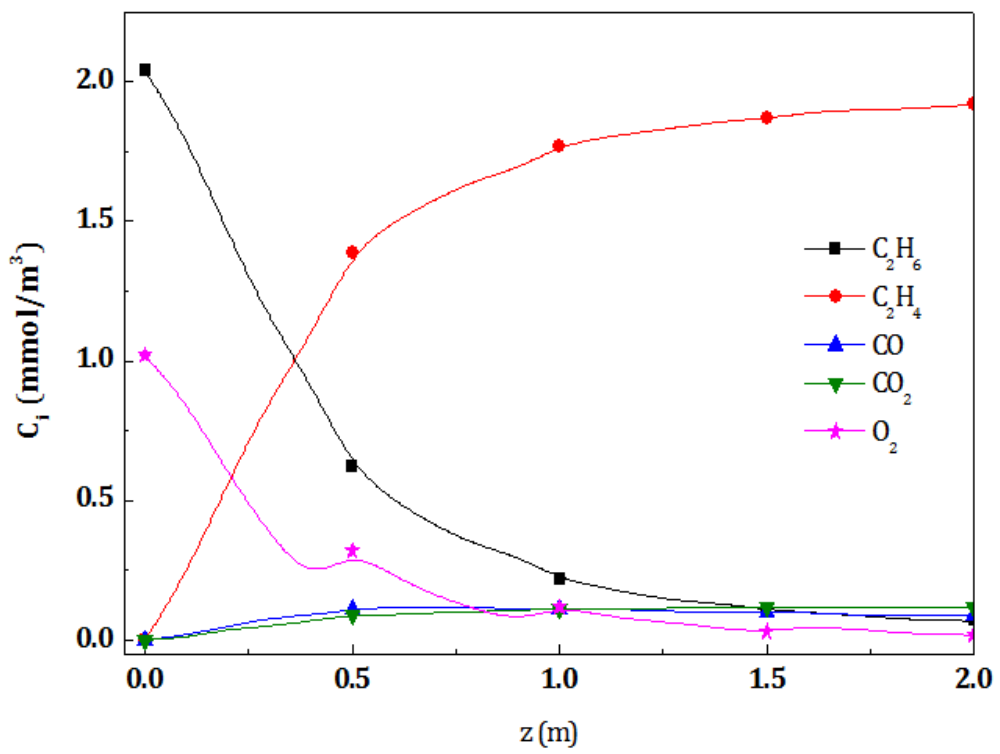

Figura 6.18: Perfiles de concentración en el reactor con distribución de oxígeno a lo largo del reactor manteniendo la tasa $\mathrm{C}_{2} \mathrm{H}_{6} / \mathrm{O}_{2}$ de 2 a 4 .

\subsubsection{Alimentación distribuída de oxígeno en función de la distancia a lo largo del reactor.}

En la Figura 6.19, se representa los perfiles de concentración a lo largo del reactor considerando una alimentación distribuída del oxígeno cada determinada distancia, aproximadamente cada $10 \mathrm{~cm}$ se alimentó un fracción de oxígeno proporcional de tal manera que la selectividad de etileno mejora controlando las reacciones de oxidación total y parcial. Sin embargo, la reacción se lleva a cabo en una sección más corta del reactor, este inconveniente podría controlarse si las proporciones de oxígeno alimentadas se consideran diferentes en cada paso, esto debido a que se puede observar pequeñas secciones en las que la reacción se detiene porque el oxígeno no es suficiente.

La Figura 6.20, presenta la conversión y rendimiento a lo largo del reactor para los diferentes casos de distribución parcial de oxigeno comparado con el caso convencional en donde sólo se alimenta oxígeno a la entrada del reactor. Se observa que los mejores resultados en términos de conversión y rendimiento, se obtienen para los dos casos donde se alimenta distribuídamente el oxígeno. No obstante para el caso en que se alimenta el oxígeno manteniendo una tasa de $\mathrm{C}_{2} \mathrm{H}_{6} / \mathrm{O}_{2}$ de 1-4 se tiene mayor confianza en las predicciones de acuerdo al estudio cinético para el catalizador estudiado. 


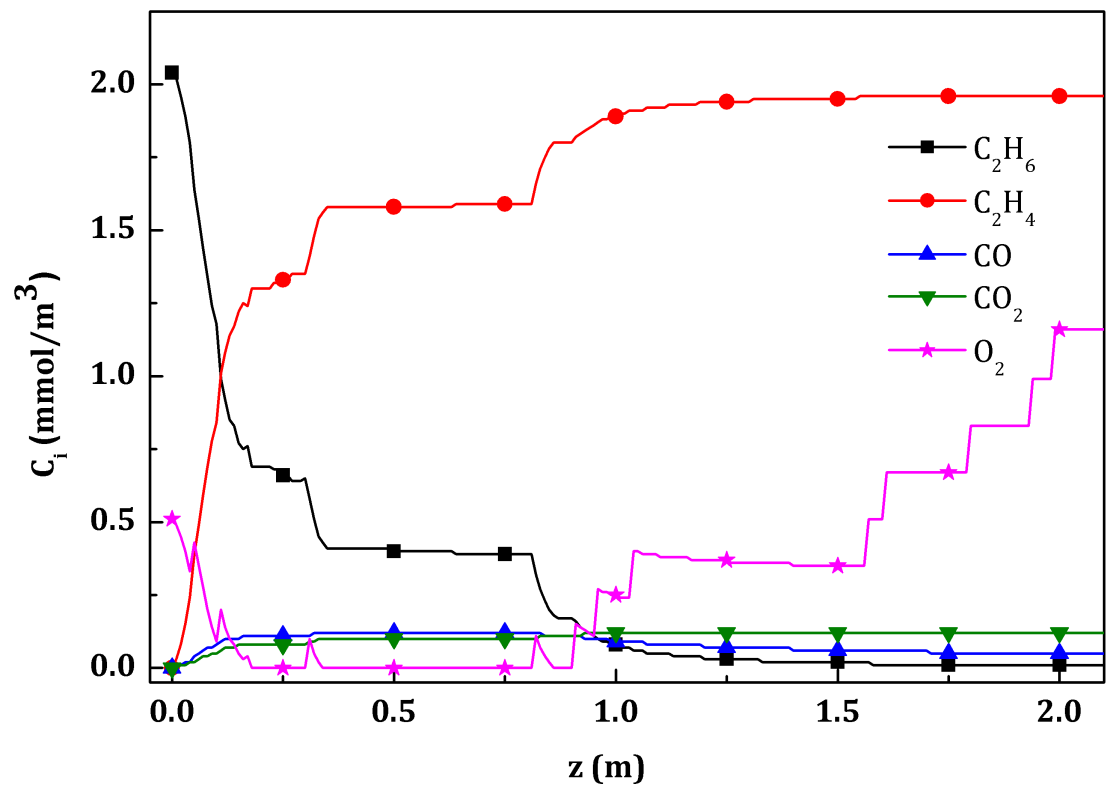

Figura 6.19: Comportamiento del reactor con alimentación distríbuda de oxígeno equidistante a lo largo del reactor.

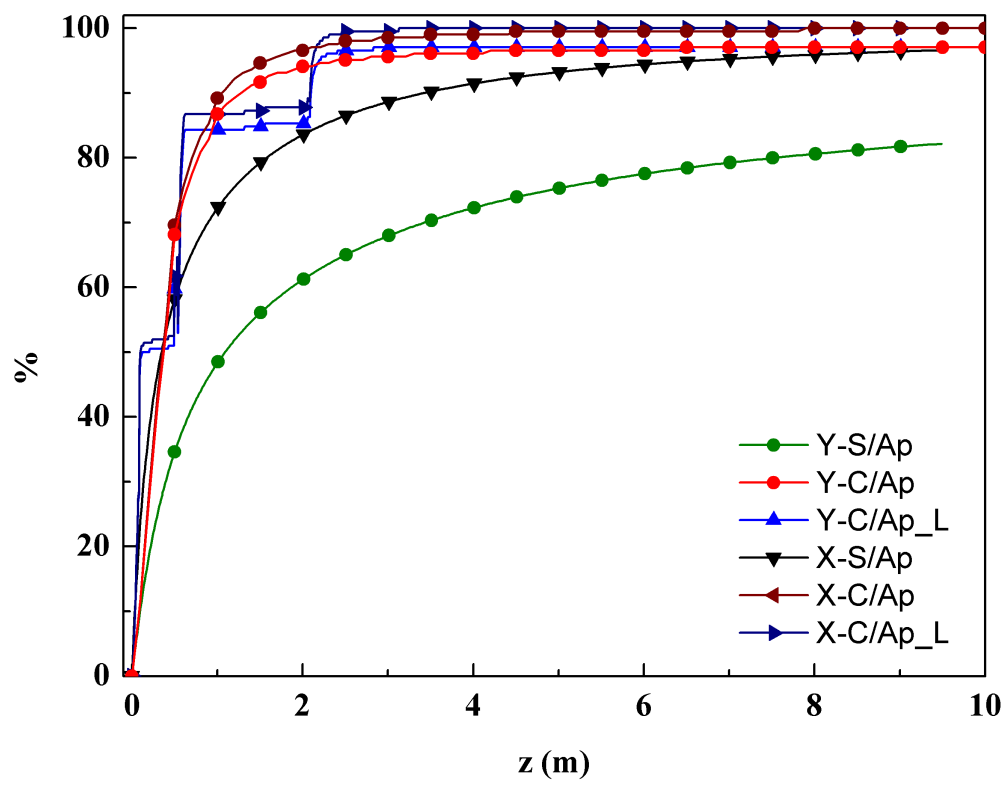

Figura 6.20: Conversión y rendimiento de los diferentes métodos de alimentación de oxígeno donde: $\mathrm{S} / \mathrm{Ap}=$ sin alimentación parcial, $\mathrm{C} / \mathrm{Ap}=$ con alimentación parcial y $\mathrm{C} / \mathrm{Ae}=$ con alimentación equidistante. 


\section{Capítulo 7}

\section{Conclusiones}

En el estudio cinético se analizó la influencia de la temperatura y el W/F sobre la actividad catalítica a partir de los datos experimentales proporcionados por el equipo de trabajo, y se pudo observar que ambos factores juegan un papel importante en la selectividad de los reactivos y por lo tanto en la producción de etileno. Debido a las características del catalizador compuesto por metales de transición las temperaturas de reacción son menores a los $600^{\circ} \mathrm{C}$. Por ejemplo a $400^{\circ} \mathrm{C}$ y un $\mathrm{W} / \mathrm{F}$ de $23.5 \mathrm{gr}_{c a t} \mathrm{~h} / \mathrm{molC}_{2}$ se obtuvo la mejor selectividad de $95.7 \%$ y una conversión de $16.5 \%$. El modelo mecanístico del tipo Mars Van Krevelen que se desarrolló describió adecuadamente los datos experimentales y por lo tanto se considera como una buena aproximación para describir el comportamiento de la reacción de DHO- $\mathrm{C}_{2}$ sobre el catalizador multimetálico NiMOTeOV.

La realización de este trabajo permitió conocer el comportamiento a diferentes condiciones de operación de un catalizador multimetálico en un reactor de lecho fluidizado a escala industrial para la producción de etileno a partir de etano por DHO.Se observó que tanto la temperatura de reacción, como velocidad inicial son los factores principales que influyen en la producción de etileno. Los mejores resultados se encontraron a una temperatura de $480^{\circ} \mathrm{C}$, con $91 \%$ de conversión y un rendimiento de $89.9 \%$. El estudio del efecto de la alimentación de oxígeno sugirió que la distribución parcial de oxígeno a lo largo del reactor favorece la conversión y rendimiento con respecto al caso donde se alimenta oxígeno a la entrada del reactor. 


\section{Perspectivas}

1. Realizar un diseño experimental que considere los efectos de las tasas de alimentación etano/oxígeno para tener certidumbre en los resultados de las simulaciones propuestas.

2. Proponer modelos cinéticos que consideren pasos de reacción siguiendo el formalismo de Langmiur-Hinshelwood Hougen and Watson o combinaciones de éste con el formalismo MVK.

3. Considerar la transferencia del calor en el modelo del reactor ya que a distancias cortas este fenómeno pudiese tener importancia.

4. Evaluación de un catalizador para reactores de lechos fluidizados con el que se permita estudiar los fenómenos mecánicos. 


\section{Referencias}

1. A comparative study on non-catalytic and catalytic oxidative dehydrogenation of ethane to ethylene. S.A.R. Mulla, O.V. Buyevskaya yM. Baerns. (2002), Applied Catalysis A: General, Vol. 226, págs. 73-78.

2. The oxidative dehydrogenation of ethane and propane as an alternative way for the production of light olefins. F., Cavani F. yTrifiró. (1995), Catalysis Today, Vol. 24, págs. 307-313.

3. Ethane Oxidative Dehydrogenation Pathways on Vanadium Oxide Catalysts. Morris D. Argyle, Kaidong Chen, Alexis T. Bell, and Enrique Iglesia. 2002, J. Phys. Chem. B, Vol. 106, págs. 5421-5427.

4. Kinetics of Oxidative Dehydrogenation of $C_{2}-C_{3}$ Alkanes on Oxide Catalysts. Grabowski, R.: Catalysis Reviews, (2006), Vol. 48, págs. 199-268.

5. Oxidative dehydrogenation of ethane over $\mathrm{BaF}_{2}$ promoted $\mathrm{SmO}_{3}-\mathrm{LaF}_{3}$ catalysts. J.Z. Luo, X.R Zhou, Z.S. Chao, H.L. Wan. 1997, Applied Catalysis A: General, Vol. 159, págs. 9-19.

6. Mo-V-Nb Oxide Catalysts for the Partial Oxidation of Ethane I. Preparation and Structural Characterisation. K. Ruth, R. Kieffer,y R. Burch. (1998), Journal of Catalysis, Vol. 175, págs. 16-26.

7. Selective oxidative dehydrogenation od ethane on MoVTeNbO mixed metal oxide catalyst. Botella P., García-Gonzalez E., Dejoz A. (2004), Journal of Catalysis, Vol. 225, págs. 428-438.

8. Oxidative dehydrogenation of ethane over $\mathrm{Ni}-\mathrm{W}-\mathrm{O}$ mixed metal oxide catalysts. B. Solsona, J.M. López Nieto, P. Concepción, A. Dejoz, F. Ivars, M.I. Vázquez. (2011), Journal of Catalysis, Vol. 280, págs. 28-39.

9. Oxidative dehydrogenation of ethane to ethylene over alumina-supported vanadium oxide catalysts: Relationship between molecular. M.V. Martínez-Huerta a, X. Gao b, H. Tian b, I.E. Wachs b, J.L.G. Fierro c, M.A. Bañares. 2006, Catalysis Today , Vol. 118 , págs. 279-287. 
10. Oxidative dehydrogenation of ethane over $\mathrm{LaF}_{3}-\mathrm{CeO}_{2}$ catalysis. J.Z. Luo, H.L. Wan. 1997, Applied Catalysis A: General, Vol. 158, págs. 137-144.

11. Acid SAPO-34 Catalysts for Oxidative Dehydrogenation of Ethane. Marchese L., Frache A., Gatti G., Coluccia S., Lisi L.,Ruoppolo G., Russo G., y Pastore H. O. (2002), Journal of Catalysis, Vol. 208, págs. 479-484.

12. Kinetic and Isotopic Study of Ethane Dehydrogenation over a Semicommercial Pt, $\mathrm{Sn} / \mathrm{Mg}(\mathrm{Al}) \mathrm{O}$ Catalyst. Virnovskaia Anastasia, Rytter Erling,and Olsbye Unni. 2008, Ind. Eng. Chem. Res., Vol. 47, págs. 7167-7177.

13. The Oxidative Dehydorgenation of Ethane over Catalysts Containind Mixed Oxides of Molybdenum and Vanadium. Thorsteinson E. M., Wilson T. P. y Young F. G. (1978), Journal of Catalysis, Vol. 52, págs. 113-132.

14. Mo-V-Nb mixed oxides as catalysts in the selective oxidation of ethane. P. Botella, J.M. López Nieto, A. Dejoz , M.I. Vázquez, A. Martínnez-Arias. (2003), Vol. 78, págs. 507-512.

15. Oxidative dehydrogenation of ethane in a fluidized bed menbrane reactor. Desislava Ahchieva, Mirko Peglowa, Stefan Heinrich, Lothar Mörl, Tania Wolff, Frank Klose. (2005), Applied Catalysis A: General, Vol. 296, págs. 176-185.

16. Oxidative dehydrogenation of ethane on Te-containing MoVNbO catalysts. J.M. López Nieto, P. Botella, P. Concepción, A. Dejoz y M.I. Vázquez. (2004), Catalysis Today, Vols. 91-92, págs. 241-245.

17. Mo-V-Nb Oxide Catalysts for the Partial Oxidation of Ethane II. Chemical and Catalytic Properties and Structure Function Relationships. Ruth K., Burch R., y Kieffery R. (1998), JOURNAL OF CATALYSIS, Vol. 175, págs. 27-39.

18. $\mathrm{TiO}_{2}$ supported vanadyl phosphate as catalyst for oxidative dehydrogenation of ethane to ethylene. Ciambelli P., Galli P., Lisi L., Massucci M.A., Patrono P., Pirone R., Ruoppolo G., G. Russo. (2000) , Applied Catalysis A: General, Vol. 203, págs. $133-142$.

19. Kinetics and Mechanism od Ethane Oxidation to Acetic Acid on Catalysed Based on Mo- $V$ - Nb Oxides. Iglesia, Xuebing Li y Enrique. (2008), J. Phys. Chem. C, Vol. 112, págs. 15001-150008.

20. Catalytic Partial Oxidation of Ethane to Acetic Acid over $M_{1} V_{0.25} N_{0.12} P d_{0.0005} O_{x} I$. Catalyst Performance and Reaction Mechanism. David Linke, Dorit Wolf, Manfred Baerns, Olaf Timpe,y Robert Schlögl. (2002), Journal of Catalysis, Vol. 205, págs. 16-31. 
21. Partially reduced heteropolyanions for the oxidative dehydrogenation of ethane to ethylene and acetic acid at atmospheric pressure. J.M. Galownia, A.P. Wight, A. Blanc, J.A. Labinger, M.E. Davis. (2005), Journal of Catalysis, Vol. 236, págs. 356-365.

22. Catalytic partial oxidation of ethane to acetic acid over $M o_{1} V_{0.25} N b_{0.12} P d_{0.0005} O_{x}$ : reactor operation. David Linke, Dorit Wolf, Manfred Baerns, Sabine Zey, Uwe Dingerdissen y Leslaw Mleczko. (2002), Chemical Engineering Science, Vol. 57, págs. 39-51.

23. Platinum-tin and platinum-copper catalysts for autothermal oxidative dehydrogenation of ethane to ethylene. Yokoyama, C. 1996, Catalysis Letters, Vol. 38, págs. 181-188.

24. Ethylene Formation by Oxidative Dehydrogenation of Ethane over Monoliths at Very Short Contact Times. D., Huff M. y Schmidt L. (1993), J. Phys. Chem. , Vol. 97, págs. 11815-11822.

25. $\mathrm{Ni}-\mathrm{Nb}-\mathrm{O}$ mixed oxides as highly active and selective catalysts for ethene production via ethane oxidative dehydrogenation. Part II: Mechanistic aspects and kinetic modeling. A.A., Lemonidou E. y Heracleous. (2006), Journal of Catalysis, Vol. 237, págs. 175-189.

26. Investigation of Ni-based alumina-supported catalysts for the oxidative dehydrogenation of ethane to ethylene: structural characterization and reactivity studies. E. Heracleous, A.F. Lee, K. Wilson, A.A. Lemonidou. (2005), Journal of Catalysis, Vol. 231, págs. 159-171.

27. Kinetic study of oxidative dehydrogenation od ethane over MoVTeNb mixed oxide catalyst. Valente J., Quintana-Solorzano R., Armendáris Herrera H., López Nieto J., Barragán Rodríguez A. G.,. (2013), Industrial \& Engineering Chemistry Research

28. A Numerical Model Of Gas-Fluidezed Beds. Kuipers J. A, Van Duin K.J, Van Beckum F.P., and Van Swaaij W.P. 1992, Chemical Engineering Science, Vol. 47, págs. 1913-1924.

29. Discrete particle simulation of solids motion in a gas-solid fluidized bed. Limtrakul S., Chalermwattanatai A., Unggurawirote K., Tsuji Y., Kawaguchi T., Tanthapanichakoon W. 2003, Chemical Engineering Science, Vol. 58, págs. 915-921.

30. DEM modeling and simulation of a catalytic gas-solid fluidized bed reactor: a spouted bed as a case study. Limtrakul S., Boonsrirat A., Vatanatham T. 2004, Chemical Engineering Science, Vol. 59, págs. 5225 - 5231.

31. Oxidative dehydrogenation of ethane to ethylene in a membrane reactor: $A$ theoretical study. Maria L. Rodriguez, Daniel E. Ardissone, Eleni Heracleous, Angeliki 
A. Lemonidou, Eduardo López, Marisa N. Pedernera y Daniel O. Borio. (2010) , Catalysis Today , Vol. 157, págs. 303-309.

32. Modeling of a Fluidized Bed Membrane Reactor for the steam reforming od Methane: Advantages of oxynen addition for favorable hydrogen production. K.I., Rakib M.A. y Alhumaizi. 2005, Energy \& Fuels, Vol. 19, págs. 2129-2139.

33. Operation modes of packed-bed membrane reactors in the catalytic oxidation of hydrocarbons. Frank Klose, Tania Wolff, Sascha Thomas, A. Seidel-Morgenstern. 2004, Applied Catalysis A: General, Vol. 257, págs. 193-199.

34. Use of a Ceramic Membrane Reactor for the Oxidative Dehydrogenation of Ethane to Ethylene and Higher Hydrocarbons. Joaquin Coronas, Miguel Menendez y Jesús Santamaria. (1995), Ind. Eng. Chem. Res., Vol. 34, págs. 4229-4234.

35. High selectivity of oxidative dehydrogenation of ethane to ethylene in an oxygen permeable membrane reactor. Wang H., Cong Y. y Yang W. 2002, CHEM. COMMUN, págs. 1468-1469.

36. DaizoKunii, Octave Levenspiel. Gross behavior of fluidized beds. Fluidization Engineering. s.l. : John Wiley \& Sons, INC, 1969, págs. 64-90.

37. Daneshpayeh M., Mostoufi N.,Sotudeh - Gharebagh R., Mortazavi Y. Modeling of Stagewise feeding in fluidized Bed reactor of Oxidative Coupling of methane. s.l. : Energy \& Fuels, 2009. págs. 3745-3752. Vol. 23.

38. A comparision of two. and single-phase Models for Fluidized-Bed reactors. Navid Mostoufi, Heping Cui and Chaouki. 2001, Ind. Eng. Chem. Res., Vol. 40, págs. 55265532 .

39. Fluidized Reactors Models: 1. For bubbling beds of fine, Intermediate, and large paticles. 2. For the Lean Phase: Freenoard and Fast Fluidization. levenspiel, Daizo Kunii and Octave. 7, 1990, Ind. Eng. Chem. Res., Vol. 29, págs. 1226-1239.

40. Welty, James R. Fundamentos de transferencia de momento, calor y masa. s.l. : Jonh Wiley \& Sons INC, 1994, págs. 546-554.

41. C., Reid Robert. Diffusion Coefficients. The properties of Gases \& Liquids. Fourth Edition. s.l. : McGraw-Hill, 1976, págs. 577-626.

42. Two-phase model for a catalytic turbulent fluidized-bed reactor: Application to ethylene synthesis. Jamal Chaouki, Ali Gonzazlez, Christophe Guy, Danilo Klva. 1999, Chemical Engineering Science, Vol. 54, págs. 2039-2045.

43. Bischoff, Gilbert F. Froment and Kenneth B. Chemical ReactorAnalysis and Design. s.l. : John Wlley \& Sons. Inc, 1979. 
44. Smith, Van Ness, Abott. Primera ley y equilibrio. Introducción a la termodinámica en Ingeniería Química. s.l. : McGraw Hill, 1997, págs. 21-27.

45. Hou K., Hughes R., Ramos R. Simulation of a membrane reactor for oxidative dehydrogenation of propane, incorporating radial concentration and temperature. 2001.

46. Continuos oxygen ion transfer medium as a catalyst for high selective oxidative dehydrogenation of ethane. Haihui Wang, You Cong y Weishen Yang. (2002), Catalysis Letters, Vol. 84, págs. 101-106.

47. Combinatorial discovery of oxidative dehydrogenation catalysts within the $M o-V-N b-O$ system. Peijun Cong, Ahmad Dehestani, Robert Doolen, Daniel M. Giaquinta, Shenheng Guan, Victor Markov, Damodara Poojary, Kyle Self, Howard Turner, and W. Henry Weinberg. (1999), Proc. Natl. Acad. Sci. USA, Vol. 96, págs. 11077-11080.

48. Oxidative dehydrogenation of ethane over iron phosphate catalysts. James E. Miller, Mary M. Gonzales, Lindsey Evans, Allen G. Sault,Conrad Zhang, Rajeev Rao, George Whitwell. (2002), Applied Catalysis A: General, Vol. 231, págs. 281292.

49. Modeling of a Fluidized Bed Membrane Reactor for the Steam Reforming of Methane: Advantages of Oxygen. Alhumaizi, M. A. Rakib and K. I. (2005), Energy \& Fuels , Vol. 19, págs. 2129-2139.

50. Oxidative dehydrogenation of ethane and propane: How far from commercial implementation. F. Cavani, N. Ballarini y A. Cericola. (2007), Catalysis Today, Vol. 127, págs. 113-131.

51. Support effects on the catalytic behavior of $\mathrm{NiO} / \mathrm{Al}_{2} \mathrm{O}_{3}$ for oxidative dehydrogenation of ethane to ethylene. Xinjie Zhang, Jixin Liu, Yi Jing, Youchang Xie. (2003), Applied Catalysis A: General, Vol. 240, págs. 143-150.

52. Kinetics of Oxidative Dehydrogenation of $C_{2}-C_{3}$ Alkanes on Oxide Catalysts. R., Grabowski. (2006), Catalysis Reviews, Vol. 48, págs. 199-268.

53. Kinetic and Isotopic Study of Ethane Dehydrogenation over a Semicommercial Pt,Sn/Mg $(\mathrm{Al}) \mathrm{O}$ Catalyst. Virnovskaia A., Rytter E. y Olsbye U. (2008), Ind. Eng. Chem. Res. , Vol. 47, págs. 7167-7177.

54. Modeling of fluidized bed reactor for ethylene polymerization: effect of parameters on the single pass ethylene conversion. Hassab Farag, Mona Ossman, Moutsapha Mansour and Yousra Farid. 2013, International Journal of Industrial Chemistry, págs. 4-20. 


\section{Apéndice A}

\section{Cálculos termodinámicos}

El procedimiento para calcular las variables termodinámicas descritas en el documento se basó según lo reportado por Smith [46]:

La entalpía de reacción dependiente de la temperatura se calculó con:

$$
\Delta H_{r x n}=\left.\Delta H\right|_{r x n} ^{\circ}+\int_{298^{\circ} C}^{T} \Delta C_{p} \Delta T
$$

Dónde:

$\left.\Delta H\right|_{\text {rxn }} ^{\circ}=\left.\Delta H\right|_{\text {prod }} ^{\circ}-\left.\Delta H\right|_{\text {react }} ^{\circ}$, es la entalpía de reacción estándar calculada a temperatura ambiente, los valores estándar se presentan en Tabla A.

Tabla A.1: Valores de Entalía y Energía libre de Gibss para los compuestos de las reacciones

\begin{tabular}{lcc}
\hline & $\Delta \mathrm{H}(\mathrm{KJ} / \mathrm{mol})$ & $\Delta \mathrm{G}(\mathrm{KJ} / \mathrm{mol})$ \\
\hline & & \\
$\mathrm{C} 2 \mathrm{H} 6$ & -83.82 & -31.86 \\
$\mathrm{C} 2 \mathrm{H} 4$ & 52.5 & 68.48 \\
$\mathrm{H} 2 \mathrm{O}$ & -241.81 & -228.42 \\
$\mathrm{CO}$ & -110.53 & -137.16 \\
$\mathrm{CO} 2$ & -393.51 & -394.38 \\
\hline
\end{tabular}

$\Delta C_{p}=$ Capacidad calorífica de los componentes de la reacción se calcula similar a la entalpía estándar. 
El Cp por componente se calculó por:

$$
C_{p}=A+B T+C T^{2}+D T^{3}
$$

El efecto de la temperatura en la constante de equilibrio se tiene de la siguiente expresión:

$$
\ln K=\int \frac{\Delta H_{r x n}}{R T^{2}} d T
$$

\section{A.1. Criterios para determinar el modelo intrínseco}

La determinación del estado intrínseco de la reacción se llevó mediante la realización de dos experimentos, representativos del catalizador en donde se evaluaron criterios como el tipo flujo, caída de presión y gradientes a nivel de partícula. Para ambos ensayos se utilizaron 6 g de catalizador con un tamaño de partícula promedio de 150 micrones asumiendo una porosidad del lecho de 0.3. Las propiedades físicas del catalizador no mencionadas así como las condiciones iniciales de los dos experimentos realizados, se describen en las tablas siguientes:

Tabla A.2: Propiedades físicas del catalizador utilizado en los experimentos para las limitaciones de transporte

\begin{tabular}{lc}
\hline Propiedad & Valor \\
\hline & \\
Área superficial específica & $20 \mathrm{~m}^{2} / \mathrm{g}$ \\
Porosidad del pellet & 0.6 \\
Densidad del bulto & $900 \mathrm{~kg} / \mathrm{m}^{3}$ \\
Tortuosidad & 5 \\
Conductividad térmica & $0.36 \mathrm{~W} / \mathrm{mK}^{-1}$ \\
\hline
\end{tabular}

Ambos experimentos de acuerdo a la Tabla Resultados de la evaluación del patrón de flujo, caída de presión y limitaciones al transporte para los dos experimentos representativos. se efectuaron en un régimen donde las limitaciones al transporte de masa son despreciables pues se encuentran debajo de lo sugerido por la literatura y que las caídas de presión son inferiores a lo establecido. 
Tabla A.3: Condiciones iniciales de los ensayos de limitaciones de transporte Experimento-1 Experimento-2

$\begin{array}{lcc}\text { Masa de catalizador }(\mathrm{g}) & 0.6 & 0.6 \\ \text { Temperatura }(\mathrm{K}) & 440 & 440 \\ \mathrm{~W} / \mathrm{F}^{\circ}\left(\mathrm{g}_{\text {cat }} \mathrm{h} / \mathrm{mol}_{\text {etano }}\right) & 36.0 & 72.0 \\ \text { Presión total }(\mathrm{atm}) & 0.77 & 0.77 \\ \text { Presión parcial etano }(\mathrm{atm}) & 0.07 & 0.07 \\ \text { Presión parcial oxígeno }(\mathrm{atm}) & 0.05 & 0.05 \\ \text { Presión parcial nitrógeno }(\mathrm{atm}) & 0.65 & 0.65 \\ \text { Etano/oxigeno/nitrógeno alimentado }(\mathrm{mol}) & 9 / 7 / 84 & 9 / 7 / 84 \\ \text { Flujo total alimentado }(\mathrm{sccm}) & 77 & 38\end{array}$

Tabla A.4: Resultados de la evaluación del patrón de flujo, caída de presión y limitaciones al transporte de masa para lis dos experimentos representativos.

\begin{tabular}{|c|c|c|c|c|c|c|}
\hline & \multirow{2}{*}{$\begin{array}{c}\text { Experimento-1 } \\
\text { Valor }\end{array}$} & \multicolumn{5}{|c|}{ Experimento-2 } \\
\hline & & & Límite & Valor & & Límite \\
\hline \multicolumn{7}{|l|}{ Patrón de flujo } \\
\hline $\mathrm{Lb} / \mathrm{dp}$ & 56 & $>$ & 12.5 & 56 & $>$ & 40.0 \\
\hline $\mathrm{dt} / \mathrm{dp}$ & 66 & $>$ & $10(11)$ & 66 & $>$ & $10(11)$ \\
\hline Caída de presión, $\mathrm{kPa}$ & 48 & $<$ & 95 & 24 & $<$ & 95 \\
\hline \multicolumn{7}{|l|}{ Gradientes externos } \\
\hline Concentración (Ca) & $3.1 \times 10^{-4}$ & $<$ & $5 \times 10^{-2}$ & $2.75 \times 10^{-4}$ & $<$ & $5 \times 10^{-2}$ \\
\hline Térmico $(\Delta \mathrm{T}$ film $)),{ }^{\circ} \mathrm{C}$ & 0.017 & $<$ & 2.35 & 0.145 & $<$ & 2.35 \\
\hline \multicolumn{7}{|l|}{ Gradientes internos } \\
\hline Concentración, $\Phi$ & $3.3 \times 10^{-3}$ & $<$ & $8 \times 10^{-2}$ & $2.7 \times 10^{-3}$ & $<$ & 0.08 \\
\hline Térmico $(\Delta \mathrm{T}$ pellet $),{ }^{\circ} \mathrm{C}$ & $1.23 \times 10^{-3}$ & $<$ & 2.35 & $1.0 \times 10^{-3}$ & $<$ & 2.35 \\
\hline \multicolumn{7}{|c|}{ Gradientes intra-reactor } \\
\hline Térmico radial, ${ }^{\circ} \mathrm{C}$ & 1.3 & $<$ & 2.35 & 1.24 & $<$ & 2.35 \\
\hline
\end{tabular}




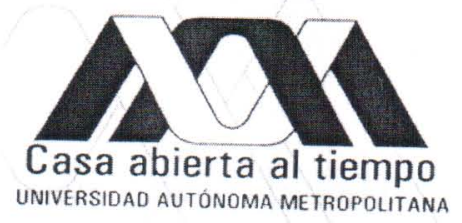

Modelado del comportamiento de una reacción de Oxidación Catalítica en un Reactor de Lecho Fluidizado

TESIS QUE PARA OBTENER EL GRADO DE MAESTRA EN CIENCIAS EN INGENIERÍA QUÍMICA

\section{Presenta:}

I. A. Ilda Olivia Santos Mendoza

Asesores:

Dr. Carlos Omar Castillo Araiza

Dr. Richard S. Ruiz Martínez

Jurado Calificador :

Presidente: Dr. Carlos Martínez Vera

Secretario: Dr. Carlos Omar Castillo Araiz

Vocal:

Dra. Miriam Nohemí Moreno Montiel

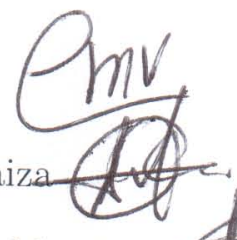

10/Octubre/2013 